Energy Use of Televisions and Videocassette Recorders in the U.S.

RECEIVED

Final Report

OSTI

Prepared by

Lawrence Berkeley National Laboratory

for

U.S. Department of Energy

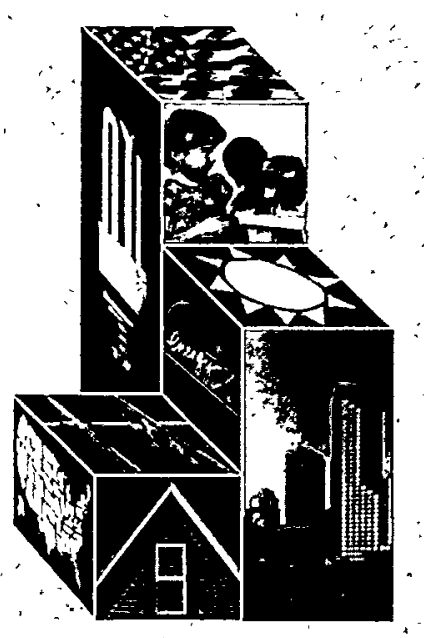

O FFIC E OF

\title{
BUILDING thenologr.
}

STATE AND COMMUNITY PROGRAMS

March 1999 


\section{DISCLAIMER}

This document was prèpared as an account of work sponsored by the United States Government. While this document is believed to contain correct information, neither the United States Government nor any agency thereof, nor The Regents of the University of California, nor any of their employees, makes any warranty, express or implied, or assumes any legal responsibility for the accuracy, completeness, or usefulness of any information, apparatus, product, or process disclosed, or represents that its use would not infringe privately owned rights. Reference herein to any specific commercial product, process, or service by its trade name, trademark, manufacturer, or otherwise, does not necessarily constitute or imply its endorsement, recommendation, or favoring by the United States Government or any agency thereof, or The Regents of the University of California. The views and opinions of authors expressed herein do not necessarily state or reflect those of the United States Government or any agency thereof, or The Regents of the University of California.

This report has been reproduced directly from the best available copy.

Available to DOE and DOE Contractors

from the Office of Scientific and Technical Information

P.O. Box 62, Oak Ridge, TN 37831

Prices available from (615) $576-8401$

Available to the public from the National Technical Information Service

U.S. Department of Commerce

5285 Port $/$ Royal Road, Springfield, VA 22161

Ernest Orlando Lawrence Berkeley National Laboratory is an equal opportunity employer. 


\section{DISCLAIMER}

\section{Portions of this document may be illegible in electronic image products. Images are produced from the best available original document.}




\title{
Energy Use of Televisions and Videocassette Recorders in the U.S.
}

\author{
Karen B. Rosen and Alan K. Meier \\ Environmental Energy Technologies Division \\ Lawrence Berkeley National Laboratory \\ University of California \\ Berkeley, California 94720
}

March 1999

This report is available online at:

http://eetd.lbl.gov/ea/reports/42393/

This work was supported by the Assistant Secretary for Energy Efficiency and Renewable Energy of the U.S. Department of Energy under Contract No. DE-AC03-76SF00098. 


\section{EXECUTIVE SUMMARY}

This study was undertaken to estimate current energy use of residential televisions (TVs) and videocassette recorders (VCRs) in the United States. Ownership and usage statistics were taken from media research, while average power values were derived from power measurements of nearly 500 units, shown in Figure ES-1.

Figure ES-1. Power levels of TVs and VCRs measured for this study

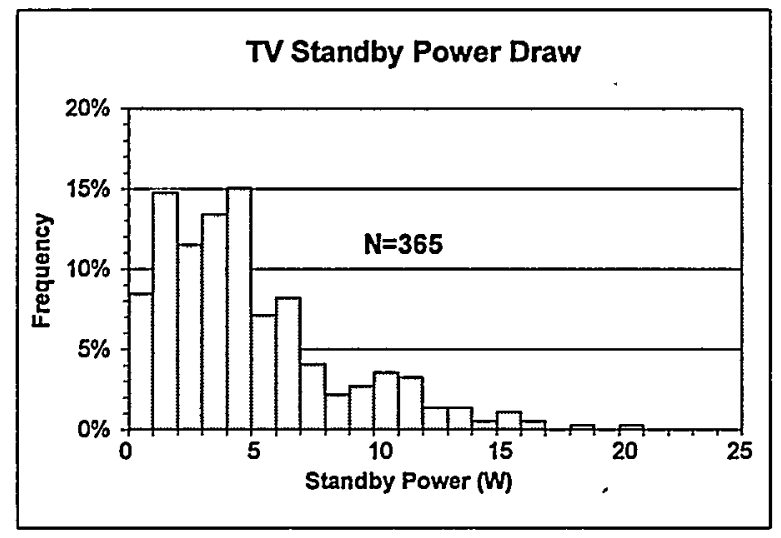

(a)

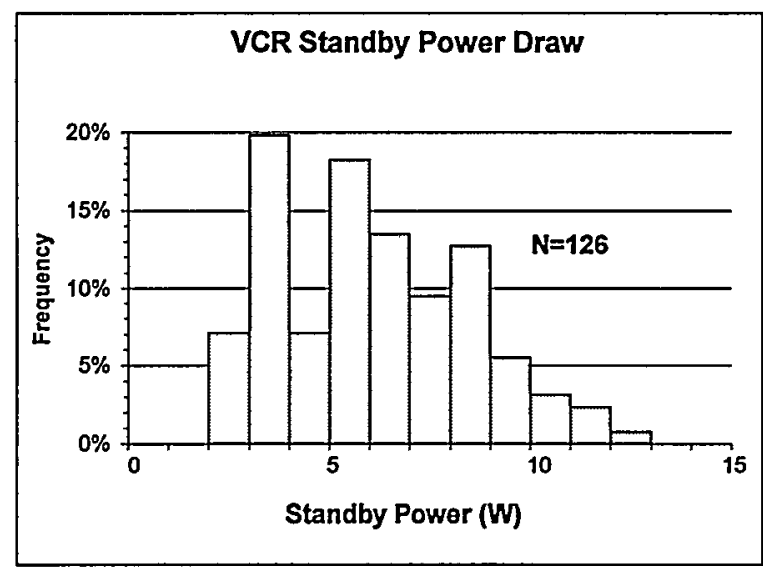

(c)

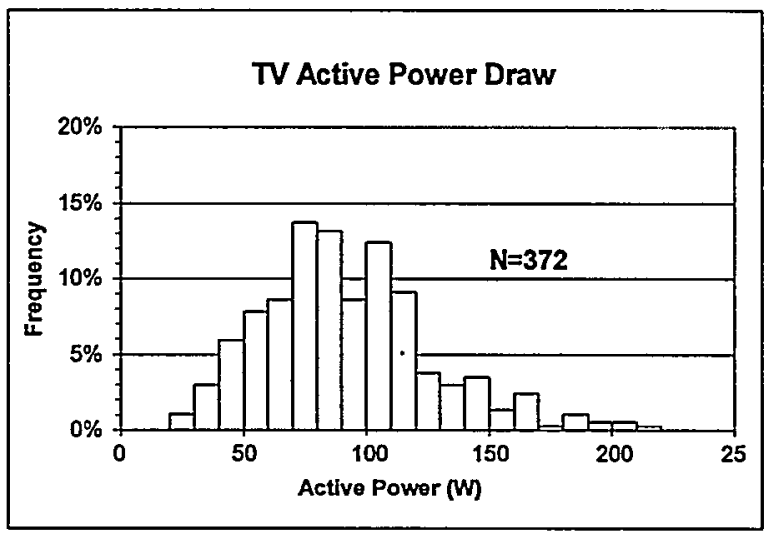

(b)

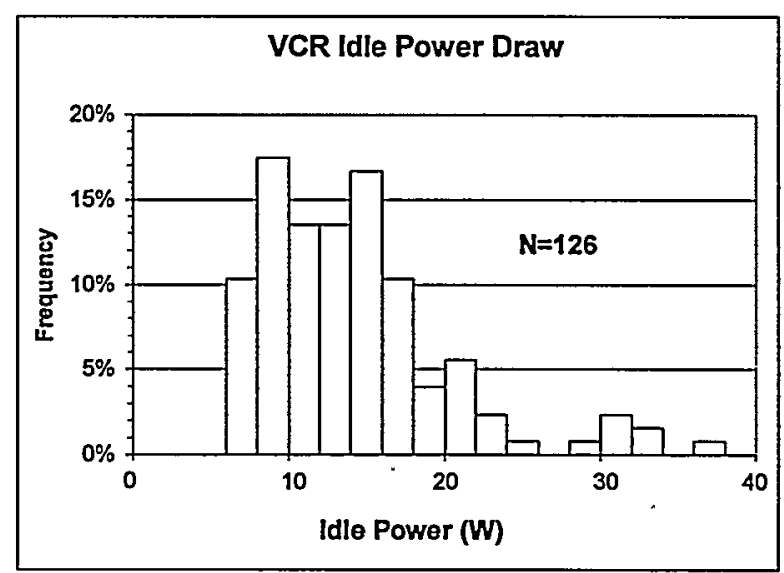

(d)

When grouped by product characteristics, these power measurements indicate that TV active power draw is closely related to screen size (see Table ES-1) and manufacturer, while TV standby power draw is related only to manufacturer. VCR idle and standby power draw levels are related to manufacturer and year of manufacture: VCR power draw values have been steadily decreasing since 1985 . Because of these relationships, average power values were weighted by industry-based estimates of the age, manufacturer, and size distributions of U.S. TVs and VCRs to ensure average power draw estimates that are representative of current U.S. stock. 
Table ES-1. Average TV power draw by screen size

\begin{tabular}{ccc}
\hline $\begin{array}{c}\text { Screen Size } \\
\text { (inches) }\end{array}$ & \multicolumn{2}{c}{ Average Power } \\
Active (watts) & Standby (watts) \\
\hline$<=18$ & 47 & 3.1 \\
$19-20$ & 68 & 5.1 \\
$25-27$ & 90 & 4.9 \\
$30-36$ & 114 & 5.3 \\
$39+$ & 142 & 3.5 \\
\hline Weighted average & $\mathbf{7 5}$ & $\mathbf{4 . 5}$ \\
\hline
\end{tabular}

To estimate national TV and VCR energy consumption values, ranges of power and mode usage were created to represent usage patterns in homes with more than one unit. Average energy use for homes with one unit, two units, etc. were calculated and summed to provide estimates of total national TV and VCR energy consumption.

Results indicate that TVs and VCRs comprise $3.6 \%$ of U.S. residential electricity consumption. In homes with at least one TV, the average annual household TV energy consumption is $310 \mathrm{kWh}, 23 \%$ of which is consumed while the sets are off. In homes with at least one VCR, the average annual household VCR energy consumption is 100 $\mathrm{kWh}$, over $50 \%$ of which is consumed while the units are off. A summary of U.S. TV and VCR energy use is shown in Table ES-2. Calculated values are rounded to two significant digits.

Table ES-2. Summary of residential TV and VCR energy use in the U.S.

\begin{tabular}{|c|c|c|c|c|}
\hline & TVs & & \multicolumn{2}{|c|}{ VCRs } \\
\hline Average active power (watts) & 75 & & $\mathbf{1 7 . 0}$ & \\
\hline Average idle power (watts) & -- & & 13.5 & \\
\hline Average standby power (watts) & 4.5 & & 5.9 & \\
\hline Average household energy use & (kWh/home) & $(\%)^{\mathrm{a}}$ & (kWh/home) & $(\%)^{\mathrm{a}}$ \\
\hline 1 unit home & 260 & $32 \%$ & 71 & $63 \%$ \\
\hline 2 unit home & 310 & $38 \%$ & 140 & $28 \%$ \\
\hline 3 unit home & 340 & $19 \%$ & 210 & $8.2 \%$ \\
\hline 4 unit home & 370 & $7.8 \%$ & & \\
\hline 5 unit home & 400 & $2.8 \%$ & & \\
\hline Weighted Average (kWh/home) & 310 & & 100 & \\
\hline Total U.S. energy (TWh/yr) & 31 & & 9.1 & \\
\hline $\begin{array}{l}\text { Percentage of U.S. } \\
\text { residential electricity use }\end{array}$ & $2.8 \%$ & & $0.82 \%$ & \\
\hline
\end{tabular}

${ }^{a}$ Share of U.S. homes

This report estimates the energy use of TVs and VCRs in the residential sector only. Total U.S. TV and VCR energy consumption is expected to be roughly 10 to $15 \%$ higher, depending on the number of TVs and VCRs in the U.S. commercial and industrial sectors and the usage of those units. 


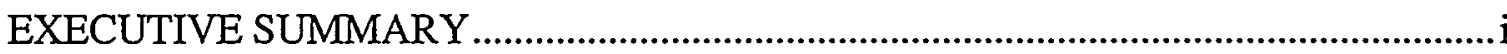

TABLE OF CONTENTS ................................................................................................

LIST OF TABLES ………...................................................................................... v

LIST OF FIGURES......................................................................................................... vi

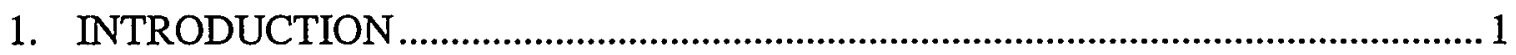

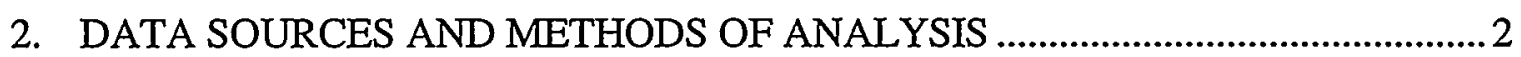

2.1. Stock and Usage Statistics ....................................................................................... 2

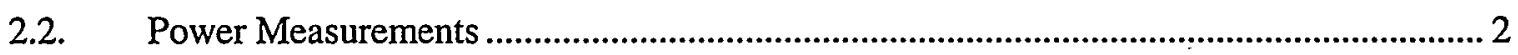

2.3. Minimizing Bias in the Sample of Power Measurements ................................................. 3

2.4. Calculation of Unit Energy Consumption.................................................................. 8

2.5. Calculation of Household and National Energy Consumption ........................................ 8

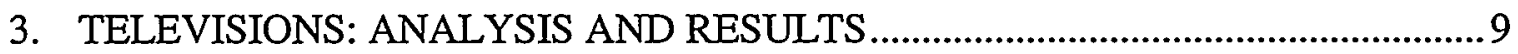

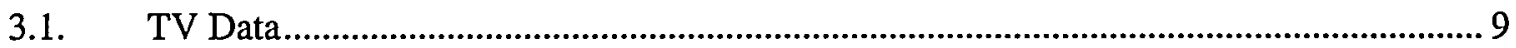

3.2. Representativeness of the Collected TV Data Sample.................................................... 14

3.3. Effects of Manufacturer, Screen Size, and Year on TV Power Draw............................. 16

3.4. Average TV Power Draw Levels .............................................................................. 17

3.5. Household and National TV Energy Consumption..................................................... 18

3.6. Sources of Uncertainty in the Calculation of National TV Energy Consumption ........... 23

4. VIDEOCASSETTE RECORDERS: ANALYSIS AND RESULTS..........................25

4.1. VCR Data .......................................................................................................... 25

4.2. Representativeness of the Collected VCR Data Sample ............................................... 28

4.3. Effects of Manufacturer and Year on VCR Power Draw................................................ 29

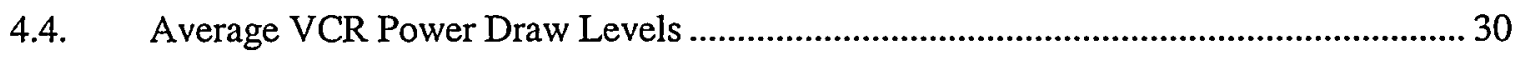

4.5. Household and National VCR Energy Consumption.....................................................30

4.6. Sources of Uncertainty in the Calculation of National VCR Energy Consumption ........ 35

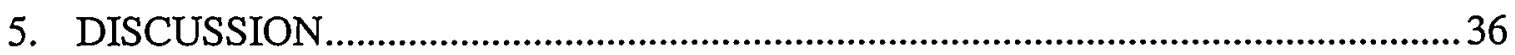

5.1. Summary of Recommended Values and Comparison to Other Studies.............................36

5.2. Forces and Trends That May Change These Results in the Future.................................. 38

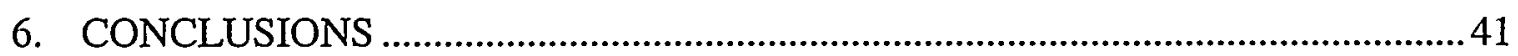

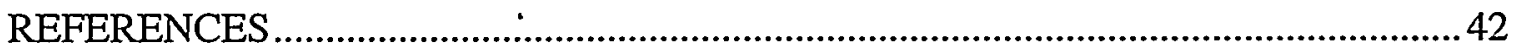


LBNL-42393

APPENDIX A: SINGLE PHASE POWER MULTIMETER, MODEL PLM-1-LP ...... 45

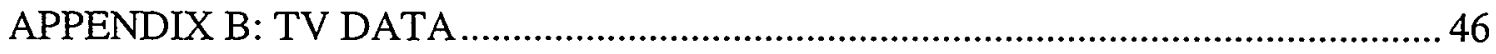

APPENDIX C: RELIABILITY OF POWER MEASUREMENTS............................. 57

APPENDIX D: TV AND VCR MANUFACTURER CODES AND RANKINGS ....... 58 APPENDIX E: SCATTER PLOTS OF POWER MEASUREMENT DATA................59 APPENDIX F: HISTORIC TRENDS IN TV AND VCR POWER DRAW ................. 64 APPENDIX G: EFFECT OF TV SCREEN SIZE ON POWER DRAW ...................... 66 APPENDIX H: VCR POWER MEASUREMENT DATA .......................................6 68 APPENDIX I. VCR POWER MEASUREMENTS USED TO DETERMONE AVERAGE

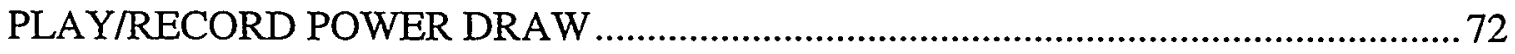




\section{LIST OF TABLES}

Table 2-1. Manufacturer market shares of TVs shipped in the U.S., 1985-1998 [13] ................... 6

Table 2-2. Manufacturer market shares of VCRs shipped in the U.S., 1985-1998 [13] ................. 6

Table 3-1. Average daily national and household TV usage ....................................................... 11

Table 3-2. Results of an analysis of variance conducted on TV data measured at repair and retail shops, with main effect 'manufacturer' and covariates 'screen size' and' year of manufacture'. 17

Table 3-3. Average unit TV power draw values: comparison of results obtained using different

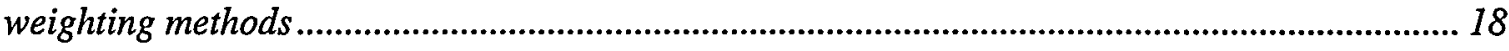

Table 3-4. Distribution of U.S. TVs by usage rank [3].............................................................. 18

Table 3-5. TV screen sizes: expected screen size distribution and average TV power draw values 19

Table 3-6. Average power use of TVs by usage rank (watts/unit) ................................................ 19

Table 3-7. Average household and unit TV usage in homes with 1, 2, 3, 4, and 5 TV sets (hrs/day)

Table 3-8. Average annual household and unit TV energy use by number of TVs in home ( $k W h / y r)$

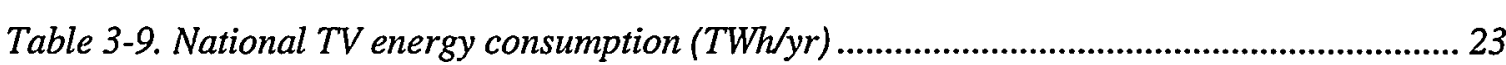

Table 4-1. Average household VCR usage (hrs/week/VCR-home) ................................................ 26

Table 4-2. Results of an analysis of variance conducted on VCR data measured at repair and retail shops, with main effect 'manufacturer' and covariate 'year of manufacture' 29

Table 4-3. Average unit VCR power draw values: comparison of results obtained using different weighting methods (watts/unit)................................................................................................... 30

Table 4-4. Distribution of U.S. VCRs by usage rank [3]............................................................. 31

Table 4-5. VCR year of manufacture: expected distribution and average VCR power draw values

Table 4-6. Average power use of VCRs by usage rank (watts/unit) ............................................ 32

Table 4-7. Average household and unit VCR usage in homes with 1, 2, and 3 VCRs (hrs/day) ... 33

Table 4-8. Average annual household and unit VCR energy use by number of VCRs in the home

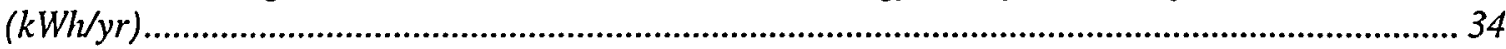

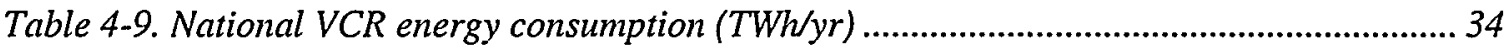

Table 5-1. Recommended average household TV and VCR energy consumption values.............. 36

Table 5-2. Recommended power and energy consumption values for TVs in the U.S. residential sector compared to results of other studies

Table 5-3. Recommended power and energy consumption values for VCRs in the U.S. residential sector compared to the results of other studies 


\section{LIST OF FIGURES}

Figure 2-1. The 4/3 Retirement Function [9] ...................................................................... 4

Figure 2-2. Number of TVs, VCRs, and TV/VCRs shipped in the U.S. between 1985 and 1998 [11][12]. 5

Figure 2-3. Percentage of TV screen sizes sold in the U.S. between 1985 and 1998 [13-18] ....... 7

Figure 4-1. Number of TVs in U.S. homes........................................................................... 10

Figure 4-2. TVs measured at repair shops: distribution of active power draw levels .................. 12

Figure 4-3. TVs measured at repair shops: distribution of standby power draw levels .............. 13

Figure 4-4. Age distribution of TVs measured at repair and retail shops compared to the expected distribution of an unbiased sample ........................................................................................... 14

Figure 4-5. Manufacturer market share distribution of TVs measured at repair and retail shops compared to the expected distribution of an unbiased sample 15

Figure 4-6. Screen size distribution of TVs measured at repair and retail shops compared to the expected distribution of an unbiased sample ............................................................................... 16

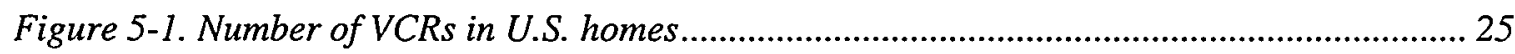

Figure 5-2. VCRs measured at repair shops: distribution of idle power draw levels .................. 27

Figure 5-3. VCRs measured at repair shops: distribution of standby power draw levels............. 27

Figure 5-4. Age distribution of VCRs measured at repair and retail shops compared to the expected distribution of an unbiased sample.

Figure 5-5. Manufacturer market share distribution of VCRs measured at repair and retail shops compared to the expected distribution of an unbiased sample 


\section{INTRODUCTION}

In an effort to more accurately determine nationwide energy consumption, the U.S. Department of Energy has recently commissioned studies with the goal of improving its understanding of the energy use of appliances in the "miscellaneous" end-use category. This study presents an estimate of the residential energy consumption of two of the most common domestic appliances in the miscellaneous end-use category: color televisions (TVs) and videocassette recorders (VCRs).

We used a bottom-up approach in estimating national TV and VCR energy consumption. First, we obtained estimates of stock and usage from national surveys, while TV and VCR power measurements and other data were recorded at repair and retail shops. Industry-supplied shipment and sales distributions were then used to minimize bias in the power measurement samples. To estimate national TV and VCR energy consumption values, ranges of power draw and mode usage were created to represent situations in homes with more than one unit. Average energy use values for homes with one unit, two units, etc. were calculated and summed to provide estimates of total national TV and VCR energy consumption.

Previous studies have estimated residential TV and VCR energy use [1][2]. This report differs in two ways: (1) the power measurement database is more extensive, and (2) the method of estimating national energy consumption is more detailed.

First, earlier studies used relatively few [1] or no [2] actual power measurements, and average power values were not adjusted to ensure representativeness of U.S. stock. In contrast, average power values used in this study were calculated from an extensive database containing power measurements for nearly 500 units. These measurements were compared to industry-published distributions of product manufacturer, year of manufacture, and screen size. Based on these comparisons, average power values were adjusted to ensure average power values representative of current U.S. stock.

Second, previous reports assume that power and usage are the same across all units in a home, implying that household TV energy consumption increases in direct proportion to the number of units. The analysis presented in this report allows for different power and usage patterns among units within a home-i.e., one unit may be used more often than the others are, or may use more or less power than the others do. We believe that the method used in this study results in a more realistic relationship between number of units and household energy consumption. 


\section{DATA SOURCES AND METHODS OF ANALYSIS}

The key factors we use to calculate national energy consumption for TVs and VCRs are:

- number of units in the U.S.

- hours of operation in each operating mode (typical usage)

- power levels in different modes

This section describes the data sources used in this study and the efforts taken to minimize bias in the power measurements.

\subsection{Stock and Usage Statistics}

Estimates of the number of TVs and VCRs in the U.S. were taken from the U.S. Energy Information Administration's 1997 Residential Energy Consumption Survey (RECS) [3], a national survey collected from a sample of 5,900 households statistically selected to represent the 101 million households in the U.S in 1997 [4]. For the 1997 RECS, all TV/VCR combination units were counted as both TVs and VCRs [5].

TV and VCR usage statistics were taken from two media research efforts. Nielsen Media Research's 1998 Report on Television bases usage estimates on data gathered from an electronic metering system placed on TV sets in 5,000 randomly selected U.S. households [6]. Media Dynamics' TV Dimensions 1998 derives its usage estimates from various media and industry sources, including Nielsen survey data that are not reported in Nielsen's Report on Television [7].

\subsection{Power Measurements}

We contracted with two repair shops-one in Berkeley, California and one in Castro Valley, California- to measure and record power draw values for TVs and VCRs after repair. ${ }^{1}$ Shops were given data log sheets, true RMS power meters capable of measuring to the nearest one-tenth of a watt (see Appendix A), and instructions to:

1. Record brand name, presence of remote control, and screen size (for TVs only).

2. Record model number, year of manufacture, and rated watts from the back/bottom panel.

3. Plug the unit into the meter and record the standby power draw when the digits on the power meter remain steady (do not fluctuate).

\footnotetext{
${ }^{1}$ For practical reasons, the repair shops did not measure VCR power in play and record modes. Instead, average play/record power values are derived from measurements recorded at LBNL. (See Section 5.1.)
} 
4. Switch the unit on. Set TVs to a station without reception, or "snow" and record the active power use. For VCRs, do not request play or any other motor driven function and record the idle power draw when the digits on the power meter remain steady (do not fluctuate).

5. Initial and date.

The repair shops earned $\$ 2$ for each appliance measured and recorded. From July through November 1998, handwritten data log sheets were collected monthly by LBNL and manually entered into an electronic database.

Some advantages of this approach include the quick and economical collection of many measurements, confidence of accuracy due to the technicians' familiarity with the appliances, and confidence that the units passing through the repair shops would be used regularly, since consumers were willing to pay for their repair.

The major disadvantage is that the sample population was unlikely to be representative of U.S. stock. For example, compared to existing stock, units requiring repair are likely to be older because newer units are less likely to need repair. This problem was partially corrected by adding measurements of newer units measured at retail shops as discussed in a later section. The methods and data sources we used to determine representative distributions of product age, and other product characteristics with the potential to effect power use, are discussed below.

\subsection{Minimizing Bias in the Sample of Power Measurements}

To determine whether the TV and VCR power measurements taken at the repair shops were representative of U.S. stock, we first estimated existing distributions for associated characteristics of U.S. TVs and VCRs. The three main characteristics that have the potential to affect power draw of TVs and VCRs are age, manufacturer, and screen size. ${ }^{2}$

To approximate characteristic distributions of existing stock, we collected industry estimates of number of units shipped, manufacturer market share, and TV sales by screen size. These distributions were adjusted for vintaging effects using a unit lifetime of 11 years [8] and the "4/3 Retirement Function" [9], which assumes that stock retires according to the function:

$$
\text { Stock Survival }= \begin{cases}1, & 0<A G E \leq \frac{2}{3} L I F E \\ 2-\frac{1.5(A G E)}{L I F E}, & \frac{2}{3} L I F E<A G E \leq \frac{4}{3} L I F E\end{cases}
$$

where $A G E$ is the age of the appliance and LIFE is the expected lifetime of the appliance.

\footnotetext{
${ }^{2}$ In some cases, different models within the same size, manufacturer, and year category also showed significant differences in power draw values.
} 
A graph of the 4/3 Retirement Function is shown in Figure 2-1. ${ }^{3}$

Figure 2-1. The 4/3 Retirement Function [9]

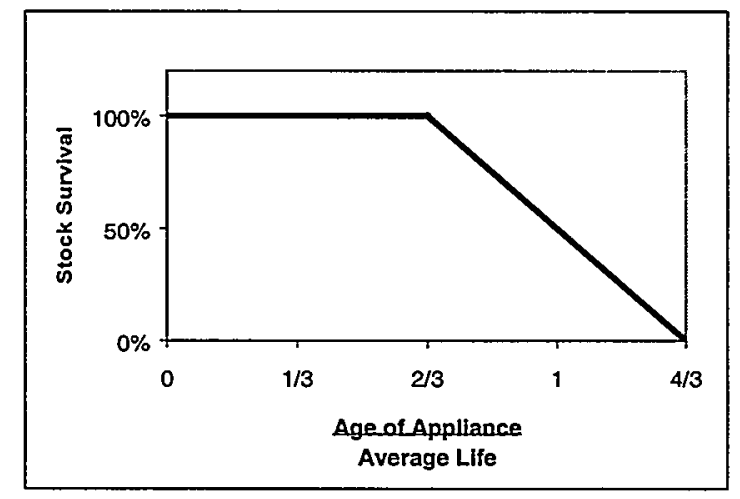

These weighted averages were then used to create "expected" distributions, i.e., the distributions of product age, manufacturer, or screen size that we would expect to find in an unbiased sample. The data used to create these expected distributions are discussed below.

\section{Age}

The age of current stock depends on the life expectancy of the appliance and the number of units sold in each year. The expected lifetime of both TVs and VCRs is 11 years [8], while the expected lifetime of a TV/VCR unit is 6 years [10]. The numbers of TVs, VCRs and TV/VCRs sold in each year between 1985 and 1997 were taken from Appliance Magazine's Statistical Review [11][12] as shown in Figure 2-2. Values for 1998 were not yet available and so were estimated to be the same as 1997.

\footnotetext{
${ }^{3}$ Although the 4/3 Retirement Function has not been thoroughly tested in the field, it did provide reasonable estimates of the age distributions for the TVs and VCRs that were measured at the repair shops. (See Sections 3.2 and 4.2.)
} 
Figure 2-2. Number of TVs, VCRs, and TVNCRs shipped in the U.S. between 1985 and 1998 [11][12]

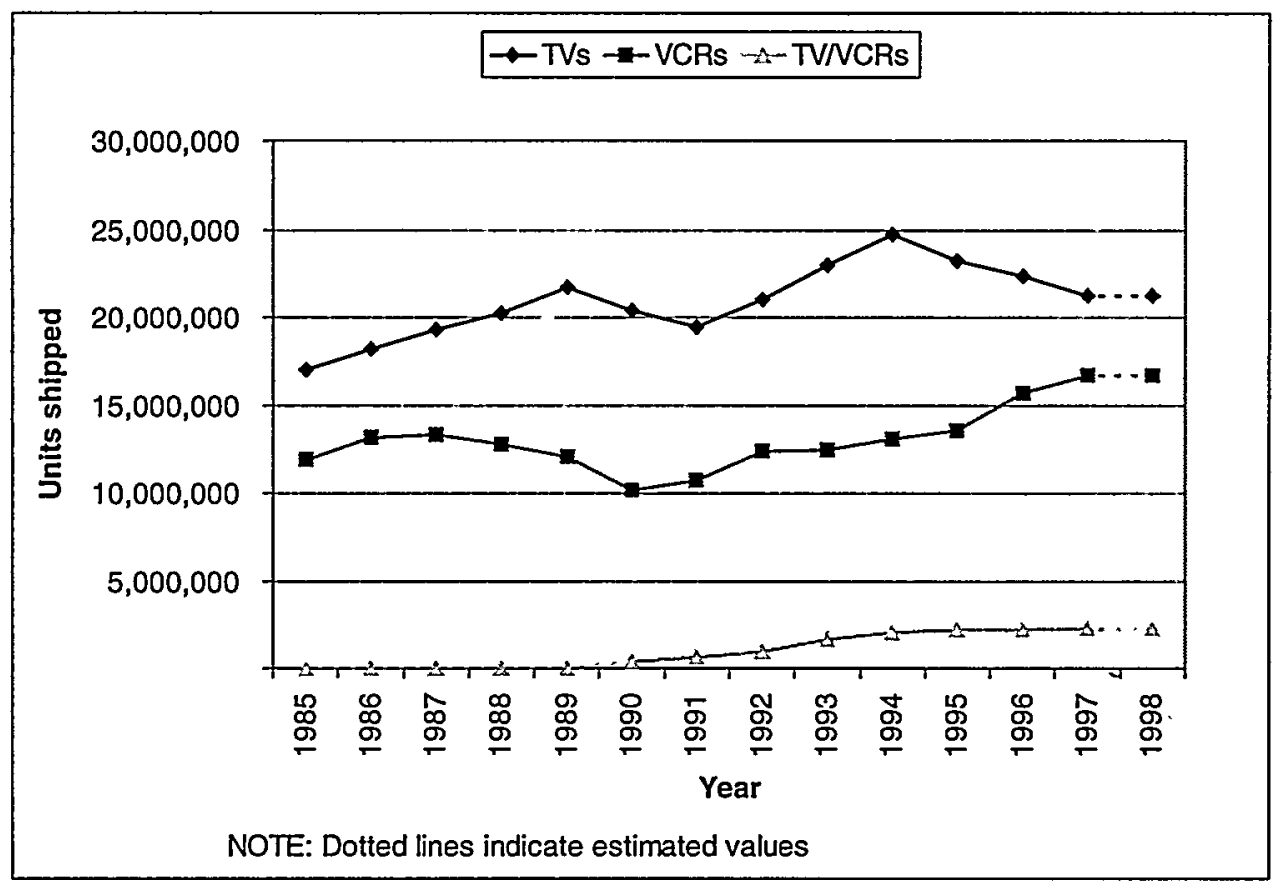

\section{Manufacturer}

Nine years (1989-97) of manufacturer market shares were taken from Appliance Magazine's Portrait of the U.S. Appliance Industry [13], which lists the U.S. market share for the top 10 to 12 appliance manufacturers. Figures for these reports are gathered from "surveys of appliance OEMs, industry suppliers, market analysts, confidential sources, and APPLIANCE magazine estimates" [8]. We estimated manufacturer market shares for the years 1985-1988 and for 1998. We also estimated 1989 market shares for VCRs due to questionable data in the first Portrait of the U.S. Appliance Industry printed in 1990. TV and VCR manufacturer market shares used in this study are shown in Tables 2-1 and 2-2. 
Table 2-1. Manufacturer market shares of TVs shipped in the U.S., 1985-1998 [13]

\begin{tabular}{|c|c|c|c|c|c|c|c|c|c|c|c|c|c|c|}
\hline \multirow{2}{*}{\begin{tabular}{|c|} 
TV \\
Manufacturer
\end{tabular}} & \multicolumn{14}{|c|}{ Year } \\
\hline & 1985 & 1986 & 1987 & 1988 & 1989 & 1990 & 1991 & 1992 & 1993 & 1994 & 1995 & 1996 & 1997 & 1998 \\
\hline Thomson $^{a}$ & 0.21 & 0.21 & 0.21 & 0.21 & 0.21 & 0.21 & 0.21 & 0.22 & 0.19 & 0.21 & 0.23 & 0.23 & 0.23 & 0.23 \\
\hline N. & 0.11 & 0.11 & 0.11 & 0.11 & 0.11 & 0.13 & 0.12 & 0.12 & 0.15 & 0.15 & 0.15 & 0.15 & 0.14 & 0.14 \\
\hline Zenith & 0.11 & 0.11 & 0.11 & 0.11 & 0.11 & 0.12 & 0.11 & 0.12 & 0.12 & 0.12 & 0.13 & 0.13 & 0.13 & 0.13 \\
\hline Sony & 0.07 & 0.07 & 0.07 & 0.07 & 0.07 & 0.07 & 0.07 & 0.06 & 0.06 & 0.07 & 0.08 & 0.09 & 0.10 & 0.10 \\
\hline Sharp & 0.06 & 0.06 & 0.06 & 0.06 & 0.06 & 0.05 & 0.05 & 0.05 & 0.05 & 0.05 & 0.06 & 0.06 & 0.07 & 0.07 \\
\hline Sanyo & 0.05 & 0.05 & 0.05 & 0.05 & 0.05 & 0.05 & 0.06 & 0.06 & 0.07 & 0.07 & 0.06 & 0.06 & 0.06 & 0.06 \\
\hline Matsushita $^{c}$ & 0.06 & 0.06 & 0.06 & 0.06 & 0.06 & 0.06 & 0.06 & 0.05 & 0.04 & 0.04 & 0.04 & 0.04 & 0.05 & 0.05 \\
\hline Toshiba & 0.03 & 0.03 & 0.03 & 0.03 & 0.03 & 0.05 & 0.06 & 0.05 & 0.05 & 0.05 & 0.04 & 0.04 & 0.05 & 0.05 \\
\hline Mitsubishi & 0.04 & 0.04 & 0.04 & 0.04 & 0.04 & 0.03 & 0.03 & 0.02 & 0.02 & 0.02 & 0.02 & 0.01 & 0.01 & 0.01 \\
\hline Samsung & 0.03 & 0.03 & 0.03 & 0.03 & 0.03 & 0.05 & 0.05 & 0.04 & 0.03 & 0.03 & 0.02 & 0.03 & 0.03 & 0.03 \\
\hline Goldstar $^{\mathrm{d}}$ & 0.04 & 0.04 & 0.04 & 0.04 & 0.04 & 0.03 & 0.03 & 0.02 & 0.02 & 0.03 & 0.02 & 0.02 & 0.02 & 0.02 \\
\hline Hitachi & 0.02 & 0.02 & 0.02 & 0.02 & 0.02 & 0.02 & nal & nal & na & na & na & na & na & na \\
\hline Others & 0.17 & 0.17 & 0.17 & 0.17 & 0.17 & 0.13 & 0.15 & 0.19 & 0.20 & 0.16 & 0.15 & 0.14 & 0.12 & 0.12 \\
\hline Total & 1.00 & 1.00 & 1.00 & 1.00 & 1.00 & 1.00 & 1.00 & 1.00 & 1.00 & 1.00 & 1.00 & 1.00 & 1.00 & 1.00 \\
\hline \multicolumn{15}{|l|}{${ }^{a} \mathrm{RCA}, \mathrm{GE}$} \\
\hline \multicolumn{15}{|c|}{ b Philips-Magnavox } \\
\hline \multicolumn{15}{|c|}{${ }^{\mathrm{c}}$ Panasonic, Quasar } \\
\hline \multicolumn{15}{|c|}{ ' Goldstar, LG Electronics } \\
\hline 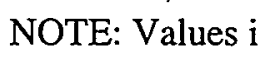 & & & & & & & & & & & & & & \\
\hline
\end{tabular}

Table 2-2. Manufacturer market shares of VCRs shipped in the U.S., 1985-1998 [13]

\begin{tabular}{|c|c|c|c|c|c|c|c|c|c|c|c|c|c|c|}
\hline \multirow{2}{*}{$\begin{array}{c}\text { VCR } \\
\text { Manufacturer }\end{array}$} & \multicolumn{14}{|c|}{ Year } \\
\hline & 1985 & 1986 & 1987 & 1988 & 1989 & 1990 & 1991 & 1992 & 1993 & 1994 & 1995 & 1996 & 1997 & 199 \\
\hline Thomson $^{\text {a }}$ & 0.15 & 0.15 & 0.15 & 0.15 & 0.15 & 0.15 & 0.15 & 0.14 & 0.16 & 0.18 & 0.18 & 0.21 & 0.19 & 0.19 \\
\hline Matsushita ${ }^{b}$ & 0.21 & 0.21 & 0.21 & 0.21 & 0.21 & 0.21 & 0.18 & 0.15 & 0.11 & 0.12 & 0.10 & 0.9 & 0.13 & 0.13 \\
\hline N.A.P. ${ }^{c}$ & 0.09 & 0.09 & 0.09 & 0.09 & 0.09 & 0.09 & 0.11 & 0.11 & 0.11 & 0.11 & 0.12 & 0.11 & 0.11 & 0.11 \\
\hline Sony & 0.04 & 0.04 & 0.04 & 0.04 & 0.04 & 0.04 & 0.04 & 0.05 & 0.05 & 0.05 & 0.05 & 0.07 & 0.07 & 0.07 \\
\hline JVC & 0.05 & 0.05 & 0.05 & 0.05 & 0.05 & 0.05 & 0.05 & 0.05 & 0.06 & 0.07 & 0.06 & 0.06 & 0.06 & 0.06 \\
\hline Sharp & 0.07 & 0.07 & 0.07 & 0.07 & 0.07 & 0.07 & 0.07 & 0.07 & 0.06 & 0.06 & 0.05 & 0.05 & 0.05 & 0.05 \\
\hline Zenith & 0.04 & 0.04 & 0.04 & 0.04 & 0.04 & 0.04 & 0.04 & 0.04 & 0.05 & 0.05 & 0.05 & 0.05 & 0.05 & 0.05 \\
\hline Sanyo/Fisher & 0.04 & 0.04 & 0.04 & 0.04 & 0.04 & 0.04 & 0.05 & 0.05 & 0.05 & 0.06 & 0.05 & 0.04 & 0.04 & 0.04 \\
\hline Toshiba & 0.04 & 0.04 & 0.04 & 0.04 & 0.04 & 0.04 & 0.04 & 0.03 & 0.02 & 0.02 & 0.03 & 0.04 & 0.04 & 0.04 \\
\hline Hitachi & 0.02 & 0.02 & 0.02 & 0.02 & 0.02 & 0.02 & 0.03 & 0.03 & 0.03 & 0.04 & 0.03 & 0.03 & 0.03 & 0.03 \\
\hline Mitsubishi & 0.03 & 0.03 & 0.03 & 0.03 & 0.03 & 0.03 & 0.03 & 0.03 & 0.03 & 0.03 & 0.03 & 0.03 & 0.03 & 0.03 \\
\hline Goldstar $^{d}$ & 0.04 & 0.04 & 0.04 & 0.04 & 0.04 & 0.04 & 0.04 & 0.03 & 0.03 & 0.05 & 0.04 & 0.04 & 0.02 & 0.02 \\
\hline Samsung & 0.04 & 0.04 & 0.04 & 0.04 & 0.04 & 0.04 & 0.04 & 0.03 & 0.03 & 0.05 & 0.03 & na & na & na \\
\hline Others & 0.05 & 0.05 & 0.05 & 0.05 & 0.05 & 0.05 & 0.13 & 0.19 & 0.24 & 0.11 & 0.18 & 0.18 & 0.18 & 0.18 \\
\hline Total & 1.00 & 1.00 & 1.00 & 1.00 & 1.00 & 1.00 & 1.00 & 1.00 & 1.00 & 1.00 & 1.00 & 1.00 & 1.00 & 1.00 \\
\hline \multicolumn{15}{|l|}{${ }^{\mathrm{a}} \mathrm{RCA}, \mathrm{GE}$} \\
\hline \multicolumn{15}{|c|}{${ }^{\mathrm{b}}$ Panasonic, Quasar } \\
\hline \multicolumn{15}{|c|}{${ }^{c}$ Philips-Magnavox } \\
\hline \multicolumn{15}{|c|}{${ }^{\mathrm{d}}$ Goldstar, LG Electronics } \\
\hline
\end{tabular}




\section{Screen Size}

Screen size sales were taken from industry sales to dealers data reported in Television Digest [14][15][16][17][18][19]. We estimated values for 1985-88 and 1997-98 based on trends seen in years for which statistics were available. Percentages of TVs sold in each of five screen size categories-less than or equal to 18 inches, 19-20 inches, 25-27 inches, 30-35 inches, and greater than or equal to 39 inches-are shown in Figure 2-3.

Figure 2-3. Percentage of TV screen sizes sold in the U.S. between 1985 and 1998 [13-18]

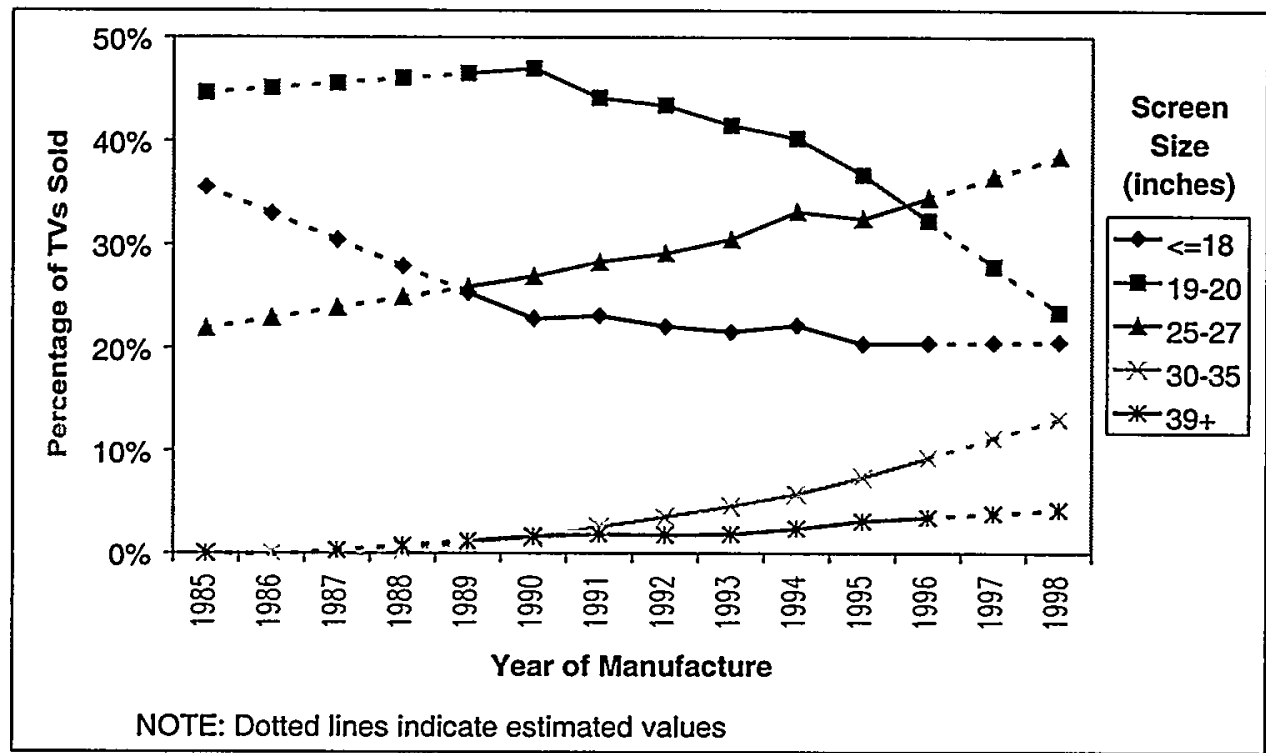

Television Digest did not report sales figures for TV/VCR units by screen size, as was done for direct view and projection TVs. Since the vast majority of TV/VCR units have 13 or 20 inch screens, we split the TV/VCR sales figures evenly between the " $<=18$ " inch and "19-20" inch categories for this study. Although TVs and TV/VCR units have different expected lifetimes, the effect of this difference is negligible since TV/VCR units represented less than five percent of TVs in the U.S. 


\subsection{Calculation of Unit Energy Consumption}

Nearly all consumer appliances have at least two power modes and many have more than two. Annual unit energy consumption $(U E C)$ of any appliance can be estimated as:

$$
U E C=\sum_{i=1}^{M} P_{i} \cdot T_{i}
$$

where $M$ is the number of available appliance modes, $P_{i}$ is the average power draw of the appliance in mode $i$, and $T_{i}$ is the number of hours per year that the appliance is in mode $i$. For each appliance, $\Sigma T_{i}=8760$ hours per year.

Televisions sold in the U.S. generally have only standby (off) and active (on) modes, while VCRs have standby (off), idle (on), and several active modes involving the playing, recording, rewinding, pausing, etc. of videocassettes. For this report, we will address the time spent in and power consumed during the active and standby modes of both appliances. Of the many VCR modes that could be considered "active" modes, this study includes only play and record modes. The VCR "idle" mode will be investigated as well. This mode occurs when the VCR is on but not active.

\subsection{Calculation of Household and National Energy Consumption}

Many households have more than one of any given appliance. For each unit in a household, UEC is calculated using Equation 2. Average annual household energy consumption values for households with $\mathrm{N}$ units $\left(H E C_{N}\right)$ are calculated as the sum of the $N$ UEC values:

$$
H E C_{N}=\sum_{i=1}^{N} U E C_{i}
$$

National energy consumption $(E)$ attributable to a specific appliance is then calculated as:

$$
E=\sum_{N=1}^{U} H_{N} \cdot H E C_{N}
$$

where $U$ is the maximum number of units in a home, $H_{N}$ is the number of homes in the U.S. with $\mathrm{N}$ units, and $H E C_{N}$ is the average aggregate energy consumption for homes with $\mathrm{N}$ units. 


\section{TELEVISIONS: ANALYSIS AND RESULTS}

In this section, we first present a summary of all TV data used in this study, including number of color TVs in the U.S., ${ }^{4}$ typical operating hours, and power measurements. Effects of TV age, manufacturer, and screen size on power levels are calculated, and, where appropriate, industry shipment and sales distributions are used to weight average unit power draw values derived from the power measurements. Household and national energy consumption values are estimated using ranges of power and usage values. Results presented include average unit, average household, and total national energy consumption of color TVs in the U.S.

\subsection{TV Data}

This section describes the number of TVs in U.S. homes, typical usage, and TV power measurements collected at repair shops.

\section{Number of TVs}

There are 211.5 million TVs in U.S. homes [3], an estimated 10.8 million of which are TV/VCR combination units [9][13]. The U.S. Energy Information Administration (EIA) provided information about the number of color TVs in each of the 101 million U.S. homes [3] as shown in Figure 4-1. Nielsen reported similar findings [6], also shown in Figure 4-1 for comparison.

\footnotetext{
${ }^{4}$ Black and white TVs are not included in this study.
} 
Figure 3-1. Number of TVs in U.S. homes

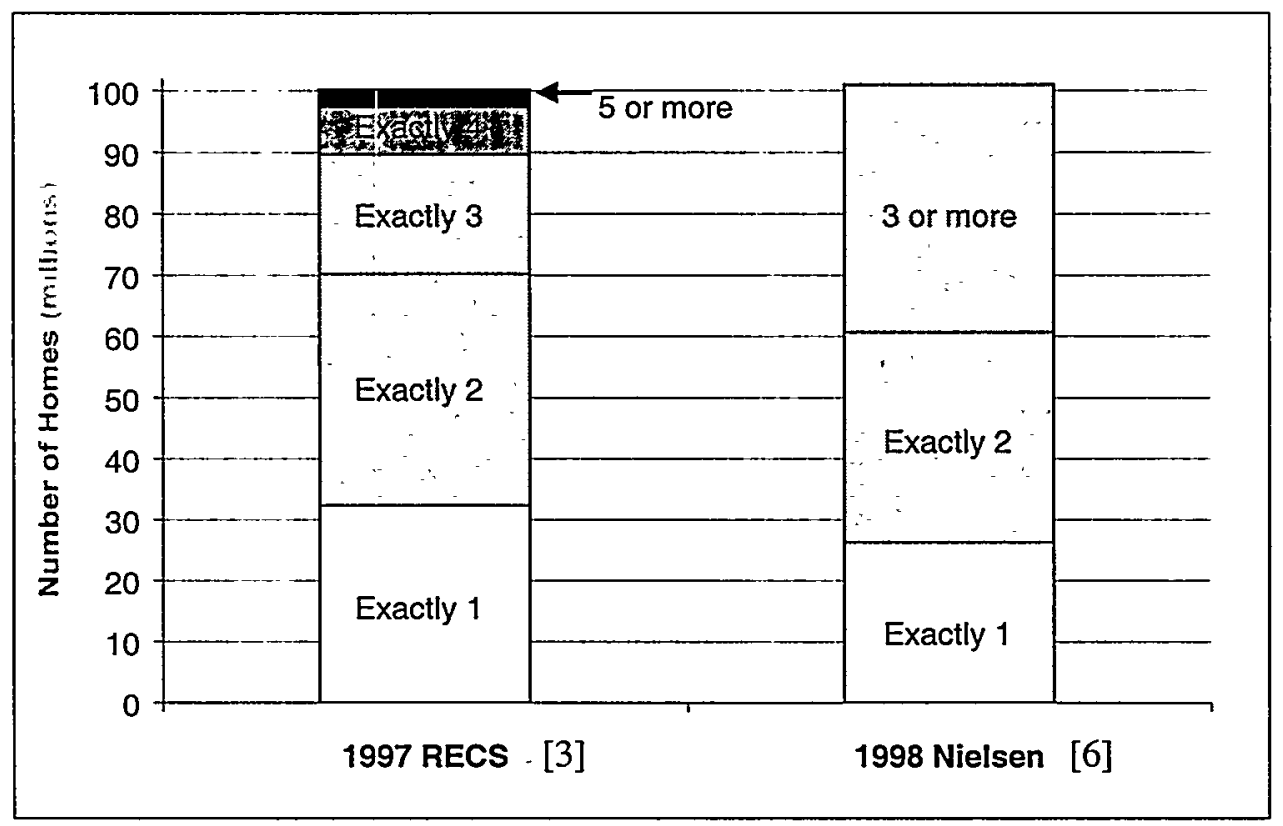

Using an average TV lifetime of 11 years [8], an average TV/VCR lifetime of 6 years [10], shipment data [11][12] and the 4/3 Retirement Function [9], about 238 million of the 308 million TVs and TV/VCR combination units shipped since 1985 should still be operating. The difference between this number and the number obtained by the EIA survey is about 26 million units. This difference could be partially attributed to the commercial TVs that are counted in shipment data, but are not counted by the EIA survey. The uncertainty in the average lifetime of TVs and TV/VCRs is also likely to be a factor.

\section{TV Usage}

We calculated household TV usage as the sum of three different activities: watching broadcast television, watching videocassettes, and playing video games. Average time per household spent in each of these activities was derived from media research and used to calculate average household TV usage as follows.

The total number of broadcast television viewing hours was calculated from several different values. Nielsen [6] reports that the average U.S. home watches broadcast television for 7.2 hours per day. This number is not an accurate estimate of TV set usage because it includes all recording activity, whether or not the TV is on during the recording session. In addition, the Nielsen estimate does not include videocassette watching, video game playing, or the time multiple sets are watched simultaneously.

To transform the Nielsen estimate of "broadcast viewing hours" to a number that represents "TV set usage hours" we first subtracted the average amount of time that 
households record broadcast television with the TV off-about 0.15 hours per day per TV-home ${ }^{5}[7]$-from Nielsen's estimate. The resulting value is about 7.05 hours per day per TV-home.

Next, we added the amount of time two or more sets are tuned in simultaneously. This is necessary because Nielsen reports only the amount of time that at least one TV is tuned in. For example, if a husband and wife both watch TV from 7:00 to 10:00 every night, but the husband watches TV1 in the living room while the wife watches TV2 in the bedroom, Nielsen reports that the household television usage is 3 hours per day [20]. For our purposes, we would like to know the aggregate viewing hours for all TV sets, which would be TV1 usage plus TV2 usage, or 6 hours per day. According to media sources, two or more TVs are simultaneously tuned to different channels for $12 \%$ of the time that broadcast television is watched in homes with more than one TV [7]. Therefore, the average TV usage for a house with one TV remains 7.05 hours, while the average TV usage for households with more than one TV is 7.05 plus $12 \%$ of 7.05 , or 7.9 hours. $^{6}$

In the $88.9 \%$ of U.S. households that own a VCR, TVs are used to watch videocassettes for 4.0 hours per week [7], or 0.57 hours per day. In addition, in the $33 \%$ of homes that own video game equipment, video games are used 3 to 3.5 hours weekly [7]. For this report we use a video game usage of 3.25 hours per week, or 0.46 hours per day. These values were converted to hours per TV-home and added to the values calculated above to obtain average daily usage values of 7.7 hours for homes with one TV set, and 8.6 hours for homes with more than one TV set. A summary of average daily U.S. national and household TV usage is presented in Table 4-1.

Table 3-1. Average daily national and household TV usage

\begin{tabular}{|c|c|c|c|c|}
\hline & $\begin{array}{l}\text { Homes w/ } \\
\text { Appliance } \\
\text { (millions) }\end{array}$ & $\begin{array}{c}\text { Avg. Usage per } \\
\text { Home w/ Appliance } \\
\text { (hrs/day/home) }\end{array}$ & $\begin{array}{c}\text { U.S. Total } \\
\text { Usage } \\
\text { (MM hrs/day) }\end{array}$ & $\begin{array}{l}\text { Avg. Usage per } \\
\text { TV-Home } \\
\text { (hrs/day/TV-home) }\end{array}$ \\
\hline Broadcast (ITV) & $32.3^{\mathrm{a}}$ & 7.1 & 228 & 7.1 \\
\hline Broadcast $(2+\mathrm{TVs})$ & $67.9^{a}$ & 7.9 & 536 & 7.9 \\
\hline$\overline{\mathrm{VCR}}$ & $88.9^{\mathrm{a}}$ & 0.57 & 51 & 0.51 \\
\hline Video Game & $33.3^{b}$ & 0.46 & 15 & 0.15 \\
\hline Total 1 TV-home & \multicolumn{3}{|c|}{ [Broadcast $($ ITV $)+V C R+$ Video Game] } & 7.7 \\
\hline Total 2+ TV-home & \multicolumn{3}{|c|}{ [Broadcast $(2+T V s)+V C R+$ Video Game] } & 8.6 \\
\hline U.S. Total & & & 830 & 8.3 \\
\hline
\end{tabular}

\footnotetext{
"A "TV-home" is a home with at least one TV.

${ }^{6}$ These values do not include the number of hours that three or more TVs are tuned in simultaneously. For more information on the possible effects of this omission on our results, see Section 4.6.
} 


\section{TV Power Measurements}

This section provides a summary of the 321 TVs measured at the repair shops. For a complete list of the TV power measurements used in this study, see Appendix B.

Figure 4-2 shows the distribution of power levels measured while the TVs were active. In an attempt to obtain comparable results, all TVs were set to a channel with no reception ("snow"); however, even this method does not guarantee reliable measurements, since "snow" on one channel may be brighter or dimmer than the "snow" on another channel. See Appendix $\mathrm{C}$ for more information on the reliability of power measurements.

Figure 3-2. TVs measured at repair shops: distribution of active power draw levels

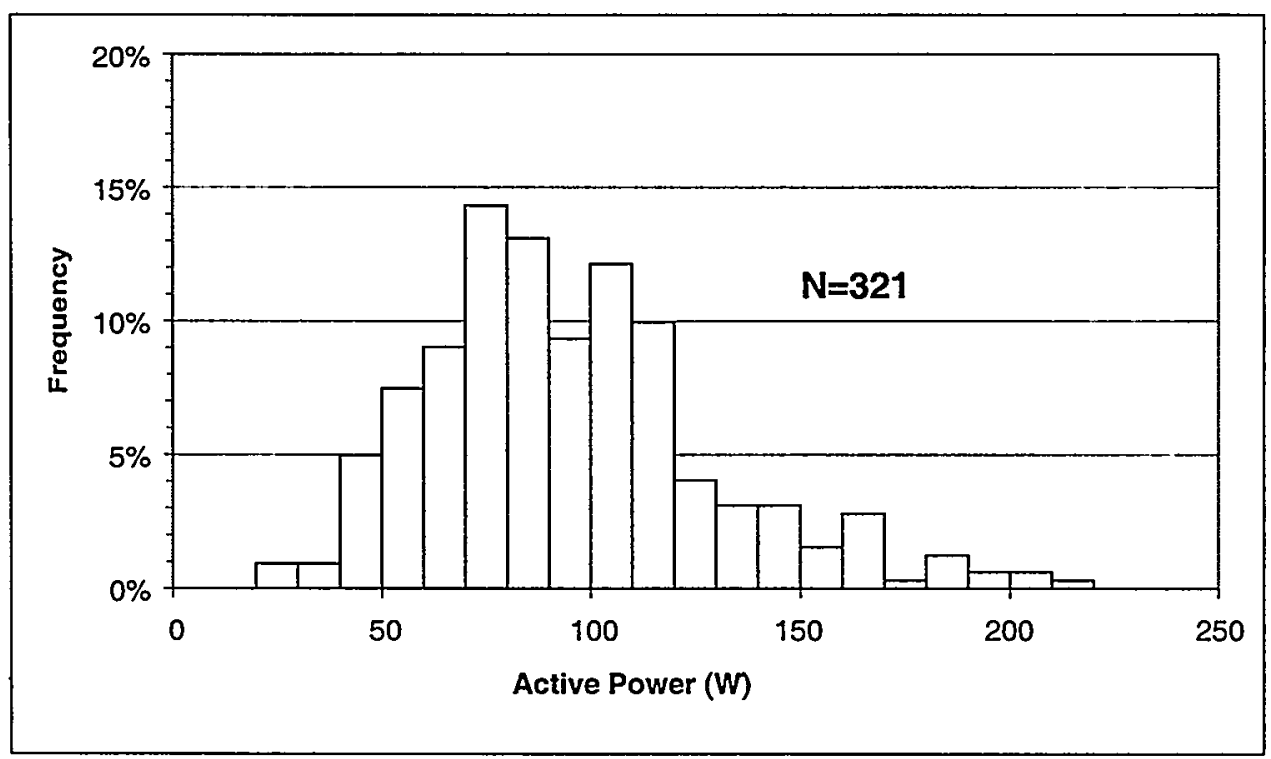


Figure 4-3 shows the distribution of power measurements taken while the TVs were in standby mode. This graph excludes 7 of the 321 TVs measured at the repair shop because they did not use power in standby mode.

Figure 3-3. TVs measured at repair shops: distribution of standby power draw levels

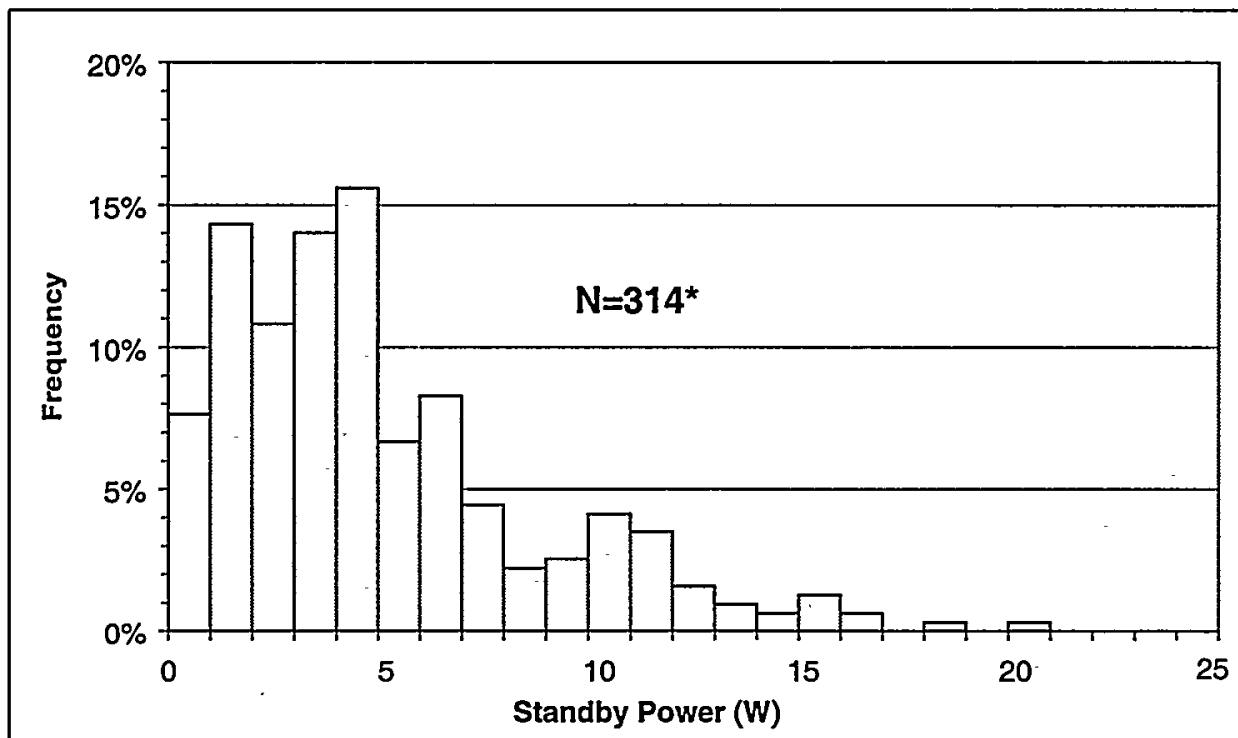

"NOTE: Excludes the 7 of 321 TVs (2.2\%) that did not use power in the standby mode.

Because the measurements represented in Figures 4-2 and 4-3 were taken at repair shops, it is likely that they are not representative of U.S. TV stock. The following section will address this issue. 


\subsection{Representativeness of the Collected TV Data Sample}

This section compares characteristics of the power measurement data set used in this study to characteristics we would expect to see in an unbiased data set. In particular, this section compares the collected distributions of TV age (year of manufacture), manufacturer, and screen size to "expected" distributions calculated from industry data as described in Section 2.3.

Age

As one might expect, relatively few new TVs were measured at the repair shops. To offset this lack of newer units, the data set was supplemented by retail shop measurements of twenty-eight 1996 units measured by the Florida Solar Energy Center (FSEC), and twenty-three 1998 units measured by Lawrence Berkeley National Laboratory (LBNL). Figure $4-4$ shows a comparison between the complete data set of 372 TVs and the expected age distribution, which was obtained as described in Section 2.3. For a complete list of power measurements used in this study, see Appendix B.

Figure 3-4. Age distribution of TVs measured at repair and retail shops compared to the expected distribution of an unbiased sample

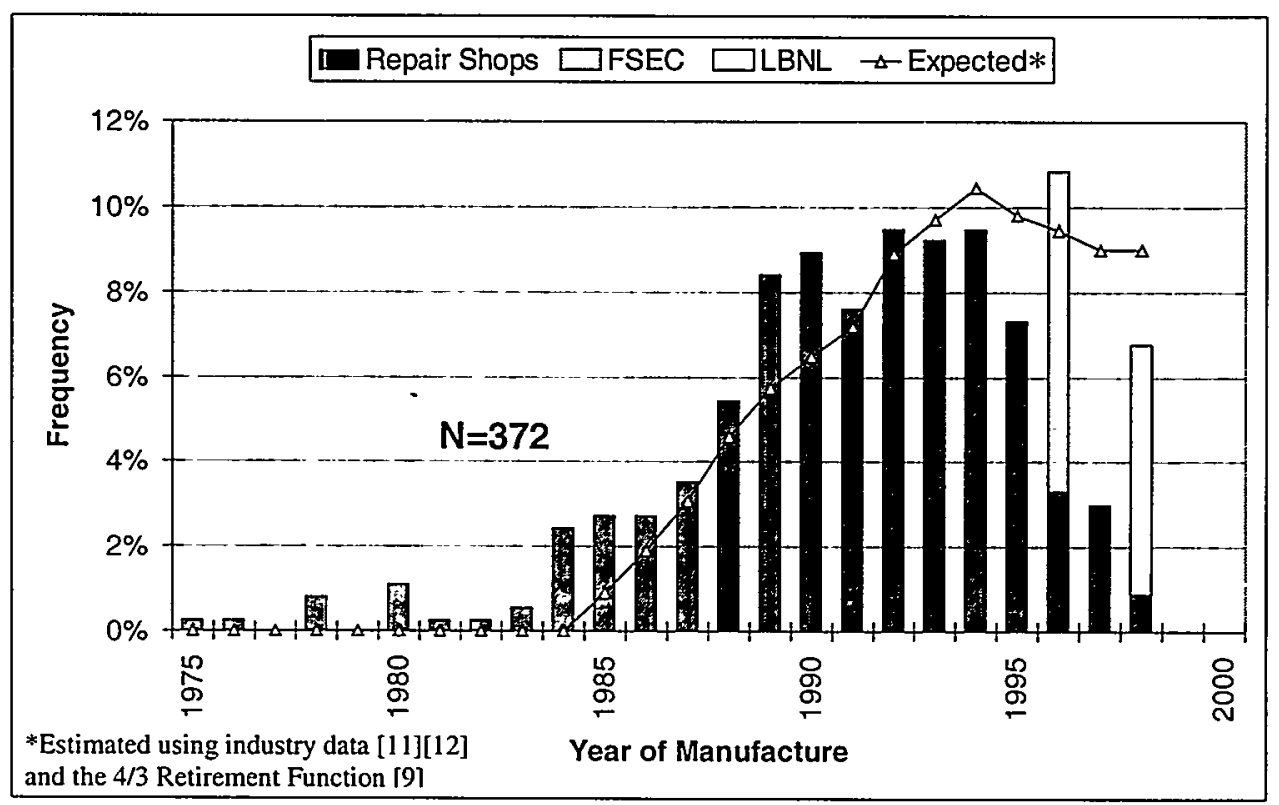




\section{Market Share}

Figure 4-5 shows the market share distribution of the TVs measured for this study compared to the expected distribution, which was obtained as described in Section 2.3. See Appendix D for a chart matching code letters $A$ through $M$ to the respective manufacturers' names.

Figure 3-5. Manufacturer market share distribution of TVs measured at repair and retail shops compared to the expected distribution of an unbiased sample

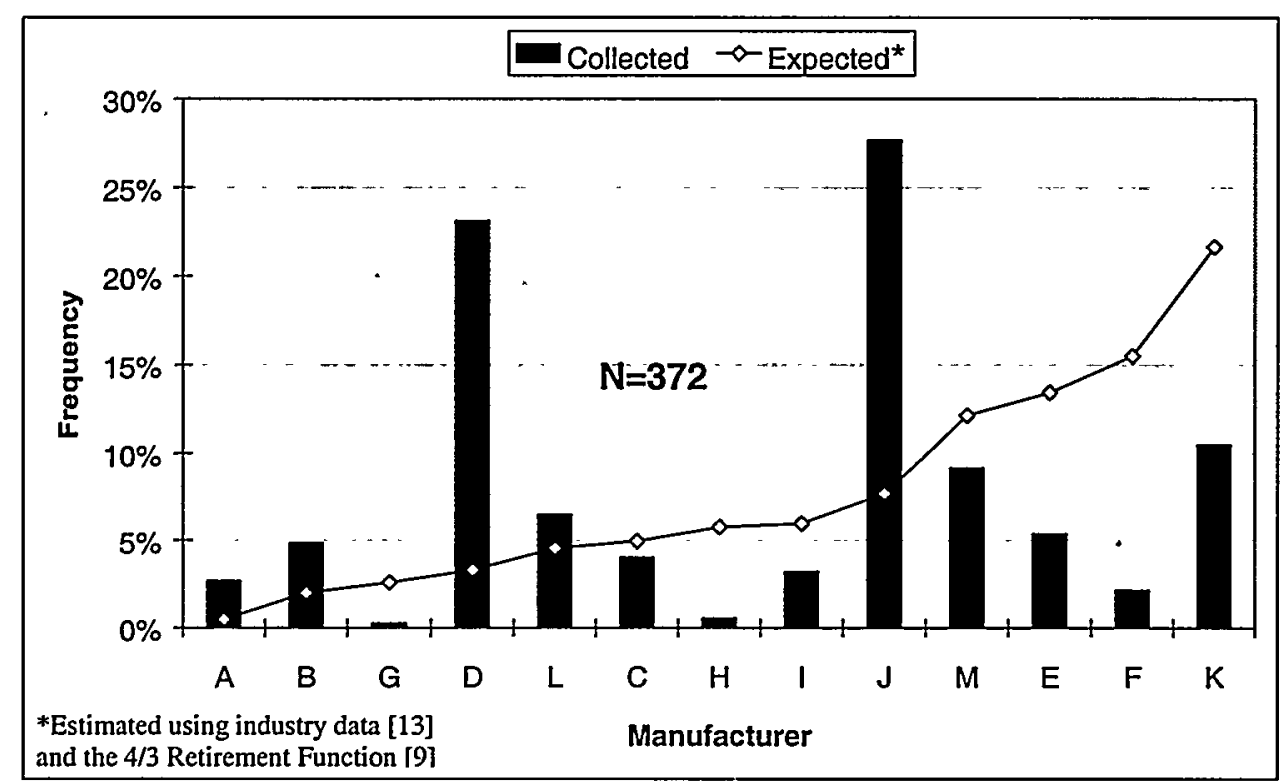

Figure 4-5 shows that the market-share distribution found in our sample deviates significantly from the expected distribution. One might think that the high frequency of manufacturers $D$ and $J$ in the repair shops indicate that these manufacturers produce TVs that are more likely to require repair; however, surveys show that this is not true [21][22][23]. One reason for this discrepancy may be that these brands are more valued and thus more likely to be repaired than replaced. Another possibility is that our sample population has been affected by local manufacturer bias; i.e. the distribution of TVs in California may not be representative of the national average. 


\section{Screen Size}

Figure 4-6 shows the screen size distribution of the TVs measured for this study compared to the expected distribution, which was obtained as described in Section 2.3.

Figure 3-6. Screen size distribution of TVs measured at repair and retail shops compared to the expected distribution of an unbiased sample

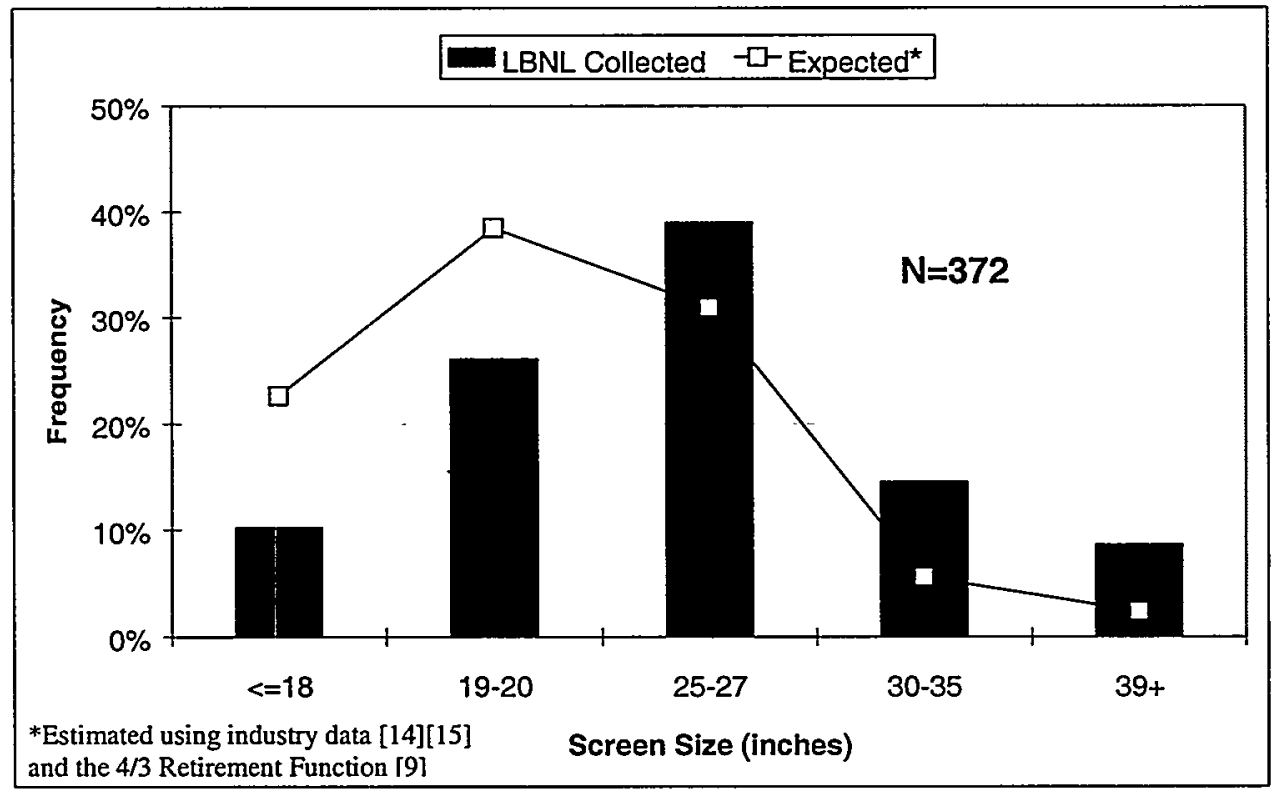

It can be seen from Figure 4-6 that, overall, the screen sizes in our sample are larger than the expected distribution. This implies that consumers are more likely to discard smaller, less expensive units than to repair them. See Section 4.6 for a discussion of this issue.

\subsection{Effects of Manufacturer, Screen Size, and Year on TV Power Draw}

This section describes the results of an analysis of variance conducted on the TV data measured for this study. For plots showing the effects of manufacturer, year of manufacture, and screen size on the power levels of these TVs, see Appendix E.

Results of an analysis of variance ${ }^{7}$ indicate that 'screen size' and 'manufacturer' are significant in predicting active power draw, while 'year of manufacture' is not. For standby power draw, only 'manufacturer' has a significant effect, while 'screen size' and 'year of manufacture' do not. A summary of the results of the analysis of variance is given in Table 4-2.

\footnotetext{
${ }^{7}$ Main effect: 'manufacturer.' Covariates: 'screen size,' 'year of manufacture.'
} 
Table 3-2. Results of an analysis of variance conducted on TV data measured at repair and retail shops, with main effect 'manufacturer' and covariates 'screen size' and' year of manufacture'

\begin{tabular}{lrcccccc}
\hline Variable & \multicolumn{3}{c}{ Active } & \multicolumn{3}{c}{ Standby } \\
$\cdot$ & $\mathrm{F}$ & $\mathrm{df}$ & $\mathrm{p}$ & $\mathrm{F}$ & $\mathrm{df}$ & $\mathrm{p}$ \\
\hline Manufacturer & 3.0 & 12 & $<0.0005$ & 11.8 & 12 & $<0.0005$ \\
Screen Size & 367.3 & 1 & $<0.0005$ & 3.0 & 1 & 0.084 \\
Year of Manufacture & 0.6 & 1 & 0.421 & 0.2 & 1 & 0.639 \\
\hline
\end{tabular}

Further analysis showed that that there is a positive correlation between active power draw and screen size (Pearson $r=0.740$ ). These results imply that (1) some manufacturers consistently make more efficient TVs than other manufacturers, (2) larger TVs use more power when they are on than smaller TVs do, and (3) neither active nor standby TV power use has changed significantly since 1985. (See Appendix F)

While the effect of screen size on standby power draw is not statistically significant at the 0.05 alpha level, the probability of only $8.4 \%$ shown in Table 4-2 suggests that further investigation may be warranted. For more information about the relationship between TV screen size and power draw, see Appendix G.

\subsection{Average TV Power Draw Levels}

Because power draw is related to both size and manufacturer, and because the distributions of size and manufacturer in our database were not representative of U.S. stock, average power draw values were weighted according to expected distributions bàsed on industry data. The average TV power draw $\left(\overline{P_{T V}}\right)$ is calculated as:

$$
\overline{P_{T V}}=\sum_{m=1}^{M} \sum_{s=1}^{S} f_{s} f_{m} \overline{P_{s m}}
$$

where $M$ is the number of manufacturers, $S$ is the number of screen size categories, $f_{s}$ is the expected market share for screen size $s, f_{m}$ is the expected market share for TV manufacturer $m$, and $\overline{P_{s m}}$ is the mean power draw (based on the power measurement database containing $372 \mathrm{TVs}$ ) for all of the size $s$ units shipped by manufacturer $m$.

Table 4-3 shows that the average active and standby TV power levels calculated using Equation 5 are 75 watts and 4.5 watts, respectively. Average values derived using only screen size, only market share or no weighting strategies are also presented for comparison. 
Table 3-3. Average unit TV power draw values: comparison of results obtained using different weighting methods

\begin{tabular}{lcc}
\hline Weighting method & $\begin{array}{c}\text { Active } \\
\text { (watts/unit) }\end{array}$ & $\begin{array}{c}\text { Standby } \\
\text { (watts/unit) }\end{array}$ \\
\hline None & 92 & 4.9 \\
Expected manufacturer market share & 81 & 4.9 \\
Expected screen size & 77 & 4.5 \\
Expected market share \& screen size & $\mathbf{7 5}$ & $\mathbf{4 . 5}$ \\
\hline
\end{tabular}

NOTE: Values used in this study are in bold

\subsection{Household and National TV Energy Consumption}

In Section 4.3 we showed that there is a positive correlation between the screen size and the active power draw of TVs. This implies that watching a larger TV is more energyintensive than watching a smaller TV. Since more than two-thirds of U.S. homes have more than one TV set and nearly one-third have more than two [3], TV size distributions within homes and the relationship between screen size and viewing hours must be considered.

Based on the data shown in Figure 4-1, five categories of homes were created: homes with one, two, three, four, and five TVs. For each category, a distribution of TVs was created according to "usage rank," which is based on how much the TV is used. TV1 is always the most watched TV, TV2 is the next most watched, etc. Homes with only one TV have only a TV1. TVs in a home with five TVs are named TV1, TV2, TV3, TV4, and TV5, where TV5 is the least watched TV. The numbers of TV1s, TV2s, TV3s, TV4s, and TV5s in the U.S. are shown in Table 4-4.

Table 3-4. Distribution of U.S. TVs by usage rank [3]

\begin{tabular}{ccc}
\hline Usage Rank & $\begin{array}{c}\text { No. of TVs } \\
\text { (millions) }\end{array}$ & $\begin{array}{c}\text { Percentage } \\
\text { of U.S. TVs }\end{array}$ \\
\hline TV1 & 100.2 & $47.4 \%$ \\
TV2 & 67.9 & $32.1 \%$ \\
TV3 & 30.0 & $14.2 \%$ \\
TV4 & 10.6 & $5.0 \%$ \\
TV5 & 2.8 & $1.3 \%$ \\
\hline Total & $\mathbf{2 1 1 . 5}$ & $\mathbf{1 0 0 \%}$ \\
\hline
\end{tabular}

NOTE: TV1 is the most used TV in any home, TV2 the second most used TV, etc. Since there are 100.2 million homes in the U.S. with at least one TV set, there are 100.2 million TV 1 s in the U.S.

The expected TV screen size distribution and average power draw values derived from the power measurement database are given in Table 4-5. 
Table 3-5. TV screen sizes: expected screen size distribution and average TV power draw values

\begin{tabular}{cccc}
\hline $\begin{array}{c}\text { Screen Size } \\
\text { (inches) }\end{array}$ & $\begin{array}{c}\text { Expected } \\
\text { Distribution } \\
{[9][14][15]}\end{array}$ & $\begin{array}{c}\text { Active } \\
\text { Power } \\
\text { (watts) }\end{array}$ & $\begin{array}{c}\text { Standby } \\
\text { Power } \\
\text { (watts) }\end{array}$ \\
\hline$<=18$ & $25 \%$ & 47 & 3.1 \\
$19-20$ & $36 \%$ & 68 & 5.1 \\
$25-27$ & $31 \%$ & 90 & 4.9 \\
$30-36$ & $5.6 \%$ & 114 & 5.3 \\
$39+$ & $2.4 \%$ & 142 & 3.5 \\
\hline Weighted average & & 75 & 4.5 \\
\hline
\end{tabular}

NOTE: The expected TV screen size distribution can also be seen in Figure 3-6.

Using the data in Tables 4-4 and 4-5, minimum (min), maximum (max) and recommended (rec) energy use scenarios were created. The minimum scenario is based on the assumption that the smallest $47 \%$ of U.S. TVs are the most used (TV1). The maximum scenario is based on the assumption that the largest $47 \%$ of U.S. TVs are the most used. The recommended case assumes that, where there is a choice, there is a tendency to watch the largest TV, while the second largest TV, third largest TV, etc., are watched progressively less. Evidence of this trend can be found in the following paragraphs from Consumer Reports:

TV sets with a 19 or 20 inch screen are often second or third TVs in the household, bought for someplace other than the living room-and where fancy features are likely to be less of a priority. [21]

Indeed, sets of this size ( 25 inch) are now often promoted not as the primary TV set for the living room, but as a second or even third set for a larger bedroom or family room. [22]

Recommended values are therefore calculated as the midpoint between the average TV active and standby power draw values of 75 and 4.5 watts, respectively, and the maximum power use values. The resulting active and standby power use values used in this study are shown in Table 4-6.

Table 3-6. Average power use of TVs by usage rank (watts/unit)

\begin{tabular}{lcccccc}
\hline Usage & \multicolumn{3}{c}{ Active Power } & \multicolumn{3}{c}{ Standby Power } \\
Rank & min & rec & max & min & rec & max \\
\hline TV1 & 57 & 83 & 92 & 4.0 & 4.7 & 4.9 \\
TV2 & 81 & 70 & 65 & 5.0 & 4.7 & 4.8 \\
TV3 & 93 & 61 & 47 & 4.9 & 3.8 & 3.1 \\
TV4 & 120 & 61 & 47 & 4.9 & 3.8 & 3.1 \\
TV5 & 142 & 61 & -47 & 3.5 & 3.8 & 3.1 \\
\hline
\end{tabular}

NOTE: min, rec and max indicate a range of estimates as described in the text, where $\min =$ minimum, $r e c=$ recommended, and $\max =$ maximum estimates. 
To facilitate understanding of Table 4-6, we provide here the details of the calculations for the min, max, and rec "Active" power values in the first row (TV1). In the minimum case, we assume that the smallest $47 \%$ (Table 4-4) of TVs in the U.S. are the primary TVs. Using Table 4-5, the smallest $47 \%$ of TVs include all of the TVs in the $<=18$ inch category ( $25 \%$ of the total) and 22 of the total $36 \%$ of U.S. TVs represented in the $19-20$ inch category ( $22 \%$ of the total). Also from Table 4-5, the average active power draw of $<=18$ inch and 19-20 inch TVs are 47 watts and 68 watts, respectively. Therefore, the minimum average "Active" power estimate is calculated as $(25 \% .47 \mathrm{~W}+$ $22 \% .68 \mathrm{~W}) / 47 \%$, or 57 watts. Similarly, the maximum estimate is calculated as $(2.4 \% \cdot 142 \mathrm{~W}+5.6 \% \cdot 114 \mathrm{~W}+31 \% \cdot 90 \mathrm{~W}+8 \% \cdot 68 \mathrm{~W}) / 47 \%$, or 92 watts. The recommended value is calculated as the midpoint between the average active power of 75 watts and the maximum value of 92 watts, which is 83 watts.

Since, TV1s in the minimum scenario are smaller than average, they use less power "on" than do TV1s in the maximum scenario, which are larger than average. The opposite trend is seen in the TV5 category, because the minimum energy use scenario includes all the largest TVs, and the maximum energy use scenario includes all the smallest TVs.

Assumptions must also be made about the usage of different size TVs within a home. In the minimum energy use scenario, every household uses the smallest television in the house for 7.7 hours per day, and homes with more than one television use the second smallest TV simultaneously for $12 \%$ [7] of 7.7 , or 0.8 hours per day. In the maximum energy use scenario, every household uses the largest television in the house for 7.7 hours per day, and homes with more than one unit use the second largest TV for 0.8 hours per day.

The recommended usage estimates assume a tendency toward watching the largest TV in the home. While studies show that people prefer to watch larger TVs [24], no information could be found regarding the percentage of time spent watching the different size TVs in the home. Therefore, values for the recommended usage values were estimated. First we assumed that homes with five TV sets used them, from largest to smallest: $50,25,12.5$, 7.5 and 5 percent of the time. Homes with four TVs then split the usage of the fifth TV $(5 \%)$ equally between the four sets $(+1.25 \%$ each), for a $51.25 / 26.25 / 13.75 / 8.75$ percent split. Similarly, the smallest TV usage for the 4-TV-home $(8.75 \%)$ was split equally between the 3 remaining sets to estimate usage in a 3-TV-home, etc. The resulting viewing hour assumptions are presented in Table 4-7. 
Table 3-7. Average household and unit TV usage in homes with 1,2, 3, 4, and 5 TV sets (hrs/day)

\begin{tabular}{|l|ccc|ccc|}
\hline & \multicolumn{3}{|c|}{ Active Usage } & \multicolumn{3}{c|}{ Standby Usage } \\
& $\min$ & rec & $\max$ & $\min$ & rec & $\max$ \\
\hline 1 TV-home total & $\mathbf{7 . 7}$ & $\mathbf{7 . 7}$ & $\mathbf{7 . 7}$ & $\mathbf{1 6 . 3}$ & $\mathbf{1 6 . 3}$ & $\mathbf{1 6 . 3}$ \\
TV1 & 7.7 & 7.7 & 7.7 & 16.3 & 16.3 & 16.3 \\
2 TV-home total & $\mathbf{8 . 6}$ & $\mathbf{8 . 6}$ & $\mathbf{8 . 6}$ & $\mathbf{3 9 . 4}$ & $\mathbf{3 9 . 4}$ & $\mathbf{3 9 . 4}$ \\
TV1 & 7.7 & 5.4 & $\mathbf{7 . 7}$ & 16.3 & 18.6 & 16.3 \\
TV2 & 0.8 & 3.2 & 0.8 & 23.2 & 20.8 & 23.2 \\
3 TV-home total & $\mathbf{8 . 6}$ & $\mathbf{8 . 6}$ & $\mathbf{8 . 6}$ & $\mathbf{6 3 . 4}$ & $\mathbf{6 3 . 4}$ & $\mathbf{6 3 . 4}$ \\
TV1 & 7.7 & 4.6 & 7.7 & 16.3 & 19.4 & 16.3 \\
TV2 & 0.8 & 2.5 & 0.8 & 23.2 & 21.5 & 23.2 \\
TV3 & 0.0 & 1.4 & 0.0 & 24.0 & 22.6 & 24.0 \\
4 TV-home total & $\mathbf{8 . 6}$ & $\mathbf{8 . 6}$ & $\mathbf{8 . 6}$ & $\mathbf{8 7 . 4}$ & $\mathbf{8 7 . 4}$ & $\mathbf{8 7 . 4}$ \\
TV1 & 7.7 & 4.4 & 7.7 & 16.3 & 19.6 & 16.3 \\
TV2 & 0.8 & 2.2 & 0.8 & 23.2 & 21.8 & 23.2 \\
TV3 & 0.0 & 1.2 & 0.0 & 24.0 & 22.8 & 24.0 \\
TV4 & 0.0 & 0.7 & 0.0 & 24.0 & 23.3 & 24.0 \\
5 TV-home total & $\mathbf{8 . 6}$ & $\mathbf{8 . 6}$ & $\mathbf{8 . 6}$ & $\mathbf{1 1 1 . 4}$ & $\mathbf{1 1 1 . 4}$ & $\mathbf{1 1 1 . 4}$ \\
TV1 & 7.7 & 4.3 & 7.7 & 16.3 & 19.7 & 16.3 \\
TV2 & 0.8 & 2.1 & 0.8 & 23.2 & 21.9 & 23.2 \\
TV3 & 0.0 & 1.1 & 0.0 & 24.0 & 22.9 & 24.0 \\
TV4 & 0.0 & 0.6 & 0.0 & 24.0 & 23.4 & 24.0 \\
TV5 & 0.0 & 0.4 & 0.0 & 24.0 & 23.6 & 24.0 \\
\hline
\end{tabular}

NOTE: $\min$, rec and max indicate a range of estimates as described in the text, where $\min =$ minimum, $r e c=$ recommended, $\max =$ maximum estimates.

Note that the usage values for the minimum and maximum scenarios are exactly the same: TV1 is used $7.7 \mathrm{hrs} /$ day and TV2 is used $0.8 \mathrm{hrs} /$ day. This is because, by definition, TV1 is the most used TV in the home. Minimum energy values will be calculated by assuming that TV1 is a small (low-power) set, while the maximum energy values will be calculated by assuming that TV1 is a large (high-power) set (see Table 3-6). In both cases, it is necessary to use the maximum possible usage for TV1.

Total "Standby Usage" values for homes with more than one set are greater than 24 hours per day because multiple sets are in standby mode at the same time. The total standby usage value for each home is equal to the number of sets times 24 hours per day minus the number of hours per day the TVs are used.

For each TV, unit energy consumption was calculated using Equation 2. Average household TV energy consumption values for households with $1,2,3$, 4, and 5 television sets were calculated using Equation 3 and are presented in Table 4-8. National TV. energy consumption values calculated using Equation 4 are presented in Table 4-9. To facilitate computation for the reader, values in Tables 4-8 and 4-9 are shown to three significant digits in some places; however, please keep in mind that they are only accurate to two significant digits. 
Table 3-8. Average annual household and unit TV energy use by number of TVs in home ( $k$ Wh/yr)

\begin{tabular}{|c|c|c|c|c|c|c|c|c|c|}
\hline & \multicolumn{3}{|c|}{ Active Energy } & \multicolumn{3}{|c|}{ Standby Energy } & \multicolumn{3}{|c|}{ Total Energy } \\
\hline & $\min$ & rec & $\max$ & $\min$ & rec & $\max$ & $\min$ & rec & $\max$ \\
\hline $\begin{array}{l}1 \text { TV-home total } \\
\text { (kWh/yr/home) }\end{array}$ & 160 & 233 & 258 & 24 & 28 & 29 & 184 & 261 & 287 \\
\hline TV1 (kWh/yr/unit) & 160 & 233 & 258 & 24 & 28 & 29 & 184 & 261 & 287 \\
\hline $\begin{array}{l}2 \text { TV-home total } \\
\text { (kWh/yr/home) }\end{array}$ & 185 & 243 & 278 & 66 & 67 & 70 & 251 & 311 & 348 \\
\hline TV1 (kWh/yr/unit) & 160 & 162 & 258 & 24 & 32 & 29 & 184 & 194 & 287 \\
\hline TV2 (kWh/yr/unit) & 25 & 81 & 20 & 42 & 35 & 41 & 67 & 117 & 61 \\
\hline $\begin{array}{l}3 \text { TV-home total } \\
\text { (kWh/yr/home) }\end{array}$ & 185 & 235 & 278 & 109 & 101 & 97 & 294 & 336 & 375 \\
\hline TV1 (kWh/yr/unit) & 160 & 140 & 258 & 24 & 33 & 29 & 184 & 173 & 287 \\
\hline TV2 (kWh/yr/unit) & 25 & 63 & 20 & 42 & 37 & 41 & 67 & 100 & 61 \\
\hline TV3 (kWh/yr/unit) & 0.0 & 32 & 0.0 & 43 & 31 & 27 & 43 & 63 & 27 \\
\hline $\begin{array}{l}4 \text { TV-home total } \\
\text { (kWh/yr/home) }\end{array}$ & 185 & 232 & 278 & 152 & 135 & 124 & 338 & 367 & 403 \\
\hline TV1 (kWh/yr/unit) & 160 & 133 & 258 & 24 & 34 & 29 & 184 & 166 & 287 \\
\hline TV2 (kWh/yr/unit) & 25 & 57 & 20 & 42 & 37 & 41 & 67 & 94 & 61 \\
\hline TV3 (kWh/yr/unit) & 0.0 & 26 & 0.0 & 43 & 32 & 27 & 43 & 58 & 27 \\
\hline TV4 (kWh/yr/unit) & 0.0 & 17 & 0.0 & 43 & 32 & 27 & 43 & 49 & 27 \\
\hline $\begin{array}{l}5 \text { TV-home total } \\
\text { (kWh/yr/home) }\end{array}$ & 185 & 231 & 278 & 183 & 168 & 151 & 368 & 399 & 430 \\
\hline TV1 (kWh/yr/unit) & 160 & 129 & 258 & 24 & 34 & 29 & 184 & 163 & 287 \\
\hline TV2 (kWh/yr/unit) & 25 & 54 & 20 & 42 & 37 & 41 & 67 & 92 & 61 \\
\hline TV3 (kWh/yr/unit) & 0.0 & 24 & 0.0 & 43 & 32 & 27 & 43 & 55 & 27 \\
\hline TV4 (kWh/yr/unit) & 0.0 & 14 & 0.0 & 43 & 32 & 27 & 43 & 47 & 27 \\
\hline TV5 (kWh/yr/unit) & 0.0 & 9.5 & 0.0 & 31 & 33 & 27 & 31 & 42 & 27 \\
\hline Weighted Average & 177 & 237 & 272 & 71 & 69 & 69 & 248 & 307 & 340 \\
\hline
\end{tabular}

NOTE: min, rec and max indicate a range of estimates as described in the text, where $\min =$ minimum, $r e c=r e c o m m e n d e d, \max =$ maximum estimates. Values are accurate to two significant digits. 
Table 3-9. National TV energy consumption (TWh/yr)

\begin{tabular}{|c|c|c|c|c|c|c|c|c|c|}
\hline & \multicolumn{3}{|c|}{ Active Energy } & \multicolumn{3}{|c|}{ Standby Energy } & \multicolumn{3}{|c|}{ Total Energy } \\
\hline & $\min$ & rec & $\max$ & $\min$ & rec & $\max$ & $\min$ & rec & $\max$ \\
\hline 1-TV Homes & 5.3 & 7.6 & $\overline{8.3}$ & 0.8 & 0.9 & 0.9 & 6.1 & 8.5 & 9.3 \\
\hline 2-TV Homes & 7.1 & 9.3 & 10.6 & 2.5 & 2.6 & 2.7 & 9.7 & 11.9 & 13.3 \\
\hline 3-TV Homes & 3.7 & 4.6 & 5.4 & 2.1 & 2.0 & 1.9 & 5.8 & 6.6 & 7.3 \\
\hline 4-TV Homes & 1.5 & 1.8 & 2.2 & 1.2 & 1.1 & 1.0 & 2.7 & 2.9 & 3.2 \\
\hline 5+ TV Homes & 0.5 & 0.7 & 0.8 & 0.5 & 0.5 & 0.4 & 1.0 & 1.1 & 1.2 \\
\hline Total U.S. & 18 & 24 & 27 & 7.2 & 7.0 & 7.0 & 25 & 31 & 34 \\
\hline
\end{tabular}

NOTE: $\min$, rec and max indicate a range of estimates as described in the text, where $\min =$ minimum, rec=recommended, $\max =$ maximum estimates. Values are accurate to two significant digits.

\subsection{Sources of Uncertainty in the Calculation of National TV Energy Consumption}

We used industry shipment data to derive the "expected" distribution of screen sizes as discussed in Section 2.3. According to the data collected at the repair shops, larger TVs are more likely to be repaired than smaller TVs. This may imply that smaller TVs are more likely to be retired at an earlier age, rather than being repaired. Thus, actual U.S. TV stock may contain a lower fraction of smaller TVs than the "expected" distribution used in this study. This effect would be particularly prominent in sets manufactured before 1992, which are likely to have a higher frequency of malfunction than newer sets. Based on the screen-size distribution collected at the repair shops, correction of this discrepancy could add as much as $6.5 \%$, or $2 \mathrm{TWh} / \mathrm{yr}$, to our recommended national annual TV energy use estimate. If, instead, the lack of smaller TVs at the repair shop implies that smaller TVs are used less often and are therefore less likely to malfunction, there may be a higher percentage of smaller TVs than was calculated for the expected distribution. However, since the implication of this scenario is that these smaller TVs are not being used, this would not significantly effect our results.

We did not include the percentage of time that three or more TV sets are in use simultaneously nor the time two or more televisions are tuned to the same channel. Inclusion of these factors adds a maximum of $1.8 \%$ to the national energy estimates.

Although we used 11 years for the lifetime of a television as printed in Appliance Magazine in September of 1997, the September 1998 issue reports that the average life expectancy is 9 years. We used the value published in 1997 because the expected age distribution created using an expected lifetime of 11 years provided a better fit to the data collected at the repair shops. 
The use of both the expected manufacturer market share and screen size distributions to weight average power draw values assumes that these two characteristics are independent. However, it is almost certainly true that some manufacturers sell more large TVs and some sell more small TVs. To test the effect of this assumption on the final results, we weighted average power draw values using only the expected manufacturer market share, and separately, only the expected screen size distribution (Table 3-3). Using either of these weighting methods alone assumes no independence between manufacturer and screen size, and changes the final national energy use results by less than $3 \%$.

This study does not include the energy use of black and white televisions because the number of black and white TVs in the U.S. is insignificant compared to the number of color TVs. According to shipment data [11][12] and a life expectancy of 8 years [8], there are about 5 million black and white TVs in the U.S., accounting for about $2.3 \%$ of the national TV population. Since this estimate includes green and amber monitors [12], which are not considered "TVs" for the purposes of this report, the actual number of black and white TVs in the U.S. is even less. In addition, we expect the black and white TV sets that are still in circulation to be smaller, more efficient and watched less than the average color TV. We are therefore confident that the inclusion of black and white TVs would not add significantly to the results of this study.

This study does not include television sets used in the commercial sector, for example those in hospitals and hotel rooms, due to the difficulty estimating usage of such sets. Based on the difference between shipment data and EIA survey data (see Section 4.1), we estimate that there are between 20 and 30 million commercial TVs in the U.S. Assuming that usage of commercial TVs is similar to usage of residential TVs, inclusion of commercial TV sets would increase our estimate of total national energy consumption by roughly 10 to 15 percent.

Although we assume that TVs are plugged in at all times, it is possible that some households unplug their TVs when not in use.

Appliances with low power factor, such as TVs, require more current and increase distribution losses. Accounting for these losses in our calculations would increase the supply-side energy required for U.S. TVs. 


\section{VIDEOCASSETTE RECORDERS: ANALYSIS AND RESULTS}

Our approach to estimating VCR energy consumption parallels that for TVs. First, we present a summary of all VCR data used in this study, including the number of VCRs in the U.S., typical usage, and power draw measurements. Effects of VCR age and manufacturer on unit power draw levels are calculated, and, where appropriate, industry shipment and sales distributions are used to weight average unit power draw values derived from power measurements. Results presented include average unit, average household, and total national energy consumption of U.S. VCRs.

\subsection{VCR Data}

This section describes the number of VCRs in U.S. homes, typical usage, and VCR power measurements collected at repair shops.

\section{Number of VCRs}

The EIA reports that there are 128.7 million VCRs in U.S. homes [3], an estimated 10.8 million of which are TV/VCR units [9][13]. The numbers of homes with one, two, and three or more units as reported by the EIA [3] are shown in Figure 5-1. Nielsen [6] reports similar findings, which are shown in Figure 5-1 for comparison.

Figure 4-1. Number of VCRs in U.S. homes

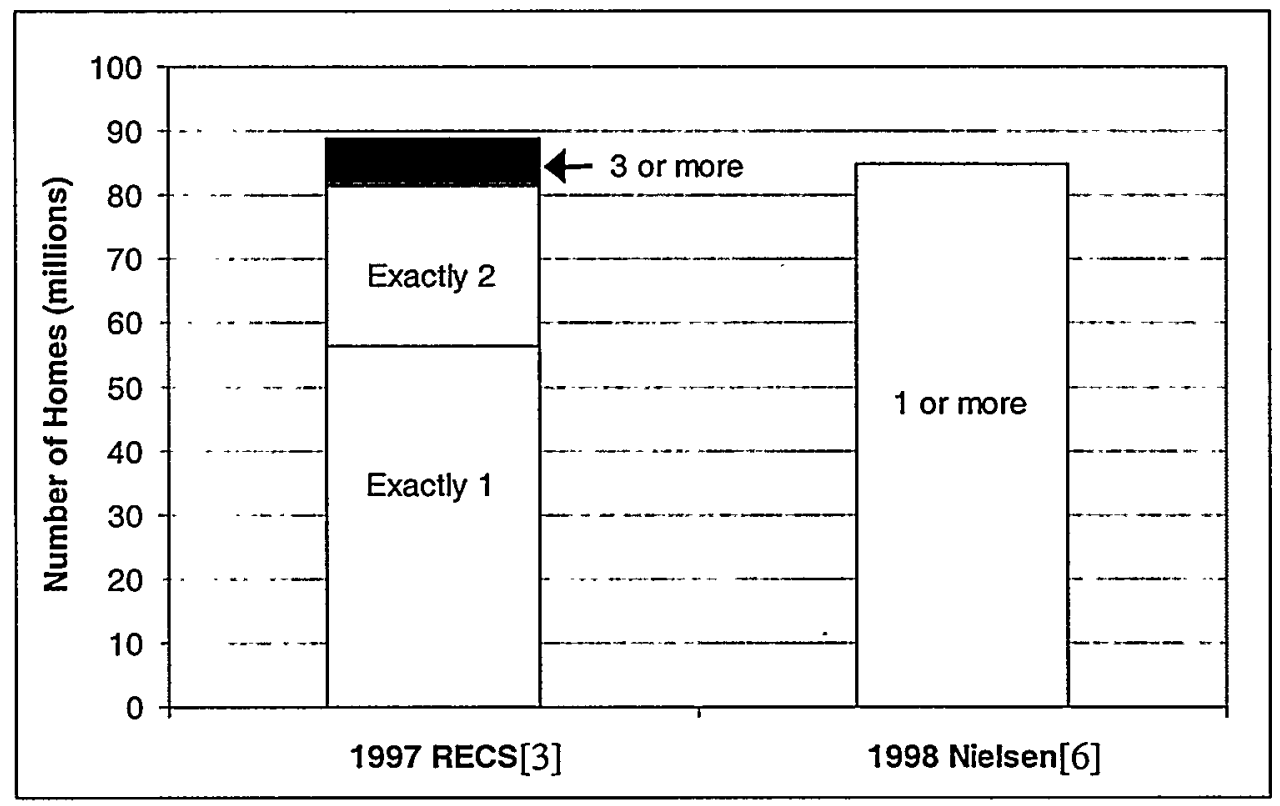


According to an average VCR lifetime of 11 years [8], an average TV/VCR lifetime of 6 years [10], shipment data [11][12] and the 4/3 Retirement Function [9], about 152 million of the 184 million VCRs and TV/VCR combination units shipped since 1985 should still be operating. The difference between this number and the number obtained by the EIA survey is about 23 million units. This difference can be partially attributed to the commercial VCRs that are counted in shipment data, but are not counted by the EIA survey. The uncertainty in the average lifetime of VCRs and TV/VCRs is also likely to be a factor.

\section{VCR Usage}

Hours of operation were taken from Media Dynamics [7]. Similar results were published in a survey of households in the Midwestern U.S. [25] and are included in Table 5-1 for comparison.

Table 4-1. Average household VCR usage (hrs/week/VCR-home)

\begin{tabular}{lccc}
\hline Source & Play & Record & Total \\
\hline Media Dynamics [7] & $\mathbf{4 . 0}$ & $\mathbf{1 . 9}$ & $\mathbf{5 . 9}$ \\
Wachter [25] & 3.3 & 1.9 & 5.3 \\
\hline
\end{tabular}

NOTE: Values used in this study are in bold

\section{VCR Power Measurements}

This section describes the VCR power measurements collected at the repair shops. For a complete list of the VCR power measurements used to determine average idle and standby power draw, see Appendix H. For a complete list of the VCR power measurements used to determine average VCR play/record power draw, see Appendix I.

Figure 5-2 shows the distribution of idle mode power levels of the 106 VCRs measured at the repair shops. These values represent power draw of the VCRs while they were on and no motor driven functions were being performed. Figure 5-3 shows the distribution of power levels measured while the VCRs were in standby mode. 
Figure 4-2. VCRs measured at repair shops: distribution of idle power draw levels

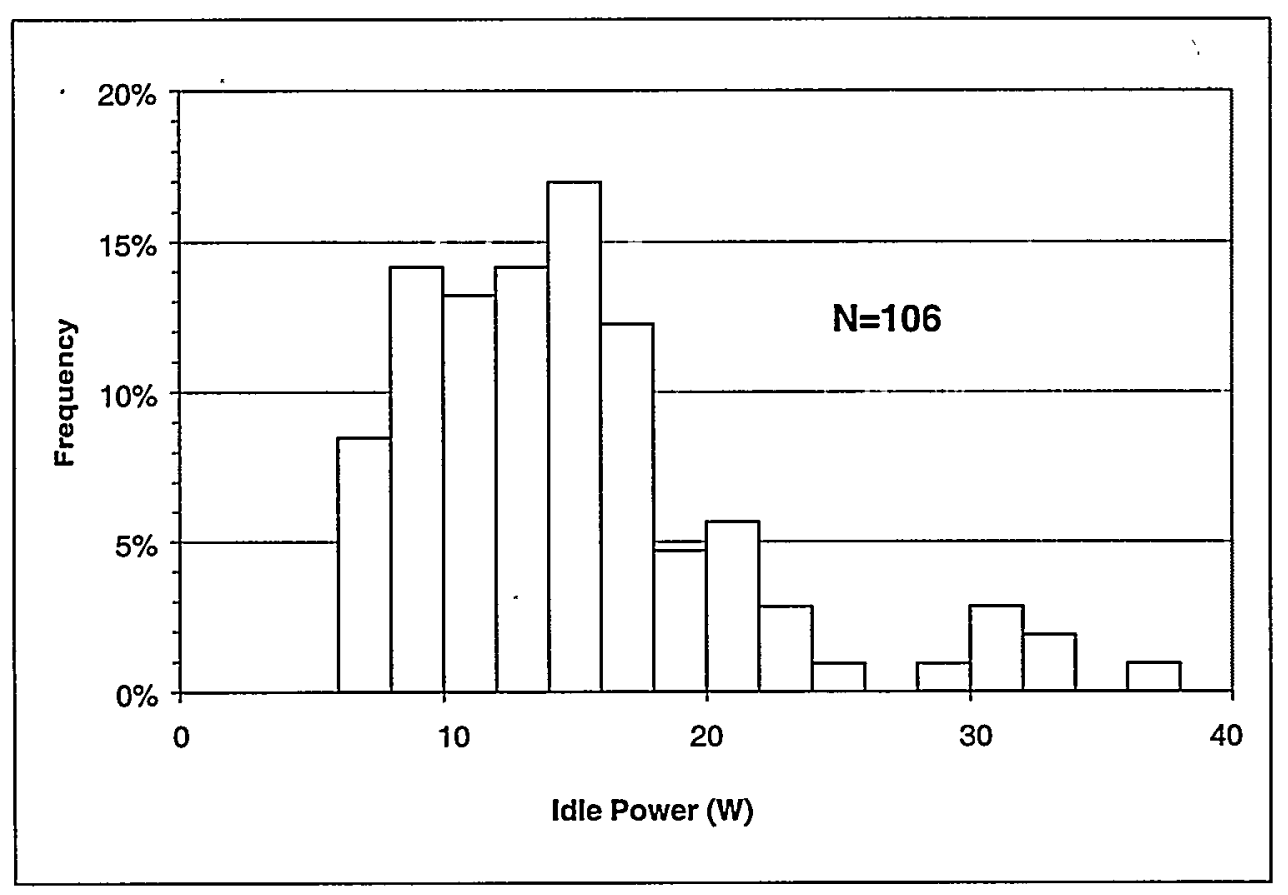

Figure 4-3. VCRs measured at repair shops: distribution of standby power draw levels

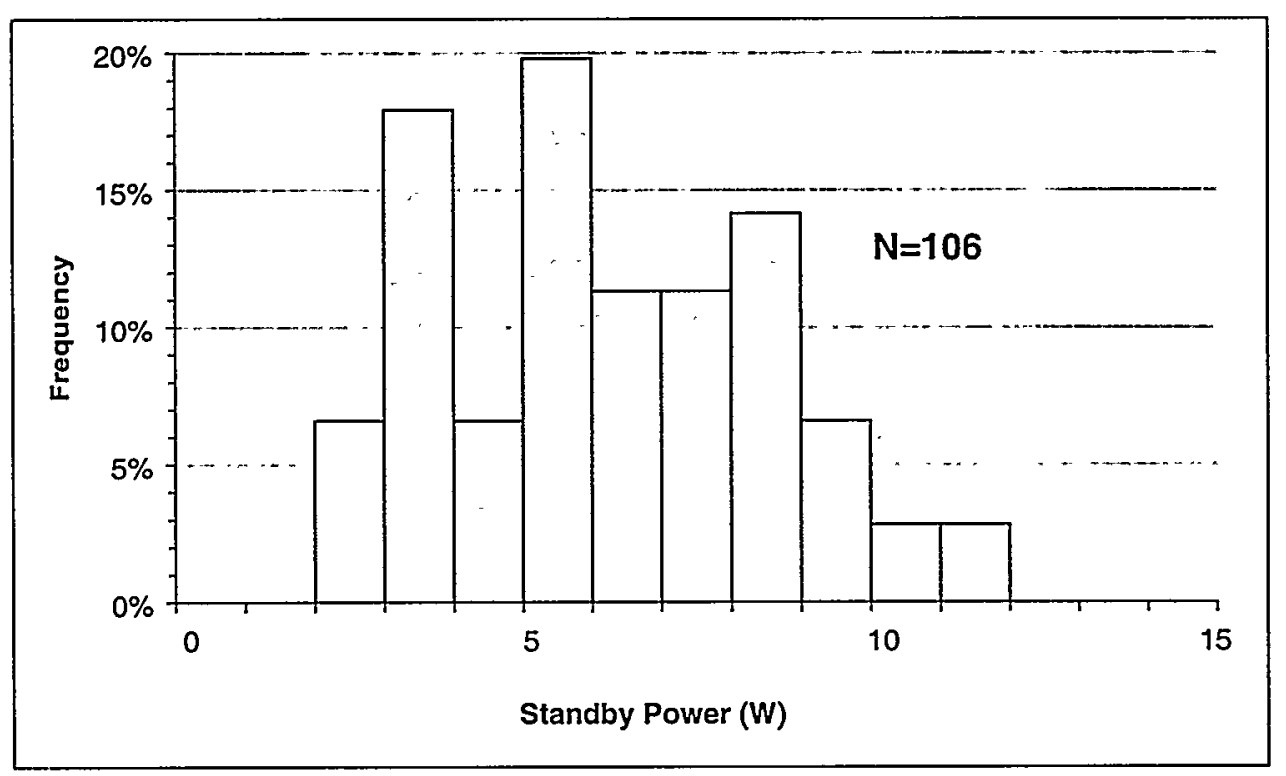


LBNL-42393

\subsection{Representativeness of the Collected VCR Data Sample}

Power measurements and other information were taken at repair shops as discussed in the study overview. To offset a lack of newer units, the 106 repair shop measurements were supplemented with four 1995 and six 1997 units measured at LBNL, and ten 1997 units measured at FSEC. Distributions of age and manufacturer of the final sample of 126 VCRs are compared to the expected distributions in Figures 5-4 and 5-5.

Figure 4-4. Age distribution of VCRs measured at repair and retail shops compared to the expected distribution of an unbiased sample

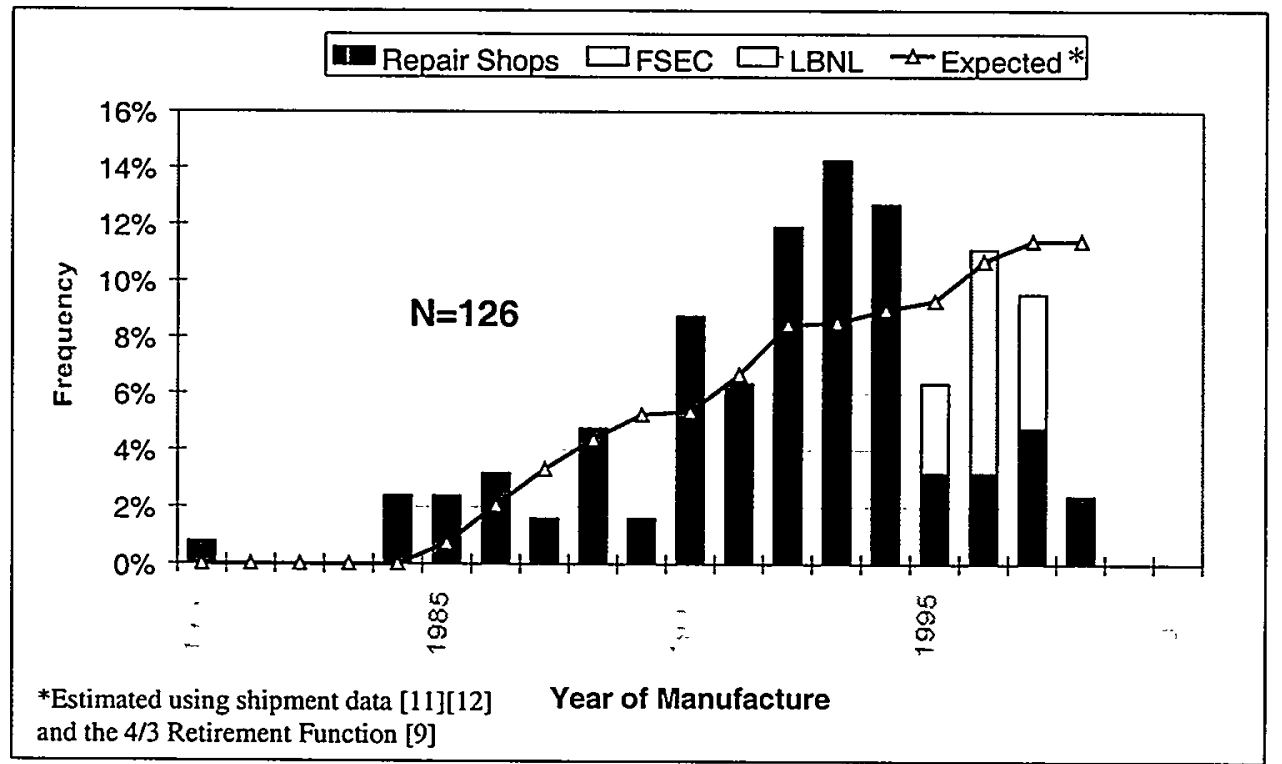


Figure 4-5. Manufacturer market share distribution of VCRs measured at repair and retail shops compared to the expected distribution of an unbiased sample

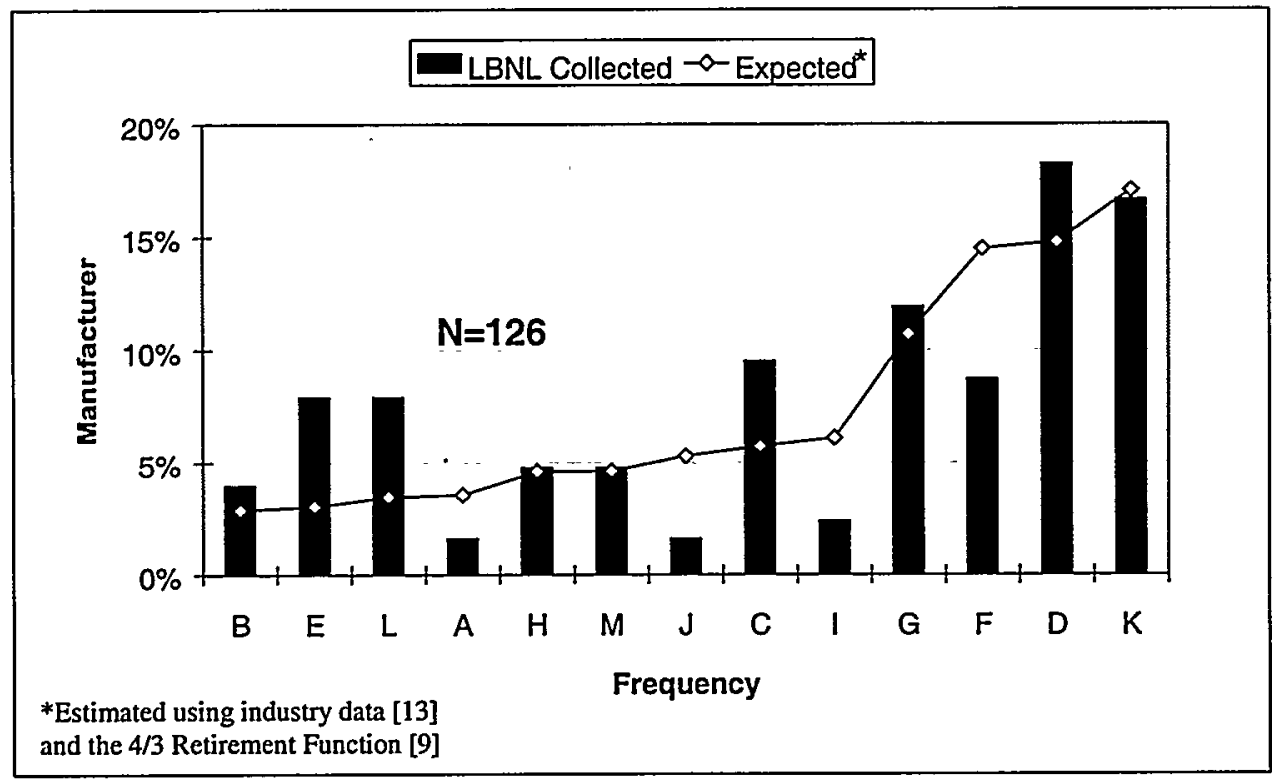

Figure 5-5 shows that our sample was fairly representative of manufacturer market share. See Appendix D for a chart matching code letters A-M to the respective manufacturers' names.

\subsection{Effects of Manufacturer and Year on VCR Power Draw}

The results of an analysis of covariance ${ }^{8}$ indicate that the manufacturer and year of manufacture were significant in predicting both idle and standby power draw levels, as shown in Table 5-2.

Table 4-2. Results of an analysis of variance conducted on VCR data measured at repair and retail shops, with main effect 'manufacturer' and covariate 'year of manufacture'

\begin{tabular}{lrccccc}
\hline Variable & \multicolumn{3}{c}{ Idle } & \multicolumn{3}{c}{ Standby } \\
& \multicolumn{1}{c}{ F } & Df & p & F & df & p \\
\hline Manufacturer & 3.5 & 12 & $<0.0005$ & 3.3 & 12 & $<0.0005$ \\
Year & 30.3 & 1 & $<0.0005$ & 5.0 & 1 & $<0.0005$ \\
\hline
\end{tabular}

Further analysis showed negative correlations between year of manufacture and power draw in both the idle (Pearson $r=-0.424$ ) and standby (Pearson $r=-0.282$ ) modes. These results imply that (1) some manufacturers consistently make more efficient VCRs, and (2) VCR energy efficiency has been improving since 1985. (See Appendix F.)

\footnotetext{
${ }^{8}$ Main effect: manufacturer. Covariate: year.
} 


\subsection{Average VCR Power Draw Levels}

Because power draw of VCRs is related to the age of the unit, and because the distribution of 'year of manufacture' in our database was not representative of U.S. stock, average VCR power draw values were weighted by the expected 'year of manufacture' distribution. The average unit power draw of VCRs $\left(\overline{P_{V C R}}\right)$ is calculated as:

$$
\overline{P_{V C R}}=\sum_{y=1988}^{1998} f_{y} \overline{P_{y}}
$$

where is $f_{y}$ is the expected frequency of stock VCRs manufactured in year $y$, and $\overline{P_{y}}$ is the mean power draw for all VCRs in our database manufactured in year $y$. Average power draw values obtained using Equation 6 are presented in Table 5-3.

Table 4-3. Average unit VCR power draw values: comparison of results obtained using different weighting methods (watts/unit)

\begin{tabular}{lccc}
\hline Weighting Method & $\begin{array}{c}\text { Play/ } \\
\text { Record }^{\text {a }}\end{array}$ & Idle & Standby \\
\hline None & 17.0 & 14.3 & 6.2 \\
Manufacturer & 17.0 & 13.6 & 6.3 \\
Year of manufacture & $\mathbf{1 7 . 0}$ & $\mathbf{1 3 . 5}$ & $\mathbf{5 . 9}$ \\
\hline
\end{tabular}

NOTE: Values used in this study are in bold.

${ }^{a}$ The average play/record power draw of 17.0 watts was derived from a sample of 21 VCRs previously measured at LBNL. See Appendix I.

\subsection{Household and National VCR Energy Consumption}

In Section 5.3 we showed that age is a significant factor in predicting power draw of VCRs, such that newer VCRs are more efficient. This implies that watching an older VCR is more energy-intensive than watching a newer one. Since more than one-third of U.S. households have more than one VCR [3], VCR age distributions within homes and the relationship between age and usage must be considered.

Based on the data shown in Figure 5-1, three categories of homes were created: homes with one, two, and three VCRs. Homes with more than three units were counted as threeunit homes. For each home, a distribution of VCRs was created according to usage rank, which is based on how much the VCR is used. VCR1 is always the "primary" or most used VCR, VCR2 is the next most used, and VCR3 is the least used. The numbers of VCR1s, VCR2s, and VCR3s in the U.S. are shown in Table 5-4. 
LBNL-42393

Table 4-4. Distribution of U.S. VCRs by usage rank [3]

\begin{tabular}{ccc}
\hline Usage Rank & $\begin{array}{c}\text { VCRs in U.S. } \\
\text { (millions) }\end{array}$ & $\begin{array}{c}\text { Percentage of } \\
\text { U.S. VCRs }\end{array}$ \\
\hline VCR1 & 88.9 & $69.1 \%$ \\
VCR2 & 32.5 & $25.3 \%$ \\
VCR3 & 7.3 & $5.7 \%$ \\
\hline
\end{tabular}

NOTE: VCR1 is the most used VCR in any home, VCR2 the second most used, etc. Since there are 88.9 million homes in the U.S. with at least one VCR, there are 88.9 million VCR1s.

The expected 'year of manufacture' distribution and average power draw values derived from the VCR power measurement database are given in Table 5-5.

Table 4-5. VCR year of manufacture: expected distribution and average VCR power draw values

\begin{tabular}{cccc}
\hline \multirow{2}{*}{ Year } & \multirow{2}{*}{$\begin{array}{c}\text { \% of U.S. VCRs } \\
\text { [9][11][12] }\end{array}$} & \multicolumn{2}{c}{ Average Power } \\
\cline { 3 - 4 } & $0.76 \%$ & 19.8 & 7.5 \\
1985 & $2.1 \%$ & 20.5 & 8.4 \\
1986 & $3.4 \%$ & 19.9 & 9.8 \\
1987 & $4.5 \%$ & 15.6 & 6.9 \\
1988 & $5.4 \%$ & 21.4 & 8.6 \\
1989 & $5.5 \%$ & 18.0 & 6.2 \\
1990 & $6.9 \%$ & 13.8 & 6.3 \\
1991 & $8.7 \%$ & 15.4 & 6.8 \\
1992 & $8.8 \%$ & 15.1 & 5.7 \\
1993 & $9.3 \%$ & 13.2 & 5.9 \\
1994 & $9.6 \%$ & 10.9 & 5.1 \\
1995 & $11 \%$ & 9.8 & 5.3 \\
1996 & $12 \%$ & 11.5 & 6.1 \\
1997 & $12 \%$ & 8.3 & 3.2 \\
1998 & & 13.5 & 5.9 \\
\hline
\end{tabular}

Using the data in Table 5-4 and the expected age distribution and average power values shown in Table 5-5, minimum (min), maximum (max) and recommended (rec) energy use scenarios were created. The minimum scenario is based on the assumption that the newest $69: 1 \%$ of U.S. VCRs are the most used (VCR1). The maximum scenario is based on the assumption that the oldest $69.1 \%$ of VCRs are the most used. For the recommended case, we assume no relationship between age and usage. The resulting idle and standby power draw values used in this study are shown in Table 5-6. 
Table 4-6. Average power use of VCRs by usage rank (watts/unit)

\begin{tabular}{lcccccc}
\hline Usage Rank & \multicolumn{3}{c}{ Idle Power } & \multicolumn{3}{c}{ Standby Power } \\
& $\min$ & rec & $\max$ & $\min$ & rec & $\max$ \\
\hline VCR1 & 11.7 & 13.5 & 15.1 & 5.3 & 5.9 & 6.5 \\
VCR2 & 17.0 & 13.5 & 10.2 & 7.0 & 5.9 & 5.2 \\
VCR3 & 19.8 & 13.5 & 8.3 & 8.8 & 5.9 & 3.2 \\
\hline
\end{tabular}

NOTE: min, rec and max indicate a range of estimates as described in the text, where $\min =$ minimum, rec=recommended, $\max =$ maximum estimates.

So, for example, the "Idle" value of 11.7 watts for VCR1 in the minimum scenario is: $(12 \% \cdot 8.3+12 \% \cdot 11.5+11 \% \cdot 9.8+9.6 \% \cdot 10.9+9.3 \% \cdot 13.2+8.8 \% \cdot 15.1+6.6 \% \cdot 15.4) / 69.1 \%$.

Likewise, the "Standby" value of 15.1 watts for VCR1 in the maximum scenario is: $(12 \% \cdot 19.8+12 \% \cdot 20.5+11 \% \cdot 19.9+9.6 \% \cdot 15.6+9.3 \% \cdot 21.4+8.8 \% \cdot 18.0+6.6 \% \cdot 13.8) / 69.1 \%$.

The critical factor in our estimates of national VCR energy consumption is the amount of time VCRs are left in the idle mode when they are not being used for playing or recording. Some VCRs may be left in this mode out of habit or to record at a preset time, while others are used for cable reception and/or changing TV channels. The minimum scenario assumes that no VCRs are ever left in idle mode. The maximum scenario assumes that all VCRs are left in idle mode at all times. The recommended scenario assumes that $25 \%$ of the time that U.S. VCRs are not being used to play or record, they are in the idle mode. ${ }^{9}$

Assumptions must also be made about the distribution of usage in homes that have more than one unit. In all scenarios, play/record usage values were therefore estimated as follows. Homes with three VCRs use the primary VCR (VCR1) $80 \%$ of the time, VCR2 $14 \%$ of the time, and VCR3 $6 \%$ of the time. Homes with two VCRs use VCR $183 \%$ of the time and VCR2 $17 \%$ of the time. The resulting usage assumptions are presented in Table 5-7.

\footnotetext{
${ }^{9}$ Since no information was available on this subject, we were forced to provide a rough estimate based on our experience.
} 
Table 4-7. Average household and unit VCR usage in homes with 1, 2, and 3 VCRs (hrs/day)

\begin{tabular}{|l|c|ccc|ccc|}
\hline & Play/Record Usage & \multicolumn{3}{|c|}{ Idle Usage } & \multicolumn{3}{|c|}{ Standby Usage } \\
& rec & $\min$ & rec & $\max$ & $\min$ & rec & $\max$ \\
\hline 1 VCR-home total & $\mathbf{0 . 8 4}$ & $\mathbf{0 . 0}$ & $\mathbf{5 . 8}$ & $\mathbf{2 3 . 2}$ & $\mathbf{2 3 . 2}$ & $\mathbf{1 7 . 4}$ & $\mathbf{0 . 0}$ \\
VCR1 & 0.84 & 0.0 & 5.8 & 23.2 & 23.2 & 17.4 & 0.0 \\
2 VCR-home total & $\mathbf{0 . 8 4}$ & $\mathbf{0 . 0}$ & $\mathbf{1 1 . 8}$ & $\mathbf{4 7 . 2}$ & $\mathbf{4 7 . 2}$ & $\mathbf{3 5 . 4}$ & $\mathbf{0 . 0}$ \\
VCR1 & 0.70 & 0.0 & 5.8 & 23.3 & 23.3 & 17.5 & 0.0 \\
VCR2 & 0.14 & 0.0 & 6.0 & 23.9 & 23.9 & 17.9 & 0.0 \\
3 VCR-home total & $\mathbf{0 . 8 4}$ & $\mathbf{0 . 0}$ & $\mathbf{1 7 . 8}$ & $\mathbf{7 1 . 2}$ & $\mathbf{7 1 . 2}$ & $\mathbf{5 3 . 4}$ & $\mathbf{0 . 0}$ \\
VCR1 & 0.67 & 0.0 & 5.8 & 23.3 & 23.3 & 17.5 & 0.0 \\
VCR2 & 0.12 & 0.0 & 6.0 & 23.9 & 23.9 & 17.9 & 0.0 \\
VCR3 & 0.05 & 0.0 & 6.0 & 23.9 & 23.9 & 18.0 & 0.0 \\
\hline
\end{tabular}

NOTE: $\min$, rec and max indicate a range of estimates as described in the text, where $\min =$ minimum, $r e c=$ recommended, $\max =$ maximum estimates.

Note that the sums of the play/record, idle, and standby usage values increase linearly with the number of VCRs in the home to account for added power draw of multiple units. Thus, the total daily usage in homes with 2 VCRs is 48 hours, while the total daily usage in homes with 3 units is 72 hours.

For each VCR, unit energy consumption is calculated using Equation 2. Results are presented in Tables 5-6 and 5-7. Average household VCR energy consumption values for households with 1, 2, and 3 VCRs are calculated using Equation 3. Results, presented in Table 5-8, are accurate to two significant digits. 
Table 4-8. Average annual household and unit VCR energy use by number of VCRs in the home $(k W h / y r)$

\begin{tabular}{|l|c|ccc|ccc|ccc|}
\hline & Play/Record & \multicolumn{3}{|c|}{ Idle } & \multicolumn{3}{c|}{ Standby } & \multicolumn{3}{c|}{ Total } \\
& rec & $\min$ & rec & $\max$ & $\min$ & rec & $\max$ & $\min$ & rec & $\max$ \\
\hline 1 VCR-home total & $\mathbf{5 . 2}$ & $\mathbf{0 . 0}$ & $\mathbf{2 8}$ & $\mathbf{1 2 8}$ & $\mathbf{4 5}$ & $\mathbf{3 8}$ & $\mathbf{0 . 0}$ & $\mathbf{5 0}$ & $\mathbf{7 1}$ & $\mathbf{1 3 3}$ \\
(kWh/yr/home) & & & & & & & & & & \\
VCR1 (kWh/yr/unit) & 5.2 & 0.0 & 28 & 128 & 45 & 38 & 0.0 & 50 & 71 & 133 \\
2 VCR-home total & & & & & & & & & \\
(kWh/yr/home) & $\mathbf{5 . 0}$ & $\mathbf{5 8}$ & $\mathbf{2 1 8}$ & $\mathbf{1 0 6}$ & $\mathbf{7 7}$ & $\mathbf{0 . 0}$ & $\mathbf{1 1 1}$ & $\mathbf{1 4 0}$ & $\mathbf{2 2 3}$ \\
VCR1 (kWh/yr/unit) & 4.3 & 0.0 & 29 & 128 & 45 & 38 & 0.0 & 50 & 71 & 133 \\
VCR2 (kWh/yr/unit) & 0.9 & 0.0 & 29 & 89 & 61 & 39 & 0.0 & 62 & 69 & 90 \\
3 VCR-home total & & & & & & & & & \\
(kWh/yr/home) & $\mathbf{5 . 2}$ & $\mathbf{0 . 0}$ & $\mathbf{8 8}$ & $\mathbf{2 9 0}$ & $\mathbf{1 8 3}$ & $\mathbf{1 1 6}$ & $\mathbf{0 . 0}$ & $\mathbf{1 8 8}$ & $\mathbf{2 0 9}$ & $\mathbf{2 9 5}$ \\
VCR1 (kWh/yr/unit) & 4.2 & 0.0 & 29 & $\mathbf{1 2 8}$ & 45 & 38 & 0.0 & 49 & 71 & 133 \\
VCR2 (kWh/yr/unit) & 0.7 & 0.0 & 29 & 89 & 61 & 39 & 0.0 & 62 & 69 & 90 \\
VCR3 (kWh/yr/unit) & 0.3 & 0.0 & 29 & 72 & $\mathbf{7 7}$ & 39 & 0.0 & $\mathbf{7 7}$ & 69 & 73 \\
Weighted Average & $\mathbf{5 . 2}$ & $\mathbf{0 . 0}$ & $\mathbf{4 2}$ & $\mathbf{1 6 6}$ & $\mathbf{7 4}$ & $\mathbf{5 5}$ & $\mathbf{0 . 0}$ & $\mathbf{7 9}$ & $\mathbf{1 0 2}$ & $\mathbf{1 7 1}$ \\
\hline
\end{tabular}

NOTE: min, rec and max indicate a range of estimates as described in the text, where $\min =$ minimum, $r e c=r e c o m m e n d e d, \max =$ maximum estimates. Values are accurate to two significant digits.

National energy consumption values calculated using the values in Table 5-8 and the number of 1-, 2- and 3-VCR homes in the U.S. [3] are presented in Table 5-9.

Table 4-9. National VCR energy consumption (TWh/yr)

\begin{tabular}{|l|c|ccc|ccc|ccc|}
\hline & Play/Record & \multicolumn{3}{|c|}{ Idle } & \multicolumn{3}{|c|}{ Standby } & \multicolumn{3}{c|}{ Total } \\
& rec & $\min$ & rec & $\max$ & $\min$ & rec & $\max$ & $\min$ & rec & $\max$ \\
\hline 1-VCR Homes & 0.3 & 0.0 & 1.6 & 7.2 & 2.5 & 2.1 & 0.0 & 2.8 & 4.0 & 7.5 \\
2-VCR Homes & 0.1 & 0.0 & 1.5 & 5.5 & 2.7 & 1.9 & 0.0 & 2.8 & 3.5 & 5.6 \\
3+ VCR Homes & 0.0 & 0.0 & 0.6 & 2.1 & 1.3 & 0.8 & 0.0 & 1.4 & 1.5 & 2.2 \\
\hline Total & $\mathbf{0 . 5}$ & $\mathbf{0 . 0}$ & $\mathbf{3 . 7}$ & $\mathbf{1 4 . 8}$ & $\mathbf{6 . 5}$ & $\mathbf{4 . 9}$ & $\mathbf{0 . 0}$ & $\mathbf{7 . 0}$ & $\mathbf{9 . 1}$ & $\mathbf{1 5 . 2}$ \\
\hline
\end{tabular}

NOTE: $\mathrm{min}, \mathrm{rec}$ and max indicate a range of estimates as described in the text, where $\min =$ minimum, $r e c=$ recommended, $\max =$ maximum estimates. Values are accurate to two significant digits. 


\subsection{Sources of Uncertainty in the Calculation of National VCR Energy Consumption}

We used 11 years for the lifetime of a VCR as printed in Appliance Magazine in September of 1997; however, the September 1998 issue reports that the average life expectancy is 6 years. We used the value published in 1997 because the expected age distribution created using an expected lifetime of 11 years provided a better fit to the data collected at the repair shops.

The idle vs. standby usage is the critical assumption in the VCR analysis. To our knowledge, there is no information available about the percentage of time VCRs are left in idle mode instead of the standby mode. Although we assume that this value is about $25 \%$, there is no way to confirm this assumption at this time.

For practical reasons, the play/record power use was not recorded at the repair shops; therefore, we used an average value obtained from VCRs measured previously by LBNL. A small error in this value would have insignificant effects on our final results because VCRs are so infrequently in the play or record modes. (See Table 5-7.)

Although we assume that VCRs are plugged in at all times, it is possible that some households unplug their VCRs when not in use. We expect that the number of such households is small, since pulling the plug would mean that real-time clock information would be lost.

This study does not include VCRs used in the commercial sector. Based on the difference between shipment data and EIA survey data (see Section 5.1), we estimate that there are between 20 and 30 million commercial VCRs in the U.S. Assuming that usage of commercial VCRs is similar to usage of residential VCRs, inclusion of these units would increase our estimate of total national VCR energy consumption by roughly $10 \%$ to $15 \%$.

VCRs have a low power factor, requiring more current and increasing distribution losses. Accounting for these losses in our calculations would increase the total supply-side energy required for U.S. VCRs. 


\section{DISCUSSION}

\subsection{Summary of Recommended Values and Comparison to Other Studies}

This section presents power and energy consumption values recommended for use by the DOE and other policy makers.

Results for TVs are based on the assumption that homes with only one TV are likely to have a larger than average unit, and that homes with more than one TV are likely to use the larger units more than the smaller units. Results for VCRs are based on the assumption that homes with only one VCR are as likely to have a new unit as an old unit, and that homes with more than one VCR are as likely to use the newer units as the older units. VCR estimates further assume that, on average, U.S. VCRs are left in idle mode $25 \%$ of the time that they are not being used to play or record.

Recommended average household TV and VCR energy consumption values, rounded to two significant digits, are listed in Table 6-1.

Table 5-1. Recommended average household TV and VCR energy consumption values

\begin{tabular}{ccc}
\hline $\begin{array}{c}\text { Number of units } \\
\text { in home }\end{array}$ & $\begin{array}{c}\text { TVs } \\
(\mathrm{kWh} / \mathrm{yr} / \mathrm{home})\end{array}$ & $\begin{array}{c}\text { VCRs } \\
(\mathrm{kWh} / \mathrm{yr} / \mathrm{home})\end{array}$ \\
\hline 1 & 260 & 71 \\
2 & 310 & 140 \\
3 & 340 & 210 \\
4 & 370 & \\
5 & 400 & \\
\hline Weighted average & $\mathbf{3 1 0}$ & $\mathbf{1 0 0}$ \\
\hline
\end{tabular}

Note: Recommended values have been rounded to two significant digits

Recommended power and energy consumption values for TVs and VCRs are presented in Tables 6-2 and 6-3, respectively. Percentages of total U.S. energy consumption are based on the 1998 national residential electricity consumption of 3.772 quadrillion BTUs, or 1105 TWh [26]. Values presented in other recent reports are listed for comparison. 
Table 5-2. Recommended power and energy consumption values for TVs in the U.S. residential sector compared to results of other studies

\begin{tabular}{lcccc}
\hline Televisions & This Study & $\begin{array}{c}\text { Sanchez et al. } \\
{[1]}\end{array}$ & $\begin{array}{c}\text { Zogg et al. } \\
{[2]}\end{array}$ & EIA \\
& & {$[27]$} \\
\hline Total number of units (millions) & 211.5 & 191 & 229 & \\
Avg. units/home & 2.1 & 1.9 & 2.3 & \\
Avg. active usage (hrs/day/home) & 8.3 & $7.8^{\mathrm{b}}$ & $9.2^{\mathrm{b}}$ & \\
Avg. active power (watts) & 75 & 77 & 60 & \\
Avg. standby power (watts) & 4.5 & 4 & 4 & \\
Avg. UEC (kWh/yr/unit) & $150^{\mathrm{c}}$ & 141 & 117 & \\
Total U.S. energy (TWh/yr) & 31 & 26 & 27 & 67 \\
Percentage of U.S. residential & $2.8 \%$ & $2.4 \%$ & $2.5 \%$ & $6.0 \%$ \\
$\quad$ electricity consumption & & & & \\
\hline
\end{tabular}

${ }^{\mathrm{a}}$ Based on 101 million U.S. homes.

${ }^{\mathrm{b}}$ For consistency, usage is described in terms of household usage (hrs/day/home), calculated as the product of the unit usage and the number of units per home.

${ }^{c}$ To be consistent with the standard UEC definition, the UEC value presented here is calculated as the total U.S. TV energy use divided by the number of TVs in the U.S.

Note that our estimate of the TV energy consumption of a 1-TV household (Table 6-1) is $260 \mathrm{kWh} /$ year. This value is much higher than the average TV UEC of $150 \mathrm{kWh} /$ year (Table 6-2) because it is based on the assumption that, on average, homes with one TV set use it for 7.7 hours per day. The UEC, on the other hand, is based on the assumption that all TVs, no matter how many units are in the household, are used for 3.9 hours per day. ${ }^{10}$ This assumption is unrealistic because it implies that the TV in an average 1-TV home is used for 3.9 hours per day, while the TVs in an average 5-TV home are used for 19.5 hours per day.

Table 5-3. Recommended power and energy consumption values for VCRs in the U.S. residential sector compared to the results of other studies

\begin{tabular}{|c|c|c|c|}
\hline Videocassette Recorders & This Study & Sanchez et al. [1] & Zogg et al. [2] \\
\hline Total number of units (millions) & 128.7 & 135 & 123 \\
\hline Avg. play/record usage (hrs/day/home) & 0.84 & $0.96^{\mathrm{a}}$ & $0.88^{\mathrm{a}}$ \\
\hline Avg. idle usage (hrs/day/home) & 8.5 & 4.6 & 4.2 \\
\hline Avg. play/record power (watts) & 17.0 & 15.7 & $15.7^{\mathrm{b}}$ \\
\hline Avg. idle power (watts) & 13.5 & 10.7 & $10.7^{\mathrm{b}}$ \\
\hline Avg. standby power (watts) & 5.9 & 5.4 & 5.6 \\
\hline Avg. UEC (kWh/yr) & 71 & 57 & 57 \\
\hline Total U.S. energy (TWh/yr) & 9.1 & 7.6 & 6.9 \\
\hline $\begin{array}{l}\text { Percentage of U.S. residential } \\
\text { electricity consumption }\end{array}$ & $0.82 \%$ & $0.7 \%$ & $0.6 \%$ \\
\hline
\end{tabular}

a Value calculated as the product of the unit usage and the number of units per home.

${ }^{b}$ Value taken from Sanchez et al. [1].

${ }^{10}$ Quotient of the average household use of $8.2 \mathrm{hrs} /$ day and the average $2.1 \mathrm{TVs} / \mathrm{home}$. 
For VCRs, the results of this study are higher than the results of both Sanchez et al. [1] and Zogg et al. [2]. This can be attributed in part to our higher estimate for time left in the idle mode. We chose to assume that VCRs are left on about $25 \%$ of the time that they are not being used to play or record, while the other studies shown in Table 6-3 appear to have used a figure closer to $15 \%$. To our knowledge, there is no information about the amount of time that VCRs are left in this mode.

Another factor causing our VCR energy use estimate to be higher is the database of power measurements used to derive average power values. The database of power measurements used in Sanchez et al. [1] and cited by Zogg et al. [2] consisted mainly of new units. As we found in this study, VCRs have become significantly more efficient over time. Since our database consisted of both new and old units, and average values were weighted using a realistic distribution of newer and older units, it is expected that our values are higher.

TV/VCR combination units are included both in the TV results and in the VCR results. Because the sum of separate TV and VCR standby power use values is 10.4 watts, while that of a TV/VCR combination unit is only about 7.6 watts, these results are not additive. Because of this 3.9-watt difference, the 10.8 million TV/VCR combination units in the U.S. use about 0.27 TWh less energy every year than would separate units. Due to rounding, this difference does not effect the final combined U.S. TV and VCR energy consumption estimate of $40 \mathrm{TWh} / \mathrm{yr}$.

\subsection{Forces and Trends That May Change These Results in the Future}

The TV and VCR markets are extremely competitive and dynamic. As a result, new technologies appear frequently and have the potential to rapidly penetrate the market. This situation is further complicated by government mandated changes in technology. Some foreseen trends and their energy impacts are discussed below.

\section{Increasing number of usage options}

A number of services are becoming available that may affect TV and VCR usage, including "pay-per-view" and "video-on-demand." Both of these services give consumers more viewing options, which may encourage them to watch more TV. At the same time, an increase in the use of these services may be offset by the reduced time spent watching videocassettes.

Thanks to new set-top boxes, people can now browse the Internet using a TV instead of a computer. TV energy use may increase if consumers use the TV to access the web; however, increased web use may simply displace broadcast TV time, leading to small net changes in TV operating hours.

\section{TV Screen Size}

Ten years ago, only $2 \%$ of TVs sold in the U.S. were larger than 27 inches. Since then, this percentage has been increasing steadily. In 1999, the number of $30+$ inch TVs is 
expected to reach $20 \%$ and the consumer preference for larger TVs is expected to continue. One popular trend that compliments large TV ownership is home theater, which consists of a large TV and a sophisticated surround sound system. Such systems are said to exist in $14 \%$ of U.S. homes [28]. Because of the continuing trend to buy larger TVs and the strong correlation between screen size and energy use, TV energy use is expected to increase in the near future.

\section{New Technologies}

New technologies and appliances will effect power levels and possibly usage as well. Digital television (DTV) receivers in particular are expected to increase TV power use significantly. By 2006, when the television industry hopes to complete conversion to DTV, most TVs will either be fitted with digital receiver boxes, or will be replaced by DTV sets that have these receivers built in. Since DTV receivers use about 16 watts and must be left on at all times [29], TV standby energy use after 2006 is expected to be more than three and a half times the current TV standby energy use.

New display technologies may also have a significant effect on TV energy use. Currently, plasma display panels (PDPs) and liquid crystal displays are vying for position as the favored flat-panel display technology. In the TV market, it seems that PDPs may have the advantage over LCDs mainly because they can be made larger. Since plasma screens have a higher active power draw than the currently popular cathode ray tubes (CRTs), they have the potential to contribute to significantly higher annual TV energy use. At present, however, prices of PDPs remain too high to pose a real threat to the CRT industry. It is impossible to predict the effect of new display technologies on long-term TV energy use because competition to produce the fastest, brightest, most efficient and cheapest display creates new technologies on a regular basis. For example, one recently announced flat panel display technology is organic electroluminescence (EL), which boasts thinner, brighter, faster and much more energy efficient displays than existing LCDs. Although the prototype is just over 5 inches diagonally, larger models are expected to begin appearing in products in 2000 [30].

Although TV/VCR combination units are not a "new" technology, sales continue to climb. Sales in the first three quarters of 1998 rose by 32 percent over sales for the same time period last year [31]. Since TV and VCR power supplies tend to waste between 1 and 5 watts each in all power modes, TV/VCR units may reduce power use by using one power supply instead of two. Integration of other appliances, such as TVs and Internet appliances, should have the same effect.

Sales of digital versatile disc (DVD) players have exploded recently, while VCR sales have been flat [31]. Because the industry is still in its infancy, the replacement of VCRs with DVD players would have an uncertain effect on energy use. Based on 20 DVD players measured at LBNL, the average standby mode power draw of DVD players is lower than that of VCRs $(4.2$ vs. $5.9 \mathrm{~W})$, while the average idle power draw was higher (15.6 vs. $13.5 \mathrm{~W}$ ). 


\section{Energy efficiency regulations and voluntary programs}

The United States does not have minimum efficiency regulations for TVs or VCRs, but Japan does and Europe is considering them. These standards, especially those in Japan, will influence the efficiency of units sold in the United States. For example, Japanese manufacturers have been informally asked by the Ministry of International Trade and Industry (MITI) to reduce TV standby losses to one watt. Other voluntary programs, such as the United States' ENERGY STAR® program and Europe's Group for Efficient Appliances (GEA) program, are also expected to result in reduced standby power use for both TVs and VCRs. 


\section{CONCLUSIONS}

This study investigated power draw levels and national residential energy use of TVs and VCRs in the U.S. We found that the active power draw levels of TVs are closely related to screen size, while standby power draw levels seem to depend only on manufacturer. In addition, it appears that some TV and VCR manufacturers consistently make more efficient units than do others. Although average power draw levels of TVs have remained relatively stable over the past 15 years, VCRs have become significantly more efficient.

The average active and standby power draw levels of U.S. TVs are 75 and 4.5 watts, respectively. Annual household energy consumption levels of TVs range from $260 \mathrm{kWh}$ for a home with one set to $400 \mathrm{kWh}$ for a home with five. Average household TV energy consumption is $310 \mathrm{kWh}$ per year. Nationally, residential TVs use $31 \mathrm{TWh}$ of electricity per year, or about $2.8 \%$ of U.S. residential electricity consumption.

The average play/record, idle, and standby power levels of U.S. VCRs are 17.0, 13.5 and 5.9 watts, respectively. Annual household energy consumption levels of VCRs range from $71 \mathrm{kWh}$ for a home with one unit to $210 \mathrm{kWh}$ for a home with three. Average household VCR energy consumption is $100 \mathrm{kWh}$ per year. Nationally, residential VCRs consume 9.1 TWh of electricity per year, or $0.8 \%$ of U.S. residential electricity consumption.

Combined, TVs and VCRs, including TV/VCR combination units, use $40 \mathrm{TWh} / \mathrm{yr}$, or $3.6 \%$ of U.S. residential electricity consumption.

Current trends demonstrate that the TV and VCR end-uses are likely to undergo many changes in the next decade. For this reason, the results presented in this report will be valid for only a brief time, perhaps less than three years, before a reassessment is needed. 


\section{REFERENCES}

1 Sanchez, M.C., J.G. Koomey, M.M. Moezzi, A.K. Meier, and W. Huber. 1998. "Miscellaneous Electricity Use in U.S. Homes: Historical Decomposition and Future Trends.” Energy Policy 26: 8, p. 585-93. (Also LBNL-40295).

2 Zogg, R.A and D.L. Alberino. 1998. Electricity consumption by small end uses in residential buildings. NTIS\#PB98-169204. Prepared by Arthur D. Little, Inc. (Ref 34732-00) for the USDOE. August.

3 United States Energy Information Administration. 1999. 1997 Residential Energy Consumption Survey. Electronic information at http://www.eia.doe.gov/emeu/recs/. Accessed 1/27/99.

4 United States Energy Information Administration. 1998. Personal communication with Robert Latta, November 17, 1998.

5 United States Energy Information Administration. 1998. Personal communication with Robert Latta, January 25, 1999.

6 Nielsen Media Research. 1998. 1998 Report on Television. Nielsen Media Research: New York, NY.

7 Media Dynamics. 1998. TV Dimensions '98. Media Dynamics, Inc.: New York, NY.

8 Appliance Magazine. 1997. "Portrait of the U.S. Appliance Industry." Appliance Magazine. September.

9 Koomey, J.G., C.A. Webber, and J.E. McMahon. 1998. Projected Regional Impacts of Appliance Efficiency Standards for the U.S. Residential Sector. Lawrence Berkeley Laboratory. LBNL-39511.

10 Appliance Magazine. 1998. "Portrait of the U.S. Appliance Industry." Appliance Magazine. September issue.

11 Appliance Magazine. 1993. "Statistical Review." Appliance Magazine. April.

12 Appliance Magazine. 1998. "Statistical Review." Appliance Magazine. April.

13 Appliance Magazine. 1989-98. "Portrait of the U.S. Appliance Industry." Appliance Magazine. September.

14 Television Digest. 1991. "Biggest TV Sizes Doubled Market Share in 1990." Television Digest 31:6, p.11 February 11. 
15 Television Digest. 1992. "Big Screen TV Up, All Others Down in 1991." Television Digest 32:8, p. 10. February 24.

16 Television Digest. 1994. "Million TVs With 30" \& Up Tubes Sold in 1993." Television Digest 34:6, p. 13. February 7.

17 Television Digest. 1996. " Giant Screens Saved 1995 Color TV Sales.” Television Digest 36:6, p11. February 5.

18 Television Digest. 1996. "Retailers Trim Low-end TVs." Television Digest 36:39, p. 12. September 23.

19 Television Digest. 1997. "Projection TVs and VCRs Post 1996 Records." Television Digest 37:4, p. 8. January 27.

20 Nielsen Media Research. 1998. Personal communication with Vincent Nasso, November 2.

21 Consumer Reports. 1997. "Basic Bargains in TV sets." Consumer Reports. February. 22 Consumer Reports. 1998. "Small Screens, Big Values." Consumer Reports. February. 23 Consumer Reports. 1998. "Not 'Big Screen,' But Maybe Big Enough.” Consumer Reports. March.

24 Grabe, M.E., M. Lombard, R.D. Reich, C.C. Bracken, and T.B. Ditton. 1998. "The Role of Screen Size in Viewer Experiences of Media Content." Submitted to Visual Communication Quarterly for publication, August.

25 Wachter, C.J. and J.R. Kelly. 1998. "Exploring VCR Use as a Leisure Activity." Leisure Sciences 20: 3, p. 213-27.

26 United States Energy Information Administration. 1999. 1999 Annual Energy Outlook. Electronic information at http://www.eia.doe.gov/oiaf/aeo.html. Accessed 1/28/99.

27 United States Energy Information Administration (EIA). 1995. Household Energy Consumption and Expenditures 1993. DOE/EIA-0321(93). October.

28 Consumer Electronics Manufacturers Association (CEMA). 1998. Hear Here. Electronic document at http://www.cemacity.org/gazette/files2/hh398.htm. March.

29 Smith, G. 1998. "HDTV: Who Really Needs It?" Earth Island Journal. Summer. 30 Popular Science. 1999. "Organic Screens." Popular Science 254: 3, p. 40. 
LBNL-42393

31 Consumer Electronics Manufacturers Association (CEMA). 1998. CEMACITY Gazette - News Desk. October 19. 


\title{
Appendix A: Single Phase Power Multimeter, Model PLM-1-LP
}

\author{
Electronic Product Design, Inc., 2145 Debra Drive, Springfield, Oregon 97477
}

\section{Functional Description}

The Single Phase Power Multimeter (model PLM-1-LP) is an electronic instrument used to measure parameters associated with power consumption by an electrical load that is normally operated from a 50 or 60 hertz power line. Power is supplied to the load via a permanent power cord exiting the rear panel and a $15 \mathrm{amp}, 120$-volt outlet on the front panel. An internal 0.1-ohm shunt, wired in series with the neutral wire, senses the current. The voltage is measured between the hot and neutral wires. Power is provided to the measuring electronics via the same power cord. Current is limited to three amps RMS with an inline, $3 \mathrm{amp}$, slow-blow fuse accessible at the rear panel.

The Single Phase Power Multimeter measures; true RMS voltage and current; true power; and peak voltage, current, and power. This meter also calculates Power-Factor, Volt-Amps, and VARS. In addition the PLM-1-LP accumulates Time and Watt-Hours.

Display information, time, and accumulations of power are stored away in a nonvolatile memory. If measuring power is lost, when it returns, the meter will power up and still retain the latest recorded information. Reset of Watt-hours and Time is accomplished via the front panel momentary switches.

A dual line, 16 character per line, LCD provides a visual output to the operator. Two front-panel pushbuttons allow sequencing through the different displays of values. All measurements and calculations are updated at 1 second intervals, and if your meter includes the RS232 option, all the measurements and calculations are output at 9600 baud, once each second. RS232 isolation is a minimum of 1500 volts.

\section{Specifications}

Operating temperature: $25 \pm 10$ degrees C. Bandpass: 100th harmonic of $60 \mathrm{~Hz}(6 \mathrm{Khz})$. Crest factor: Peak current (10 amps) divided by measured RMS current.

\begin{tabular}{lll} 
MEASUREMENT & RANGE & ACCURACY \\
\cline { 2 - 3 } RMS Voltage & 0.1 to 140.0 volts & $0.5 \%+1$ LSD \\
RMS Current & 0.001 to 3.000 amps & $0.5 \%+1$ LSD \\
Watts & 0.1 to 420.1 watts & $0.5 \%+1$ LSD \\
Peak Voltage & 0.1 to 200.0 volts & $1 \%+1$ LSD \\
Peak Current & 0.01 to 10.00 amps & $1 \%+1$ LSD \\
Peak Power & 1 to 2,000 watts & $1 \%+1$ LSD \\
Volt-Amps & 0.1 to 420.0 VA & $1 \%+1$ LSD \\
Power Factor & 0.00 to 1.00 & $1.5 \%$ \\
VARS & 1 to 420 VARS & $1.5 \%$ (PF $=0.1$ to 0.9$)$ \\
Accumulate Power $(\mathrm{Wh})$ & 0.01 to 999999.99 & $05 \%+1 \mathrm{LSD}$ \\
Hours & 0.01 to 655.36 & $0.01 \%+1 \mathrm{LSD}$
\end{tabular}




\section{Appendix B: TV Data}

\begin{tabular}{|c|c|c|c|c|c|c|c|c|}
\hline Brand & Size & Model & Year & Off & On & Rated & Remote & Source \\
\hline Hitachi & 32 & $32 \mathrm{CX} 12 \mathrm{~B}$ & 1996 & 3.1 & 132 & 143 & $\mathrm{x}$ & FSEC \\
\hline Hitachi & 46 & $46 \mathrm{UX} 20 \mathrm{~B}$ & 1996 & 2.3 & 145 & 165 & $x$ & FSEC \\
\hline Hitachi & 50 & $50 X S 18 B$ & 1996 & 1.6 & 142 & 163 & $\mathrm{x}$ & FSEC \\
\hline JVC & 13 & C13710 & 1996 & 1.9 & 35 & 60 & $\mathrm{x}$ & FSEC \\
\hline Matsushita & 20 & CT20G11 & 1996 & 1.1 & 81 & 204 & $\mathrm{x}$ & FSEC \\
\hline Matsushita & 27 & CT27G11 & 1996 & 1.2 & 102 & 240 & $\mathrm{x}$ & FSEC \\
\hline Philips-Mag & 9 & PRO91OX & 1996 & 2.8 & 38 & 55 & $\mathrm{x}$ & FSEC \\
\hline Philips-Mag & 9 & PR0910X & 1996 & 2.9 & 37 & 55 & $x$ & FSEC \\
\hline Philips-Mag & 13 & PR1356 B121 & 1996 & 6.3 & 52 & 120 & $\mathrm{x}$ & FSEC \\
\hline Philips-Mag & 19 & PS1963C & 1996 & 5.7 & 64 & 144 & $\mathrm{x}$ & FSEC \\
\hline Philips-Mag & 25 & TR2516C & 1996 & 6.5 & 114 & 180 & $\mathrm{x}$ & FSEC \\
\hline Philips-Mag & 27 & TS2753C 103 & 1996 & 6.8 & 85 & 216 & $\mathrm{x}$ & FSEC \\
\hline Sony & 20 & KV20M20 & 1996 & 5 & 49 & N/A & $\mathrm{x}$ & FSEC \\
\hline Sony & 32 & KV32XBR45 & 1996 & 4.1 & 109 & 195 & $\mathrm{x}$ & FSEC \\
\hline Thomson & 13 & E13334WH & 1996 & 2.2 & 30 & 70 & $\mathrm{x}$ & FSEC \\
\hline Thomson & 13 & E13334WH & 1996 & 2.2 & 30 & 70 & $\mathrm{x}$ & FSEC \\
\hline Thomson & 27 & PS27113 & 1996 & 4.2 & 149 & 170 & $\mathrm{x}$ & FSEC \\
\hline Thomson & 27 & 27GT616 & 1996 & 5.7 & 80 & 135 & $x$ & FSEC \\
\hline Thomson & 27 & F27675BC & 1996 & 7.1 & 109 & 120 & $\mathrm{x}$ & FSEC \\
\hline Thomson & 32 & F32632SB & 1996 & 9.6 & 93 & 140 & $x$ & FSEC \\
\hline Thomson & 35 & $\mathrm{~F} 35670 \mathrm{MB}$ & 1996 & 9.8 & 114 & 140 & $\mathrm{x}$ & FSEC \\
\hline Toshiba & 27 & $\mathrm{CF} 27 \mathrm{~F} 30$ & 1996 & 0.6 & 61 & N/A & $\mathrm{x}$ & FSEC \\
\hline Toshiba & 32 & $\mathrm{CF} 32 \mathrm{~F} 40$ & 1996 & 0.5 & 84 & 100 & $\mathrm{x}$ & FSEC \\
\hline Toshiba & 35 & CF35F50 & 1996 & 0.5 & 75 & 108 & $\mathrm{x}$ & FSEC \\
\hline Zenith & 13 & SRI324S & 1996 & 2.7 & 55 & 75 & $\mathrm{x}$ & FSEC \\
\hline Zenith & 19 & SY1951Y & 1996 & 5.5 & 46 & 90 & $\mathrm{x}$ & FSEC \\
\hline Zenith & 25 & SY2549S & 1996 & 5.5 & 59 & 110 & $\mathrm{x}$ & FSEC \\
\hline Zenith & 27 & SM2789BT8 & 1996 & 3.8 & 104 & 174 & $x$ & FSEC \\
\hline Hitachi & 36 & 36UX58B & 1998 & 13.8 & 106 & 145 & $x$ & LBNL \\
\hline JVC & 20 & AV20921 & 1998 & 0.4 & 39 & 87 & $\mathrm{x}$ & LBNL \\
\hline JVC & 20 & AV20921 & 1998 & 0.4 & 56 & 87 & $\mathrm{x}$ & LBNL \\
\hline JVC & 32 & AV32950 & 1998 & 3.2 & 77 & 130 & $x$ & LBNL \\
\hline Matsushita & 20 & CT20G23 & 1998 & 1.1 & 62 & & $x$ & LBNL \\
\hline
\end{tabular}




\begin{tabular}{|c|c|c|c|c|c|c|c|c|}
\hline Brand & Size & Model & Year & Off & On & Rated & Remote & Source \\
\hline Matsushita & 20 & CT20G23 & 1998 & 1.2 & 60 & & $\mathrm{x}$ & LBNL \\
\hline Mitsubishi & 27 & $\operatorname{CS} 27609$ & 1998 & 13.4 & 87 & 165 & $\mathrm{x}$ & LBNL \\
\hline Philips-Mag & 13 & PR1317C & 1998 & 5.0 & 43 & & $x$ & LBNL \\
\hline Philips-Mag & 13 & PR1302C & 1998 & 5.2 & 50 & & $\mathrm{x}$ & LBNL \\
\hline Philips-Mag & 25 & TS2574C & 1998 & 8.1 & 95 & & $\mathrm{x}$ & LBNL \\
\hline Philips-Mag & 27 & MX2791B & 1998 & 4.8 & 72 & & $\mathrm{x}$ & LBNL \\
\hline Sharp & 13 & $13 \mathrm{KM} 100$ & 1998 & 1.7 & 43 & 69 & $x$ & LBNL \\
\hline Sharp & 25 & $25 \mathrm{KM} 100$ & 1998 & 3.1 & 104 & & $x$ & LBNL \\
\hline Sharp & 32 & $32 \mathrm{KX} 1000$ & 1998 & 1.6 & 77 & 145 & $\mathrm{x}$ & LBNL \\
\hline Sharp & 36 & $36 \mathrm{KS} 400$ & 1998 & 1.5 & 104 & & $\mathrm{x}$ & LBNL \\
\hline Sony & 9 & KV9PT50 & 1998 & 4.0 & 25 & 53 & $\mathrm{x}$ & LBNL \\
\hline Sony & 20 & KV20V80 & 1998 & 7.0 . & 47 & 100 & $\mathrm{x}$ & LBNL \\
\hline Sony & 27 & KV27V65 & 1998 & 0.3 & 73 & 170 & $x$ & LBNL \\
\hline Sony & 32 & KB32XBR200 & 1998 & 0.9 & 126 & & $x$ & LBNL \\
\hline Thomson & 13 & E1334WH & 1996 & 2.1 & 31 & 70 & $\mathrm{x}$ & LBNL \\
\hline Thomson & 20 & F20632SE & 1998 & 11.8 & 81 & 110 & $\mathrm{x}$ & LBNL \\
\hline Toshiba & 13 & $\mathrm{CF} 13 \mathrm{H} 22$ & 1998 & 2.2 & 35 & 55 & $x$ & LBNL \\
\hline Zenith & 25 & $\mathrm{~A} 25 \mathrm{~A} 02 \mathrm{D}$ & 1998 & 4.9 & 88 & 103 & $x$ & LBNL \\
\hline Hitachi & 13 & CT13C7 & 1985 & 5.3 & 41 & 67 & $x$ & Repair \\
\hline Hitachi & 26 & CT2667 & 1987 & 0.8 & 117 & 169 & $\mathrm{x}$ & Repair \\
\hline Hitachi & 27 & $27 \mathrm{AX} 4 \mathrm{~B}$ & 1993 & 1.7 & 124 & 155 & $x$ & Repair \\
\hline Hitachi & 27 & $27 \mathrm{MX} 1 \mathrm{~B}$ & 1991 & 1.2 & 73 & 135 & $x$ & Repair \\
\hline Hitachi & 27 & СТ7970B & 1990 & 3.1 & 109 & 150 & $x$ & Repair \\
\hline Hitachi & 31 & $310 \times 5 B$ & 1994 & 4.3 & 136 & 180 & $x$ & Repair \\
\hline JVC & 13 & $\mathrm{C} 1321$ & 1991 & 4.1 & 45 & 85 & $x$ & Repair \\
\hline JVC & 13 & C1329 & 1989 & 3.9 & 44 & 85 & $x$ & Repair \\
\hline JVC & 14 & C14MIU & 1993 & 7.6 & 62 & 85 & $x$ & Repair \\
\hline JVC & 20 & AV20CM6 & 1995 & 1.0 & 88 & 115 & $x$ & Repair \\
\hline JVC & 20 & AV20CM4 & 1993 & 1.1 & 83 & 120 & $x$ & Repair \\
\hline JVC & 20 & AV20TP5 & 1995 & 1.2 & 88 & 120 & $x$ & Repair \\
\hline JVC & 20 & AV20CM3 & 1993 & 1.1 & 50 & 110 & $x$ & Repair \\
\hline JVC & 20 & AV20CM5 & 1995 & 1.1 & 86 & 120 & $x$ & Repair \\
\hline JVC & 25 & $\mathrm{C} 2570$ & 1985 & 2.0 & 92 & 130 & $x$ & Repair \\
\hline JVC & 26 & AV2672 & 1992 & 1.0 & 70 & 130 & $x$ & Repair \\
\hline
\end{tabular}




\begin{tabular}{|c|c|c|c|c|c|c|c|c|}
\hline Brand & Size & Model & Year & Off & On & Rated & Remote & Source \\
\hline JVC & 26 & AV2672S & 1992 & 1.1 & 59 & 130 & $\mathrm{x}$ & Repair \\
\hline JVC & 27 & AV27CM3 & 1992 & 1.1 & 108 & 147 & $\mathrm{x}$ & Repair \\
\hline JVC & 27 & AV27CM3 & 1993 & 1.2 & 91 & 147 & $\mathrm{x}$ & Repair \\
\hline JVC & 35 & AV35BP3 & 1992 & 0.9 & 160 & 195 & $\mathrm{x}$ & Repair \\
\hline Matsushita & 9 & UP1775E & 1986 & 0.0 & 47 & 43 & NO & Repair \\
\hline Matsushita & 20 & CTL2053R & 1989 & 1.1 & 48 & & $\mathrm{x}$ & Repair \\
\hline Matsushita & 20 & PVM2028 & 1989 & 8.5 & 48 & 120 & $\mathrm{x}$ & Repair \\
\hline Matsushita & 25 & TU9828AC & 1986 & 3.6 & 75 & 130 & $\mathrm{x}$ & Repair \\
\hline Matsushita & 25 & TU9840 & 1985 & 1.7 & 82 & 110 & $\mathrm{x}$ & Repair \\
\hline Matsushita & 27 & CT27S1R & 1993 & 1.4 & 120 & & $\mathrm{x}$ & Repair \\
\hline Matsushita & 27 & CTM2771S & 1990 & 1.1 & 82 & & $\mathrm{x}$ & Repair \\
\hline Matsushita & 27 & CT27SF12T & 1995 & 1.4 & 82 & & $\mathrm{x}$ & Repair \\
\hline Matsushita & 27 & CTN2761S & 1992 & 1.3 & 75 & 180 & $\mathrm{x}$ & Repair \\
\hline Matsushita & 31 & CTL3191S & 1990 & 0.9 & 149 & & $x$ & Repair \\
\hline Matsushita & 61 & PT61G45 & 1996 & 1.4 & 117 & & $\mathrm{x}$ & Repair \\
\hline Mitsubishi & 13 & CS1347R & 1991 & 1.0 & 40 & 75 & $x$ & Repair \\
\hline Mitsubishi & 13 & CS13103 & 1995 & 2.7 & 55 & 64 & $x$ & Repair \\
\hline Mitsubishi & 19 & CS1984R & 1984 & 3.3 & 73 & 120 & $\mathrm{x}$ & Repair \\
\hline Mitsubịshi & 19 & CS2013R & 1987 & 10.6 & 65 & 119 & $\mathrm{x}$ & Repair \\
\hline Mitsubishi & 20 & CS2011 & 1986 & 1.8 & 74 & 140 & $\mathrm{x}$ & Repair \\
\hline Mitsubishi & 20 & CS20SXI & 1992 & 2.0 & 53 & 115 & $\mathrm{x}$ & Repair \\
\hline Mitsubishi & 20 & CS20RXI & 1993 & 2.3 & 54 & 115 & $\mathrm{x}$ & Repair \\
\hline Mitsubishi & 20 & $\mathrm{CS} 20103$ & 1997 & 2.7 & 70 & 84 & $\mathrm{x}$ & Repair \\
\hline Mitsubishi & 20 & CS20102 & 1993 & 3.3 & 57 & 115 & $\mathrm{x}$ & Repair \\
\hline Mitsubishi & 20 & CS20EX1 & 1992 & 5.0 & 73 & 130 & $\mathrm{x}$ & Repair \\
\hline Mitsubishi & 20 & CS2005 & 1991 & 7.0 & 62 & 120 & $\mathrm{x}$ & Repair \\
\hline Mitsubishi & 20 & CS2060R & 1989 & 10.0 & 81 & 120 & $\mathrm{x}$ & Repair \\
\hline Mitsubishi & 20 & CS2060 & 1988 & 11.9 & 86 & 120 & $\mathrm{x}$ & Repair \\
\hline Mitsubishi & 20 & CS2052R & 1985 & 13.8 & 79 & 147 & $\mathrm{x}$ & Repair \\
\hline Mitsubishi & 25 & CS2566R & 1990 & 3.7 & 87 & 165 & $\mathrm{x}$ & Repair \\
\hline Mitsubishi & 25 & CJ2588R & 1984 & 3.2 & 86 & 165 & $\mathrm{x}$ & Repair \\
\hline Mitsubishi & 25 & CS2572R & 1983 & 4.4 & 79 & 138 & $\mathrm{x}$ & Repair \\
\hline Mitsubishi & 26 & CS2653R & & 10.7 & 79 & 150 & $\mathrm{x}$ & Repair \\
\hline Mitsubishi & 26 & CS2643R & 1986 & 2.0 & 80 & 155 & $\mathrm{x}$ & Repair \\
\hline
\end{tabular}


Appendix B: TV Data

\begin{tabular}{|c|c|c|c|c|c|c|c|c|}
\hline Brand & Size & Model & Year & $\overline{\text { Off }}$ & On & Rated & Remote & Source \\
\hline Mitsubishi & 26 & CS2671R & 1989 & 4.4 & 99 & 155 & $\mathrm{x}$ & Repair \\
\hline Mitsubishi & 26 & CK2694R & 1987 & 5.3 & 92 & 185 & $\mathrm{x}$ & Repair \\
\hline Mitsubishi & 26 & CK2690 & 1986 & 8.4 & 95 & 175 & $\mathrm{x}$ & Repair \\
\hline Mitsubishi & 26 & CS2620I & 1994 & 8.9 & 136 & 145 & $\mathrm{x}$ & Repair \\
\hline Mitsubishi & 26 & CS2656R & 1989 & 10.5 & 90 & 149 & $\mathrm{x}$ & Repair \\
\hline Mitsubishi & 26 & CS2610 & 1990 & 10.5 & 102 & 145 & $\mathrm{x}$ & Repair \\
\hline Mitsubishi & 26 & CK2600R & 1988 & 10.6 & 71 & 150 & $\mathrm{x}$ & Repair \\
\hline Mitsubishi & 26 & CS2630I & 1994 & 10.9 & 104 & 145 & $\mathrm{x}$ & Repair \\
\hline Mitsubishi & 26 & CS26ER1 & 1993 & 11.2 & 90 & 145 & $\mathrm{x}$ & Repair \\
\hline Mitsubishi & 26 & CS26EXI & 1992 & 11.5 & 108 & 145 & $\mathrm{x}$ & Repair \\
\hline Mitsubishi & 26 & CS2667 & 1985 & 18.2 & 109 & 193 & $\mathrm{x}$ & Repair \\
\hline Mitsubishi & 26 & CS2653 & 1987 & 10.6 & 69 & 150 & $\mathrm{x}$ & Repair \\
\hline Mitsubishi & 27 & CK2730R & 1990 & 1.8 & 129 & 160 & $\mathrm{x}$ & Repair \\
\hline Mitsubishi & 27 & CS2771R & 1990 & 2.1 & 108 & 187 & $\mathrm{x}$ & Repair \\
\hline Mitsubishi & 27 & CS2724R & 1991 & 2.1 & 120 & 187 & $\mathrm{x}$ & Repair \\
\hline Mitsubishi & 27 & CS2715 & 1991 & 2.4 & 113 & 165 & $\mathrm{x}$ & Repair \\
\hline Mitsubishi & 27 & CS27EX1 & 1992 & 11.6 & 90 & 150 & $\mathrm{x}$ & Repair \\
\hline Mitsubishi & 27 & CS27EX1 & 1993 & 11.8 & 103 & 150 & $\mathrm{x}$ & Repair \\
\hline Mitsubishi & 27 & CS2710R & 1992 & 12.2 & 91 & 130 & $\mathrm{x}$ & Repair \\
\hline Mitsubishi & 27 & CK27306 & 1997 & 12.0 & 98 & 165 & $\mathrm{x}$ & Repair \\
\hline Mitsubishi & 31 & CS3114R & 1990 & 2.2 & 135 & 205 & $x$ & Repair \\
\hline Mitsubishi & 31 & CS3121 & 1996 & 4.8 & 144 & 265 & $\mathrm{x}$ & Repair \\
\hline Mitsubishi & 31 & CS3120R & 1989 & 5.3 & 118 & 250 & $x$ & Repair \\
\hline Mitsubishi & 31 & CK3101 & 1987 & 5.6 & 108 & 210 & $x$ & Repair \\
\hline Mitsubishi & 31 & CK3136R & 1991 & 6.8 & 126 & 265 & $x$ & Repair \\
\hline Mitsubishi & 31 & $\mathrm{CS} 31 \mathrm{MX} 1$ & 1992 & 12.3 & 103 & 175 & $\mathrm{x}$ & Repair \\
\hline Mitsubishi & 31 & CS3131 & 1990 & 4.8 & 161 & 210 & $\mathrm{x}$ & Repair \\
\hline Mitsubishi & 31 & CK3112 & 1988 & 5.6 & 115 & 200 & $x$ & Repair \\
\hline Mitsubishi & 31 & CS31301 & 1993 & 11.9 & 114 & 175 & $\mathrm{x}$ & Repair \\
\hline Mitsubishi & 31 & $\mathrm{CS} 31 \mathrm{MX} 1$ & 1993 & 12.8 & 165 & 210 & $\mathrm{x}$ & Repair \\
\hline Mitsubishi & 32 & CS32207 & 1997 & 3.2 & 81 & 175 & $x$ & Repair \\
\hline Mitsubishi & 35 & CS35405 & 1996 & 4.5 & 86 & 195 & $x$ & Repair \\
\hline Mitsubishi & 35 & CK3531R & 1991 & 4.9 & 149 & 220 & $x$ & Repair \\
\hline Mitsubishi & 35 & CS3505R & 1989 & 5.2 & 121 & 210 & $x$ & Repair \\
\hline
\end{tabular}




\begin{tabular}{|c|c|c|c|c|c|c|c|c|}
\hline Brand & Size & Model & Year & Off & On & Rated & Remote & Source \\
\hline Mitsubishi & 35 & CS3520 & 1989 & 5.3 & 118 & 275 & $\mathrm{x}$ & Repair \\
\hline Mitsubishi & 35 & CK3502R & 1986 & 8.3 & 118 & 230 & $\mathrm{x}$ & Repair \\
\hline Mitsubishi & 35 & CK35MX2 & 1992 & 11.0 & 110 & 205 & $\mathrm{x}$ & Repair \\
\hline Mitsubishi & 35 & CS36509 & 1997 & 15.0 & 106 & 200 & $\mathrm{x}$ & Repair \\
\hline Mitsubishi & 35 & CS3520R & 1990 & 6.5 & 112 & 275 & $\mathrm{x}$ & Repair \\
\hline Mitsubishi & 35 & CS3515 & 1991 & 2.3 & 110 & 210 & $\mathrm{x}$ & Repair \\
\hline Mitsubishi & 35 & CK3536 & 1991 & 6.8 & 130 & 290 & $\mathrm{x}$ & Repair \\
\hline Mitsubishi & 35 & CK3527 & 1992 & 7.3 & 157 & 240 & $\mathrm{x}$ & Repair \\
\hline Mitsubishi & 35 & CK3526 & 1992 & 7.3 & 120 & 240 & $\mathrm{x}$ & Repair \\
\hline Mitsubishi & 40 & VS405R & 1985 & 13.7 & 114 & 200 & $\mathrm{x}$ & Repair \\
\hline Mitsubishi & 40 & VS4001 & 1989 & 4.1 & 147 & 230 & $\mathrm{x}$ & Repair \\
\hline Mitsubishi & 40 & VS410 & 1988 & 4.5 & 119 & 210 & $\mathrm{x}$ & Repair \\
\hline Mitsubishi & 40 & CS40FX1 & 1992 & 6.9 & 115 & 290 & $\mathrm{x}$ & Repair \\
\hline Mitsubishi & 40 & VS406 & 1987 & 13.7 & 115 & 200 & $\mathrm{x}$ & Repair \\
\hline Mitsubishi & 45 & VS4502R & 1990 & 3.9 & 166 & 230 & $\mathrm{x}$ & Repair \\
\hline Mitsubishi & 45 & VS4562R & 1993 & 16.4 & 155 & 200 & $\mathrm{x}$ & Repair \\
\hline Mitsubishi & 45 & VS4502 & 1989 & 2.9 & 139 & 230 & $x$ & Repair \\
\hline Mitsubishi & 45 & VS4503 & 1992 & 3.9 & 177 & 270 & $\mathrm{x}$ & Repair \\
\hline Mitsubishi & 46 & VS463 & 1987 & 6.3 & 150 & 210 & $\mathrm{x}$ & Repair \\
\hline Mitsubishi & 46 & VS468 & 1988 & 15.4 & 190 & 210 & $\mathrm{x}$ & Repair \\
\hline Mitsubishi & 50 & VS5003 & 1991 & 3.6 & 140 & 270 & $x$ & Repair \\
\hline Mitsubishi & 50 & VS5062 & 1993 & 14.2 & 145 & 260 & $\mathrm{x}$ & Repair \\
\hline Mitsubishi & 50 & VS5001 & 1989 & 4.0 & 163 & 230 & $\mathrm{x}$ & Repair \\
\hline Mitsubishi & 50 & VS5071 & 1994 & 10.0 & 170 & 280 & $\mathrm{x}$ & Repair \\
\hline Mitsubishi & 50 & VS5073 & 1994 & 15.6 & 186 & 290 & $\mathrm{x}$ & Repair \\
\hline Mitsubishi & 50 & VS5075 & 1995 & 16.3 & 135 & 250 & $\mathrm{x}$ & Repair \\
\hline Mitsubishi & 60 & VS6017 & 1992 & 3.3 & 190 & 300 & $\mathrm{x}$ & Repair \\
\hline Mitsubishi & 60 & VS6004R & 1991 & 3.8 & 162 & 270 & $\mathrm{x}$ & Repair \\
\hline Mitsubishi & 60 & VS6061R & 1993 & 15.6 & 142 & 260 & $\mathrm{x}$ & Repair \\
\hline Mitsubishi & 60 & VS6041 & 1995 & 1.8 & 120 & 250 & $\mathrm{x}$ & Repair \\
\hline Mitsubishi & 60 & VS6021R & 1990 & 3.6 & 200 & 270 & $\mathrm{x}$ & Repair \\
\hline Mitsubishi & 70 & VS7004 & 1994 & 4.6 & 168 & 270 & $x$ & Repair \\
\hline Other & 13 & 13BO81 & 1982 & 0.0 & 56 & $?$ & NO & Repair \\
\hline Other & 19 & TC1965 & 1990 & 5.1 & 84 & 102 & $x$ & Repair \\
\hline
\end{tabular}


Appendix B: TV Data

\begin{tabular}{|c|c|c|c|c|c|c|c|c|}
\hline Brand & Size & Model & Year & Off & On & Rated & Remote & Source \\
\hline Other & 19 & 6852127 & 1985 & 6.3 & 81 & 130 & $\mathrm{x}$ & Repair \\
\hline Other & 19 & CTSG9369TCT & 1996 & 11.4 & 114 & 100 & $\mathrm{x}$ & Repair \\
\hline Other & 20 & CT2030S & 1987 & 3.0 & 80 & 120 & $\mathrm{x}$ & Repair \\
\hline Other & 25 & $685-2498$ & 1992 & 0.8 & 64 & 125 & $\mathrm{x}$ & Repair \\
\hline Other & 25 & MWL2573S & 1994 & 12.0 & 97 & 106 & $\mathrm{x}$ & Repair \\
\hline Other & 27 & CT2700S & 1988 & 1.8 & 101 & 160 & $\mathrm{x}$ & Repair \\
\hline Philips-Mag & 20 & PR1901C127 & 1997 & 6.4 & 58 & $?$ & $\mathrm{x}$ & Repair \\
\hline Philips-Mag & 25 & RX4470AK01 & 1990 & 0.8 & 88 & 115 & $\mathrm{x}$ & Repair \\
\hline Philips-Mag & 25 & RG4956PE02 & 1986 & 9.8 & 76 & 120 & $\mathrm{x}$ & Repair \\
\hline Philips-Mag & 25 & RJ4910 & 1989 & 3.5 & 62 & & $\mathrm{x}$ & Repair \\
\hline Philips-Mag & 25 & CR4524 & 1994 & 5.1 & 67 & 150 & $\mathrm{x}$ & Repair \\
\hline Philips-Mag & 27 & RJ6050AK02 & 1988 & 2.8 & 70 & & $\mathrm{x}$ & Repair \\
\hline Philips-Mag & 27 & RK6070 & 1989 & 2.8 & 66 & & $\mathrm{x}$ & Repair \\
\hline Philips-Mag & 27 & RS5266 & 1987 & 5.8 & 110 & 115 & $\mathrm{x}$ & Repair \\
\hline Philips-Mag & 27 & TS2775 & 1997 & 6.9 & 60 & 180 & $\mathrm{x}$ & Repair \\
\hline Philips-Mag & 46 & RK8558 & 1990 & 3.3 & 121 & 200 & $\mathrm{x}$ & Repair \\
\hline Samsung & 25 & TC2540S & 1989 & 4.9 & 60 & 130 & $\mathrm{x}$ & Repair \\
\hline Sanyo & 20 & AVM2001 & 1993 & 6.5 & 70 & 70 & $\mathrm{x}$ & Repair \\
\hline Sanyo & 27 & AVM2504 & 1994 & 5.9 & 74 & 94 & $\mathrm{x}$ & Repair \\
\hline Sharp & 13 & 13H-M60 & 1996 & 2.6 & 48 & 62 & $\mathrm{x}$ & Repair \\
\hline Sharp & 19 & 19FM50 & 1994 & 3.8 & 58 & 80 & $\mathrm{x}$ & Repair \\
\hline Sharp & 25 & $25 \mathrm{SB} 720$ & 1991 & 3.5 & 81 & 120 & $\mathrm{x}$ & Repair \\
\hline Sharp & 25 & $25 \mathrm{AS} 120$ & 1991 & 3.9 & 89 & 110 & $\mathrm{x}$ & Repair \\
\hline Sharp & 27 & $27 \mathrm{GS} 60$ & 1995 & 3.1 & 82 & 125 & $\mathrm{x}$ & Repair \\
\hline Sharp & 27 & 27EES50 & 1993 & 5.1 & 200 & 140 & $\mathrm{x}$ & Repair \\
\hline Sharp & 27 & 27ES100 & 1993 & 5.0 & 102 & 140 & $\mathrm{x}$ & Repair \\
\hline Sharp & 27 & 27E550 & 1994 & 4.9 & 80 & 140 & $\mathrm{x}$ & Repair \\
\hline Sony & 8 & KV8AD11 & 1993 & 2.5 & 30 & 32 & $\mathrm{x}$ & Repair \\
\hline Sony & 8 & KV8AD10 & 1990 & 4.5 & 28 & 33 & $\mathrm{x}$ & Repair \\
\hline Sony & 9 & KV9PT50 & 1996 & 4.4 & 39 & 53 & $\mathrm{x}$ & Repair \\
\hline Sony & 12 & KV1206 & & 0.0 & 68 & 95 & NO & Repair \\
\hline Sony & 13 & KV13TR24 & 1991 & 2.2 & 51 & 97 & $\mathrm{x}$ & Repair \\
\hline Sony & 13 & KV13M10 & 1994 & 4.1 & 48 & 75 & $x$ & Repair \\
\hline Sony & 13 & KV1393R & 1988 & 4.6 & 56 & 97 & $\mathrm{x}$ & Repair \\
\hline
\end{tabular}




\begin{tabular}{|c|c|c|c|c|c|c|c|c|}
\hline Brand & Size & Model & Year & Off & On & Rated & Remote & Source \\
\hline Sony & 13 & KV13VM20 & 1995 & 5.6 & 57 & 85 & $\mathrm{x}$ & Repair \\
\hline Sony & 13 & KV1380R & 1989 & 6.0 & 78 & 100 & $\mathrm{x}$ & Repair \\
\hline Sony & 13 & KV1370R & & 6.0 & 59 & 97 & $\mathrm{x}$ & Repair \\
\hline Sony & 13 & KV131R24 & 1991 & 2.9 & 47 & 97 & $\mathrm{x}$ & Repair \\
\hline Sony & 13 & KV13TR25 & 1991 & 3.3 & 49 & 97 & $\mathrm{x}$ & Repair \\
\hline Sony & 17 & KV1723D & 1975 & 0.0 & 97 & 125 & NO & Repair \\
\hline Sony & 17 & KV1746 & 1981 & 3.0 & 61 & 73 & $\mathrm{x}$ & Repair \\
\hline Sony & 19 & KV1998R & 1986 & 4.3 & 101 & 140 & $\mathrm{x}$ & Repair \\
\hline Sony & 19 & DV1998R & 1987 & 4.4 & 103 & 140 & $\mathrm{x}$ & Repair \\
\hline Sony & 19 & KV19TR20 & 1990 & 4.4 & 76 & 120 & $x$ & Repair \\
\hline Sony & 19 & KV19TS20 & 1991 & 4.4 & 72 & 120 & $\mathrm{x}$ & Repair \\
\hline Sony & 19 & KV19TS20 & 1992 & 4.4 & 78 & 120 & $\mathrm{x}$ & Repair \\
\hline Sony & 19 & KV19TS20 & 1990 & 4.6 & 69 & 120 & $\mathrm{x}$ & Repair \\
\hline Sony & 19 & KV19TR20 & 1992 & 4.8 & 60 & 120 & $\mathrm{x}$ & Repair \\
\hline Sony & 20 & KV20EXR10 & 1991 & 0.9 & 85 & 130 & $x$ & Repair \\
\hline Sony & 20 & KV20EXR20 & 1992 & 1.0 & 85 & 130 & $\mathrm{x}$ & Repair \\
\hline Sony & 20 & KV20EXR20 & 1991 & 1.1 & 86 & 130 & $\mathrm{x}$ & Repair \\
\hline Sony & 20 & KV20XBR & 1984 & 1.2 & 75 & 145 & $\mathrm{x}$ & Repair \\
\hline Sony & 20 & KV20EXR20 & 1992 & 1.2 & 81 & 130 & $\mathrm{x}$ & Repair \\
\hline Sony & 20 & KV20S10 & 1994 & 3.3 & 75 & 100 & $\mathrm{x}$ & Repair \\
\hline Sony & 20 & KV20S10 & 1995 & 3.3 & 73 & 100 & $\mathrm{x}$ & Repair \\
\hline Sony & 20 & KV20S10 & 1990 & 3.4 & 41 & 100 & $x$ & Repair \\
\hline Sony & 20 & KV20S10 & 1995 & 3.4 & 65 & 100 & $\mathrm{x}$ & Repair \\
\hline Sony & 20 & KV20S10 & 1994 & 3.8 & 55 & 100 & $x$ & Repair \\
\hline Sony & 20 & KV20V50 & 1994 & 4.0 & 72 & 120 & $\mathrm{x}$ & Repair \\
\hline Sony & 20 & KV20TS32 & 1995 & 4.3 & 76 & 120 & $\mathrm{x}$ & Repair \\
\hline Sony & 20 & KV20TS27 & 1991 & 4.4 & 70 & 125 & $\mathrm{x}$ & Repair \\
\hline Sony & 20 & KV20TS20 & 1989 & 4.5 & 102 & 130 & $\mathrm{x}$ & Repair \\
\hline Sony & 20 & KV20TS20 & 1989 & 4.5 & 99 & 130 & $\mathrm{x}$ & Repair \\
\hline Sony & 20 & KV2095R & 1987 & 4.6 & 77 & 125 & $\mathrm{x}$ & Repair \\
\hline Sony & 20 & KV20TR21 & 1989 & 4.6 & 98 & 125 & $\mathrm{x}$ & Repair \\
\hline Sony & 20 & KV20TS30 & 1990 & 4.6 & 97 & 130 & $x$ & Repair \\
\hline Sony & 20 & KV20TS22 & 1989 & 5.0 & 102 & 130 & $x$ & Repair \\
\hline Sony & 20 & KV2080R & 1987 & 6.2 & 103 & 130 & $x$ & Repair \\
\hline
\end{tabular}




\begin{tabular}{|c|c|c|c|c|c|c|c|c|}
\hline Brand & Size & Model & Year & Off & On & Rated & Remote & Source \\
\hline Sony & 20 & KV20VM30 & 1998 & 6.6 & 75 & 108 & $\mathrm{x}$ & Repair \\
\hline Sony & 20 & KV20V60 & 1997 & 6.7 & 75 & 90 & $\mathrm{x}$ & Repair \\
\hline Sony & 20 & KV2093R & 1988 & 4.0 & 105 & 130 & $\mathrm{x}$ & Repair \\
\hline Sony & 25 & KV25XBR & 1984 & 1.2 & 124 & 185 & $\mathrm{x}$ & Repair \\
\hline Sony & 25 & KV25XBR & 1985 & 1.3 & 103 & 185 & $\mathrm{x}$ & Repair \\
\hline Sony & 26 & KV2643R & 1980 & 5.0 & 118 & 160 & $\mathrm{x}$ & Repair \\
\hline Sony & 27 & KV27SXR10 & 1988 & 0.6 & 125 & 170 & $\mathrm{x}$ & Repair \\
\hline Sony & 27 & KV27EXR20 & 1993 & 0.9 & 128 & 160 & $x$ & Repair \\
\hline Sony & 27 & KV27XBR10 & 1989 & 1.0 & 101 & 225 & $\mathrm{x}$ & Repair \\
\hline Sony & 27 & KV27EXR15 & 1990 & 1.0 & 101 & 165 & $\mathrm{x}$ & Repair \\
\hline Sony & 27 & KV27EXR25 & 1991 & 1.0 & 106 & 165 & $\mathrm{x}$ & Repair \\
\hline Sony & 27 & KV27EXR25 & 1992 & 1.0 & 115 & 165 & $\mathrm{x}$ & Repair \\
\hline Sony & 27 & KV27XBR10 & 1991 & 1.1 & 99 & 225 & $\mathrm{x}$ & Repair \\
\hline Sony & 27 & KV27V15 & 1995 & 3.1 & 88 & 170 & $\mathrm{x}$ & Repair \\
\hline Sony & 27 & KV27TS27 & 1991 & 3.2 & 133 & 110 & $\mathrm{x}$ & Repair \\
\hline Sony & 27 & KV27TS27 & 1992 & 3.3 & 109 & 160 & $\mathrm{x}$ & Repair \\
\hline Sony & 27 & KV27TW75 & 1992 & 3.5 & 92 & 170 & $\mathrm{x}$ & Repair \\
\hline Sony & 27 & KV27TS35 & 1992 & 3.6 & 93 & 170 & $x$ & Repair \\
\hline Sony & 27 & KV27TX40 & 1989 & 3.9 & 106 & 160 & $x$ & Repair \\
\hline Sony & 27 & KV27TS22 & 1988 & 4.1 & 89 & 160 & $\mathrm{x}$ & Repair \\
\hline Sony & 27 & KV27TS21 & 1991 & 4.2 & 125 & 160 & $\mathrm{x}$ & Repair \\
\hline Sony & 27 & KV27XBR45 & 1995 & 4.2 & 103 & 185 & $\mathrm{x}$ & Repair \\
\hline Sony & 27 & KV27XBR96 & 1994 & 4.7 & 145 & 270 & $\mathrm{x}$ & Repair \\
\hline Sony & 27 & KV27XBR96S & 1994 & 4.8 & 117 & 270 & $\mathrm{x}$ & Repair \\
\hline Sony & 27 & KV27XBR45 & 1996 & 4.8 & 106 & 185 & $\mathrm{x}$ & Repair \\
\hline Sony & 27 & KV27TS29 & 1993 & 5.6 & 82 & 165 & $\mathrm{x}$ & Repair \\
\hline Sony & 27 & KV2729R & 1987 & 6.3 & 122 & 155 & $\mathrm{x}$ & Repair \\
\hline Sony & 27 & KV2781R & 1985 & 6.4 & 117 & 165 & $\mathrm{x}$ & Repair \\
\hline Sony & 27 & KV27V20 & 1996 & 7.7 & 78 & 180 & $\mathrm{x}$ & Repair \\
\hline Sony & 27 & KV27V20 & 1996 & 8.0 & 79 & 180 & $x$ & Repair \\
\hline Sony & 27 & KV27EXR20 & 1992 & 1.0 & 97 & 160 & $\mathrm{x}$ & Repair \\
\hline Sony & 27 & KV27HSR10 & 1989 & 1.1 & 105 & 225 & $x$ & Repair \\
\hline Sony & 27 & KV27XBR15 & 1990 & 1.1 & 116 & 225 & $x$ & Repair \\
\hline Sony & 27 & KV2791 & 1986 & 6.6 & 90 & 165 & $\mathrm{x}$ & Repair \\
\hline
\end{tabular}




\begin{tabular}{|c|c|c|c|c|c|c|c|c|}
\hline Brand & Size & Model & Year & Off & On & Rated & Remote & Source \\
\hline Sony & 27 & KV27V20 & 1997 & 6.6 & 71 & 180 & $\mathrm{x}$ & Repair \\
\hline Sony & 27 & KV27DS24 & 1988 & 6.8 & 98 & 160 & $\mathrm{x}$ & Repair \\
\hline Sony & 27 & KV27V22 & 1997 & 7.5 & 70 & 180 & $x$ & Repair \\
\hline Sony & 29 & KV29XBR85 & 1992 & 1.2 & 134 & 286 & $\mathrm{x}$ & Repair \\
\hline Sony & 29 & KV29XBR05 & 1991 & 1.3 & 138 & 286 & $x$ & Repair \\
\hline Sony & 32 & KV32HSR 10 & 1989 & 1.1 & 142 & 240 & $\mathrm{x}$ & Repair \\
\hline Sony & 32 & KV32XBR 15 & 1990 & 1.1 & 164 & 240 & $\mathrm{x}$ & Repair \\
\hline Sony & 32 & KV32XBR55 & 1992 & 1.2 & 152 & 240 & $\mathrm{x}$ & Repair \\
\hline Sony & 32 & KV32XBR75 & 1991 & 1.3 & 133 & 240 & $\mathrm{x}$ & Repair \\
\hline Sony & 32 & KV32TW75 & 1992 & 3.4 & 110 & 195 & $\mathrm{x}$ & Repair \\
\hline Sony & 32 & KV32XBR35 & 1992 & 5.8 & 141 & 225 & $\mathrm{x}$ & Repair \\
\hline Sony & 32 & KV32S26 & 1998 & 7.2 & 88 & 185 & $\mathrm{x}$ & Repair \\
\hline Sony & 32 & KV32S26 & 1998 & 7.8 & 77 & 185 & $\mathrm{x}$ & Repair \\
\hline Sony & 32 & KV32XBR10 & 1990 & 1.1 & 120 & 240 & $\mathrm{x}$ & Repair \\
\hline Sony & 32 & KV32XBR37 & 1994 & 4.6 & 106 & 190 & $\mathrm{x}$ & Repair \\
\hline Sony & 32 & KV32SXR10 & 1988 & 0.7 & 99 & 185 & $\mathrm{x}$ & Repair \\
\hline Sony & 32 & KV32TS20 & 1992 & 3.6 & 90 & 185 & $\mathrm{x}$ & Repair \\
\hline Sony & 46 & KPR46EXR15 & 1993 & 5.0 & 205 & 255 & $\mathrm{x}$ & Repair \\
\hline Sony & 46 & KPR46CX25 & 1990 & 1.2 & 151 & 290 & $\mathrm{x}$ & Repair \\
\hline Sony & 53 & KV53XBR35 & 1995 & 4.1 & 211 & 350 & $\mathrm{x}$ & Repair \\
\hline Sony & 53 & KP53XBR45 & 1996 & 2.2 & 181 & 300 & $\mathrm{x}$ & Repair \\
\hline Sony & 61 & KP61XBR28 & 1994 & 3.9 & 204 & 220 & $\mathrm{x}$ & Repair \\
\hline Thomson & 13 & E13231GM & 1990 & 2.9 & 47 & 70 & $\mathrm{x}$ & Repair \\
\hline Thomson & 19 & F19201BK & 1994 & 2.1 & 75 & 85 & $\mathrm{x}$ & Repair \\
\hline Thomson & 19 & F19220BK & 1994 & 2.1 & 65 & 95 & $\mathrm{x}$ & Repair \\
\hline Thomson & 19 & F19201BK & 1994 & 2.0 & 40 & 85 & $\mathrm{x}$ & Repair \\
\hline Thomson & 19 & F19220BK & 1995 & 2.2 & 28 & 95 & $x$ & Repair \\
\hline Thomson & 19 & F19204WJ & 1995 & 3.0 & 46 & 85 & $\mathrm{x}$ & Repair \\
\hline Thomson & 20 & F20301SF & 1994 & 2.2 & 76 & 85 & $x$ & Repair \\
\hline Thomson & 20 & 20GT324 & 1994 & 2.2 & 65 & 85 & $x$ & Repair \\
\hline Thomson & 20 & 20GT324 & 1994 & 2.2 & 73 & 120 & $\mathrm{x}$ & Repair \\
\hline Thomson & 20 & $\mathrm{X} 20102 \mathrm{SG}$ & 1994 & 2.5 & 74 & 85 & $\mathrm{x}$ & Repair \\
\hline Thomson & 20 & F20345 & 1991 & 3.2 & 58 & 100 & $x$ & Repair \\
\hline Thomson & 20 & F20251WN & 1994 & 6.3 & 91 & 100 & $x$ & Repair \\
\hline
\end{tabular}


Appendix B: TV Data

\begin{tabular}{|c|c|c|c|c|c|c|c|c|}
\hline Brand & Size & Model & Year & $\overline{\text { Off }}$ & On & Rated & Remote & Source \\
\hline Thomson & 20 & F20632SE & 1997 & 9.7 & 98 & 110 & $\mathrm{x}$ & Repair \\
\hline Thomson & 20 & $\mathrm{~J} 20330 \mathrm{BL}$ & 1995 & 6.9 & 93 & 120 & $\mathrm{x}$ & Repair \\
\hline Thomson & 20 & PS20105 & 1994 & 8.1 & 92 & 110 & $\mathrm{x}$ & Repair \\
\hline Thomson & 20 & F20631SE & 1993 & 7.0 & 89 & 100 & $\mathrm{x}$ & Repair \\
\hline Thomson & 25 & $\mathrm{~F} 25190 \mathrm{SB}$ & 1992 & 5.6 & 115 & 125 & $\mathrm{x}$ & Repair \\
\hline Thomson & 25 & $\mathrm{~T} 25251 \mathrm{NN}$ & 1993 & 6.0 & 106 & 125 & $\mathrm{x}$ & Repair \\
\hline Thomson & 25 & $\mathrm{~T} 25651 \mathrm{BL}$ & 1993 & 6.1 & 108 & 125 & $\mathrm{x}$ & Repair \\
\hline Thomson & 25 & 25GT506 & 1994 & 6.3 & 111 & 125 & $\mathrm{x}$ & Repair \\
\hline Thomson & 25 & $\mathrm{~F} 25250 \mathrm{BC}$ & 1995 & 6.5 & 81 & 120 & $\mathrm{x}$ & Repair \\
\hline Thomson & 25 & 25GT520 & 1993 & 6.6 & 85 & 125 & $\mathrm{x}$ & Repair \\
\hline Thomson & 25 & GSR673T & 1984 & 0.0 & 56 & 88 & NO & Repair \\
\hline Thomson & 25 & GJR699PR & 1984 & 4.8 & 71 & 94 & $x$ & Repair \\
\hline Thomson & 25 & $25 \mathrm{NC} 168$ & 1988 & 5.9 & 69 & 125 & $\mathrm{x}$ & Repair \\
\hline Thomson & 26 & G26275CK & 1988 & 2.9 & 82 & 120 & $x$ & Repair \\
\hline Thomson & 27 & $\mathrm{~F} 27240 \mathrm{NT}$ & 1995 & 6.5 & 109 & 125 & $\mathrm{x}$ & Repair \\
\hline Thomson & 27 & 27GT65U & 1989 & 3.2 & 54 & 120 & $\mathrm{x}$ & Repair \\
\hline Thomson & 27 & PS27108 & 1995 & 8.8 & 99 & 125 & $\mathrm{x}$ & Repair \\
\hline Thomson & 31 & F31672ET & 1994 & 7.6 & 126 & 140 & $x$ & Repair \\
\hline Toshiba & .19 & CE19G10 & 1997 & 0.9 & 59 & 54 & $\mathrm{x}$ & Repair \\
\hline Toshiba & 19 & CF1922J & 1990 & 2.6 & 75 & & $\mathrm{x}$ & Repair \\
\hline Toshiba & 20 & CE909 & 1989 & 1.3 & 52 & 80 & $\mathrm{x}$ & Repair \\
\hline Toshiba & 20 & CF2010J & 1990 & 1.7 & 60 & 68 & $\mathrm{x}$ & Repair \\
\hline Toshiba & 20 & CF2028A & 1989 & 2.1 & 77 & 69 & $x$ & Repair \\
\hline Toshiba & 20 & CF2010J & 1990 & 2.1 & 74 & 68 & $x$ & Repair \\
\hline Toshiba & 20 & CF2034J & 1989 & 2.4 & 65 & & $\mathrm{x}$ & Repair \\
\hline Toshiba & 20 & CF915 & 1986 & 2.8 & 64 & 70 & $\mathrm{x}$ & Repair \\
\hline Toshiba & 20 & $\mathrm{C} 2034 \mathrm{M}$ & 1985 & 1.8 & 55 & & $\mathrm{x}$ & Repair \\
\hline Toshiba & 20 & CF2038A & 1988 & 3.8 & 72 & 75 & $\mathrm{x}$ & Repair \\
\hline Toshiba & 26 & CF2655 & 1989 & 1.0 & 110 & 98 & $x$ & Repair \\
\hline Toshiba & 26 & CX2668 & 1988 & 3.7 & 103 & 99 & $\mathrm{x}$ & Repair \\
\hline Toshiba & 27 & $\mathrm{CF} 27 \mathrm{C} 30$ & 1994 & 0.8 & 102 & 87 & $x$ & Repair \\
\hline Toshiba & 27 & CX2778 & 1989 & 4.6 & 82 & 104 & $\mathrm{x}$ & Repair \\
\hline Toshiba & 30 & CF30C50 & 1994 & 0.9 & 112 & 111 & $\mathrm{x}$ & Repair \\
\hline Toshiba & 30 & CF3060K & 1990 & 1.1 & 108 & 116 & $x$ & Repair \\
\hline
\end{tabular}




\begin{tabular}{|c|c|c|c|c|c|c|c|c|}
\hline Brand & Size & Model & Year & Off & On & Rated & Remote & Source \\
\hline Toshiba & 30 & CF30C50 & 1994 & 0.9 & 88 & 111 & $x$ & Repair \\
\hline Toshiba & 30 & CF3048 & 1992 & 2.5 & 111 & & $\mathrm{x}$ & Repair \\
\hline Toshiba & 32 & CX32D60 & 1995 & 1.0 & 94 & 112 & $\mathrm{x}$ & Repair \\
\hline Toshiba & 32 & CF3274J & 1990 & 1.3 & 169 & 163 & $x$ & Repair \\
\hline Zenith & 13 & SRV1300S & 1995 & 12.6 & 38 & 70 & $\mathrm{x}$ & Repair \\
\hline Zenith & 19 & SR1941Y & 1995 & 7.3 & 46 & 82 & $\mathrm{x}$ & Repair \\
\hline Zenith & 19 & SL7935S & 1993 & 9.5 & 62 & 86 & $x$ & Repair \\
\hline Zenith & 19 & SS1937S9 & 1993 & 10.5 & 60 & 93.5 & $\mathrm{x}$ & Repair \\
\hline Zenith & 19 & SLS1937S & 1993 & 15.1 & 111 & 99 & $\mathrm{x}$ & Repair \\
\hline Zenith & 20 & SMS20535 & 1994 & 7.1 & 51 & 79 & $\mathrm{x}$ & Repair \\
\hline Zenith & 20 & $\mathrm{H} 2071 \mathrm{H} 2$ & 1989 & 10.7 & 93 & 93 & $\mathrm{x}$ & Repair \\
\hline Zenith & 23 & SS2345P & 1983 & 4.4 & 76 & 89 & $\mathrm{x}$ & Repair \\
\hline Zenith & 23 & G4549 & 1978 & 0.0 & 113 & 180 & NO & Repair \\
\hline Zenith & 25 & SMS2550S & 1994 & 7.2 & 76 & 109 & $\mathrm{x}$ & Repair \\
\hline Zenith & 25 & SM2568S & 1995 & 9.3 & 88 & 114 & $\mathrm{x}$ & Repair \\
\hline Zenith & 25 & SR2573DT & 1995 & 11.7 & 110 & 106 & $\mathrm{x}$ & Repair \\
\hline Zenith & 25 & SM2511W7 & 1978 & 4.4 & 75 & 119 & $\mathrm{x}$ & Repair \\
\hline Zenith & 25 & A2508 & 1984 & 0.0 & 85 & 93 & NO & Repair \\
\hline Zenith & 25 & SZ2519 & 1984 & 3.6 & 84 & 93 & $\mathrm{x}$ & Repair \\
\hline Zenith & 25 & SM2527 & 1984 & 4.7 & 92 & 180 & $\mathrm{x}$ & Repair \\
\hline Zenith & 25 & SE2505 & 1988 & 5.9 & 73 & 92 & $\mathrm{x}$ & Repair \\
\hline Zenith & 27 & SL2737RK & 1993 & 10.6 & 112 & 130 & $\mathrm{x}$ & Repair \\
\hline Zenith & 27 & SY2772DT & 1996 & 7.5 & 86 & 112 & $\mathrm{x}$ & Repair \\
\hline Zenith & 27 & SG2767H & 1990 & 10.0 & 68 & 85 & $x$ & Repair \\
\hline Zenith & 27 & SM2745 & 1995 & 4.0 & 91 & 170 & $\mathrm{x}$ & Repair \\
\hline Zenith & 27 & SJ2722 & 1993 & 8.0 & 65 & 105 & $\mathrm{x}$ & Repair \\
\hline Zenith & 27 & SCS2504 & 1993 & 8.1 & 75 & 100 & $\mathrm{x}$ & Repair \\
\hline Zenith & 27 & SS2504 & 1993 & 9.9 & 88 & 100 & $x$ & Repair \\
\hline Zenith & 27 & CK2765 & 1993 & 10.4 & 61 & 100 & $\mathrm{x}$ & Repair \\
\hline Zenith & 27 & SG2721 & 1990 & 10.5 & 88 & 120 & $\mathrm{x}$ & Repair \\
\hline Zenith & 27 & SJ2722LX8 & 1992 & 11.2 & 67 & 86 & $\mathrm{x}$ & Repair \\
\hline Zenith & 27 & PL2789 & 1988 & 12.8 & 77 & 108 & $\mathrm{x}$ & Repair \\
\hline Zenith & 27 & SE2725R & 1988 & 20.7 & 95 & 118 & $\mathrm{x}$ & Repair \\
\hline
\end{tabular}




\section{Appendix C: Reliability of Power Measurements}

Power measurements are not $100 \%$ reliable. Figure $\mathrm{Cl}$ shows two examples. The first is TV model number CK3531, of which ten different units were measured. For the same model (different units), active power draw varies from 125 to about 180 watts, while standby power draw varies from 5 to 6 watts. The second example is VCR model number HSU54. The four units drew between 16 and 18 watts while active and between 5.9 and 6.2 watts in standby.

Figure C1. Measured power consumption values for different units with the same model number

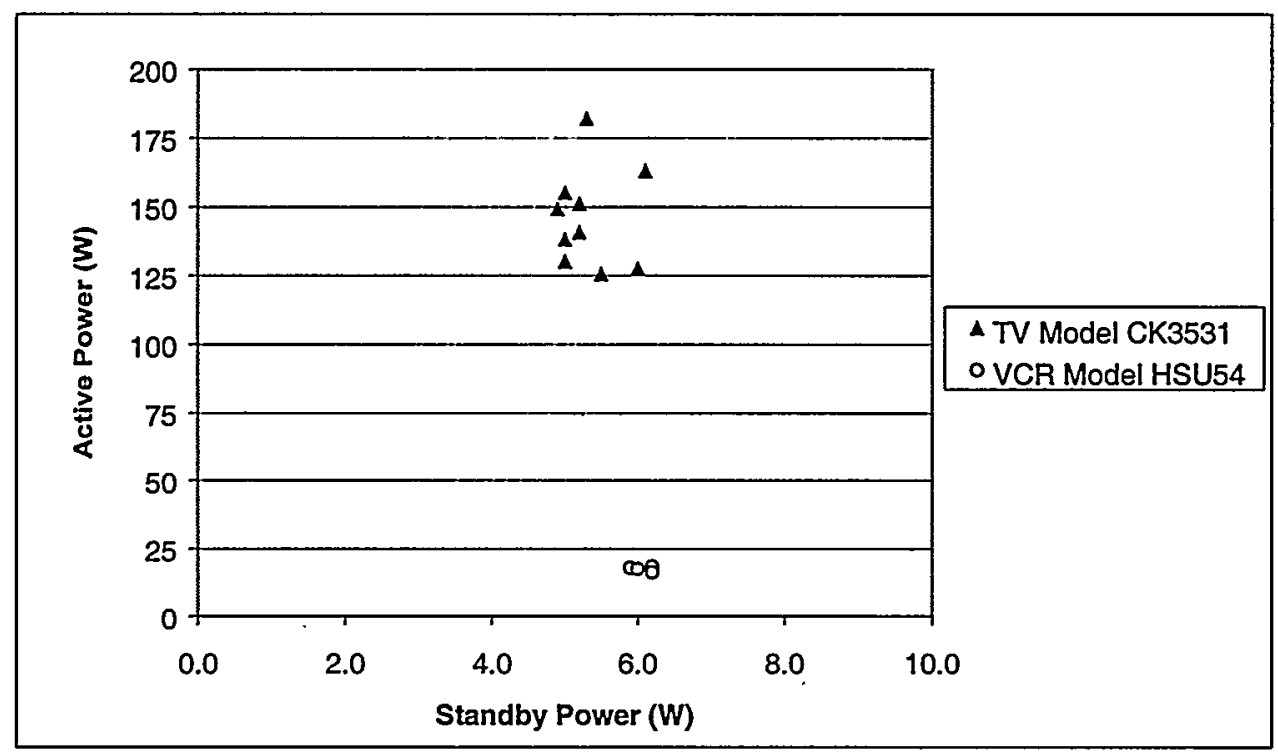




\section{Appendix D: TV and VCR Manufacturer Codes and Rankings}

Table D1 shows the manufacturer codes used in this study.

Table D1. TV and VCR manufacturer codes used in this study

\begin{tabular}{|l|l|}
\hline \multicolumn{1}{|c|}{ TVS } & \\
\hline A Hitachi & A Goldstar \\
B JVC & B Hitachi \\
C Matsushita (Panasonic, Quasar) & C JVC \\
D Mitsubishi & D Matsushita (Panasonic, Quasar) \\
E N.A.P. (Magnavox, Sylvania, & E Mitsubishi \\
F Other & F Other \\
G Samsung & G N.A.P. (Magnavox, Sylvania, \\
H Sanyo & H Sanyo \\
I Sharp & I Sharp \\
J Sony & J Sony \\
K Thomson (RCA, GE) & K Thomson (RCA, GE) \\
L Toshiba & L Toshiba \\
M Zenith & M Zenith \\
\hline
\end{tabular}

To determine whether manufacturers were consistently efficient or inefficient in the power modes measured, each manufacturer was assigned two different ranks: one for standby power draw and one for active or idle power draw, where 1 represents the most efficient manufacturer. These rankings are shown in Tables D2 and D3.

Table D2. TV manufacturer power consumption rankings

\begin{tabular}{|l|c|c|c|c|c|c|c|c|c|c|c|c|c|}
\hline & A & B & C & D & E & F & G & H & I & J & K & L & M \\
\hline Standby Rank & 6 & 3 & 1 & 12 & 7 & 10 & 8 & 11 & 4 & 5 & 9 & 2 & 13 \\
\hline Active Rank & 12 & 3 & 7 & 13 & 6 & 2 & 1 & 9 & 10 & 11 & 4 & 8 & 5 \\
\hline
\end{tabular}

Table D3. VCR manufacturer power consumption rankings

\begin{tabular}{|l|c|c|c|c|c|c|c|c|c|c|c|c|c|}
\hline & A & B & C & D & E & F & G & H & I & J & K & L & M \\
\hline Standby Rank & 5 & 13 & 1 & 6 & 8 & 12 & 2 & 11 & 10 & 7 & 4 & 3 & 9 \\
\hline Idle Rank & 5 & 12 & 7 & 1 & 11 & 10 & 3 & 8 & 2 & 13 & 4 & 9 & 6 \\
\hline
\end{tabular}

There seems to be no correlation between the active and standby rankings of the TV manufacturers $(r=-0.066)$. A correlation analysis of the VCR rankings suggests that there is a tendency for manufacturers that make VCRs with high standby power consumption to also make VCRs with high idle power consumption ( $\mathrm{r}=0.37)$. 


\section{Appendix E: Scatter Plots of Power Measurement Data}

Figure E1. Effect of age on TV power use

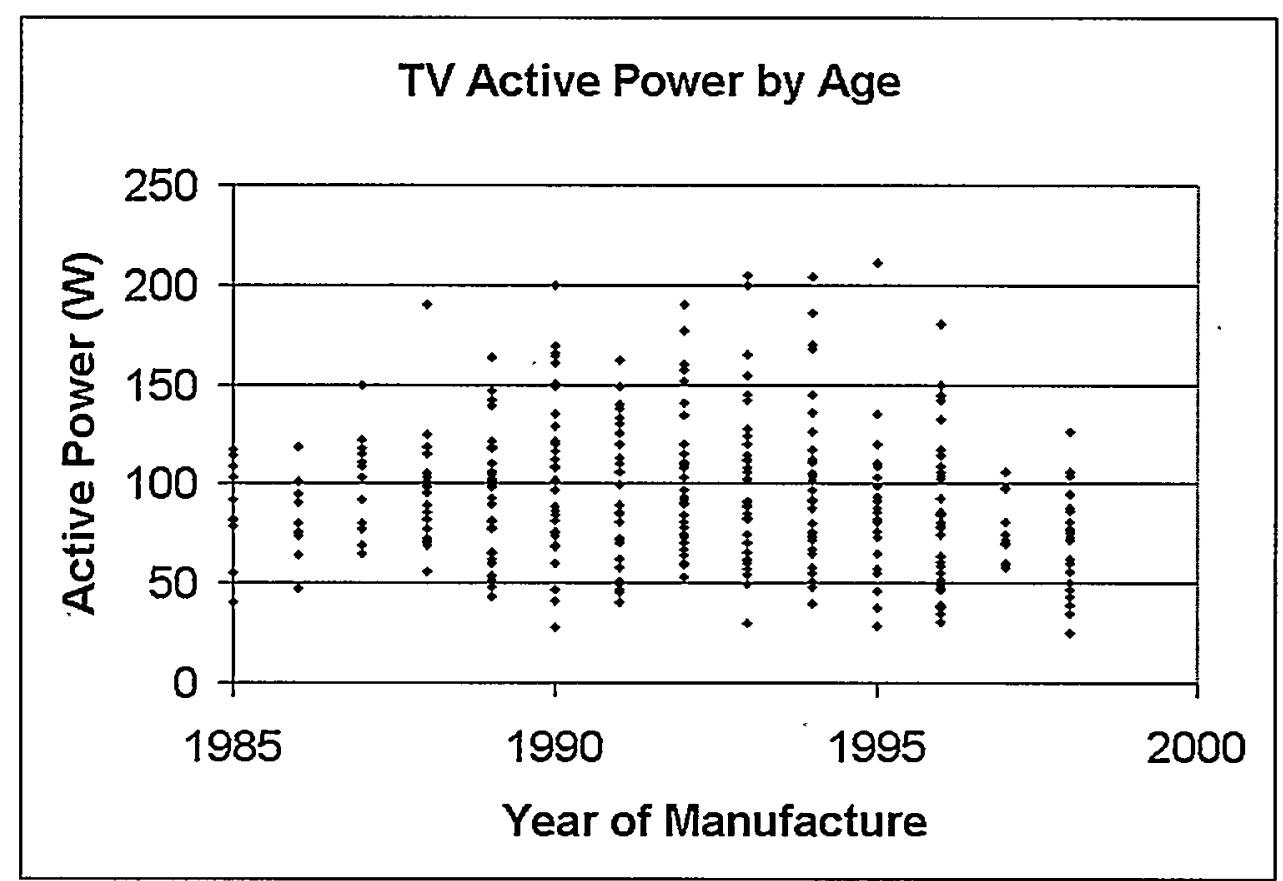

(a)

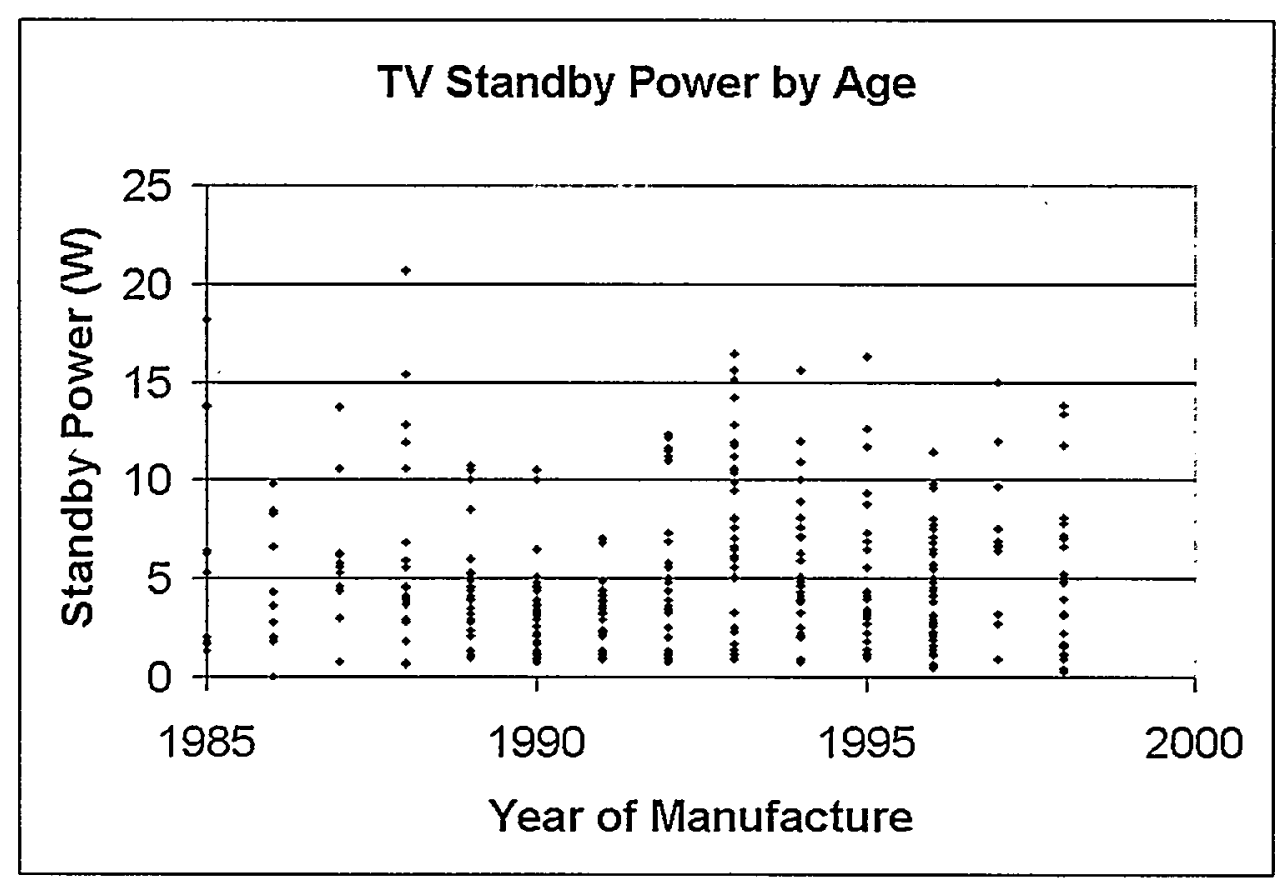

(b) 
Appendix E: Scatter Plots of Power Measurement Data

Figure E2. Effect of manufacturer on TV power use

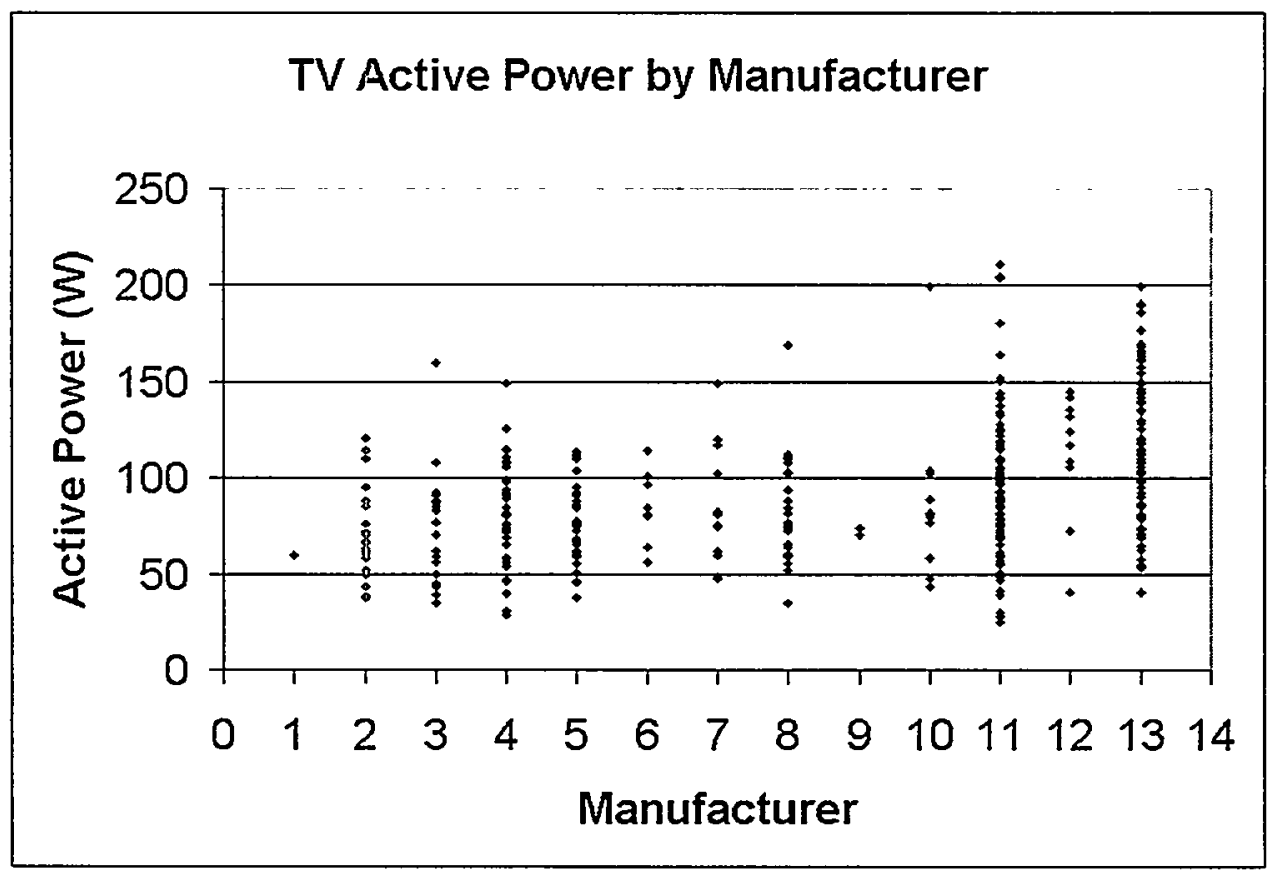

(a)

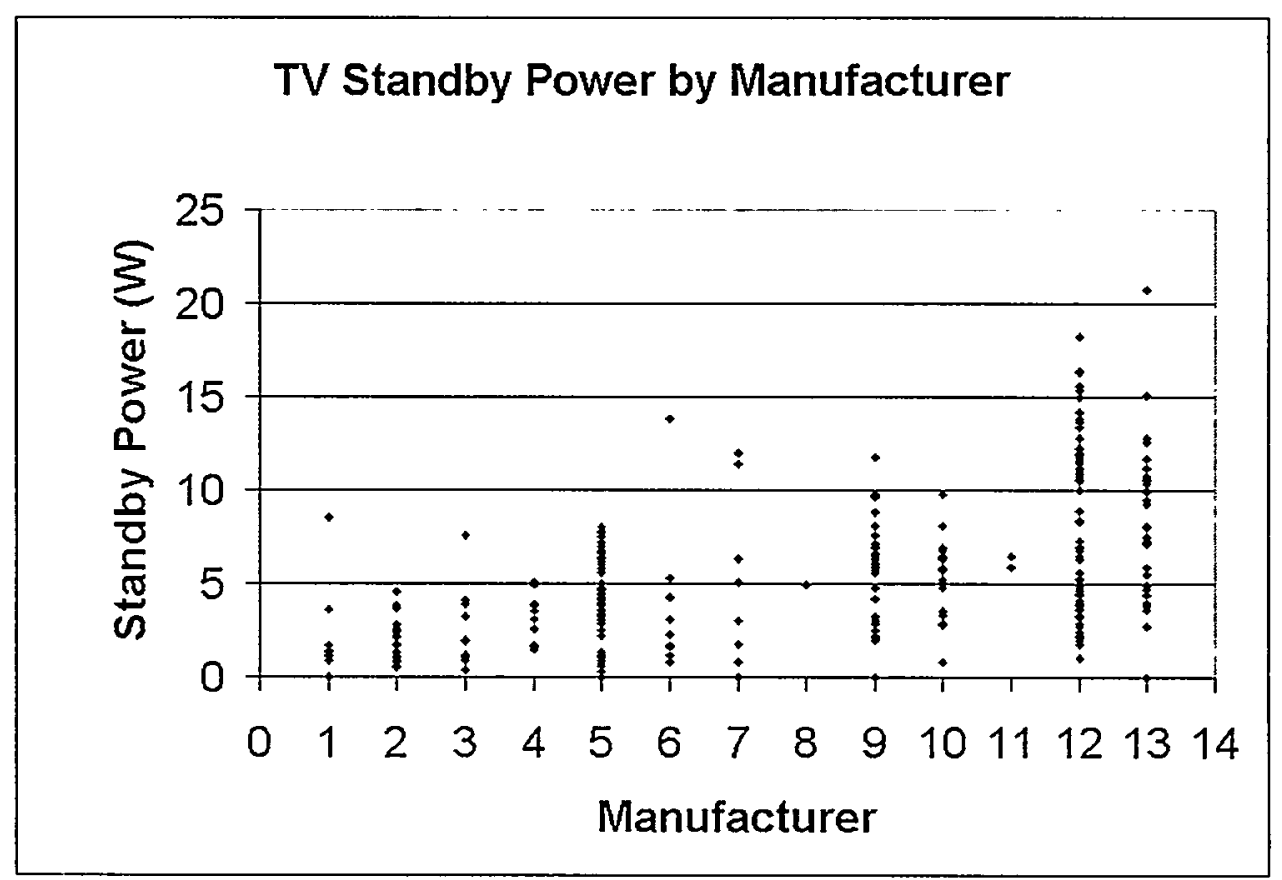

(b) 
Appendix E: Scatter Plots of Power Measurement Data

Figure E3. Effect of screen size on TV power use

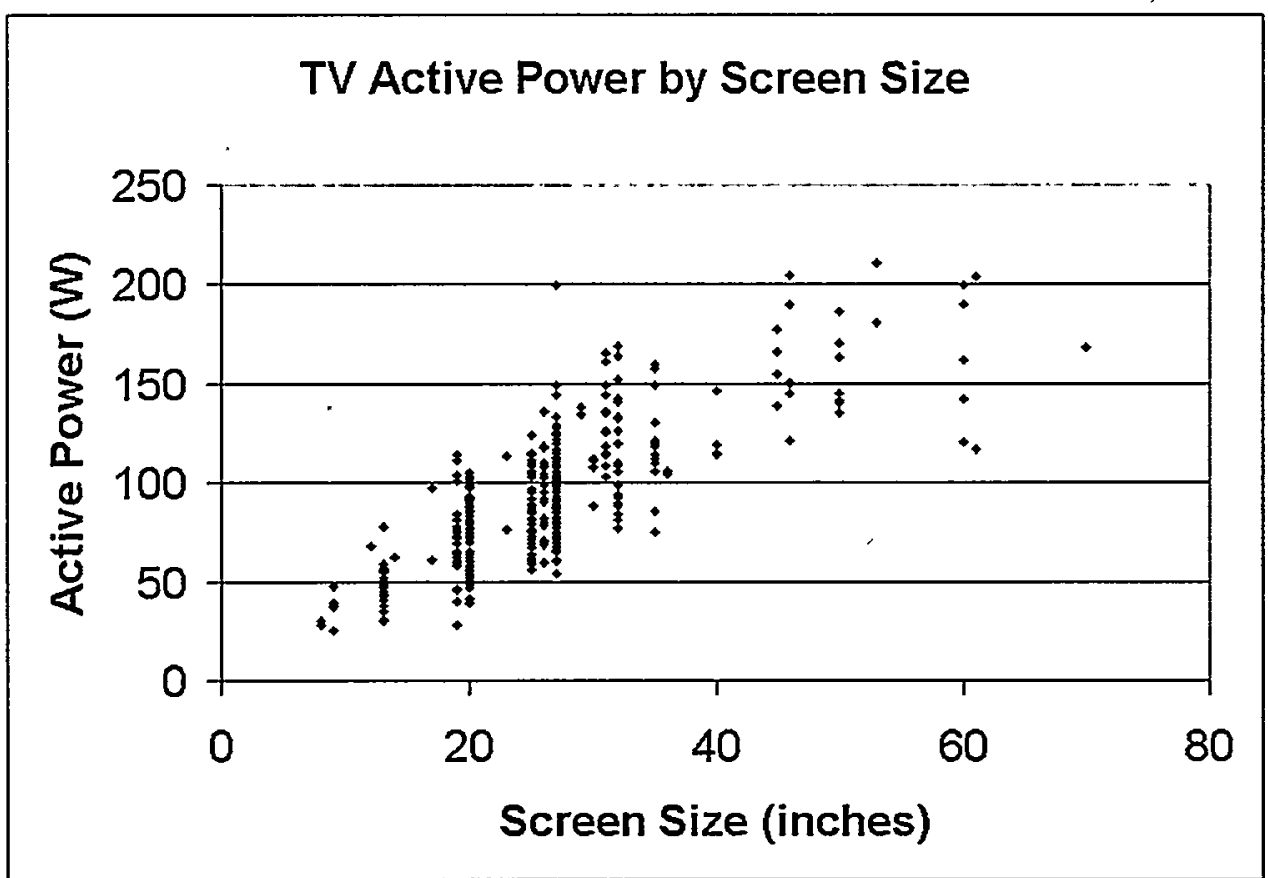

(a)

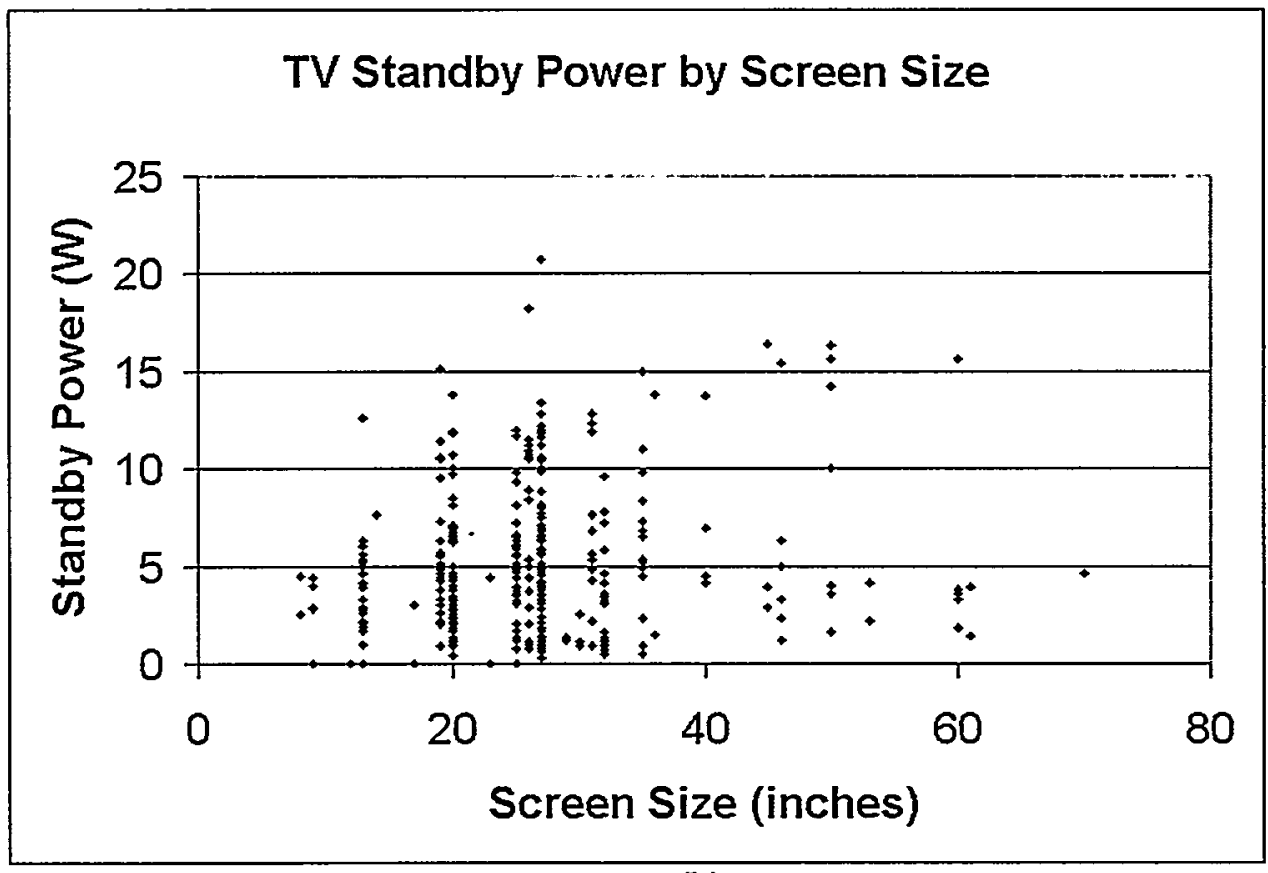

(b) 


\section{VCRs}

Figure E4. Effect of age on VCR power use

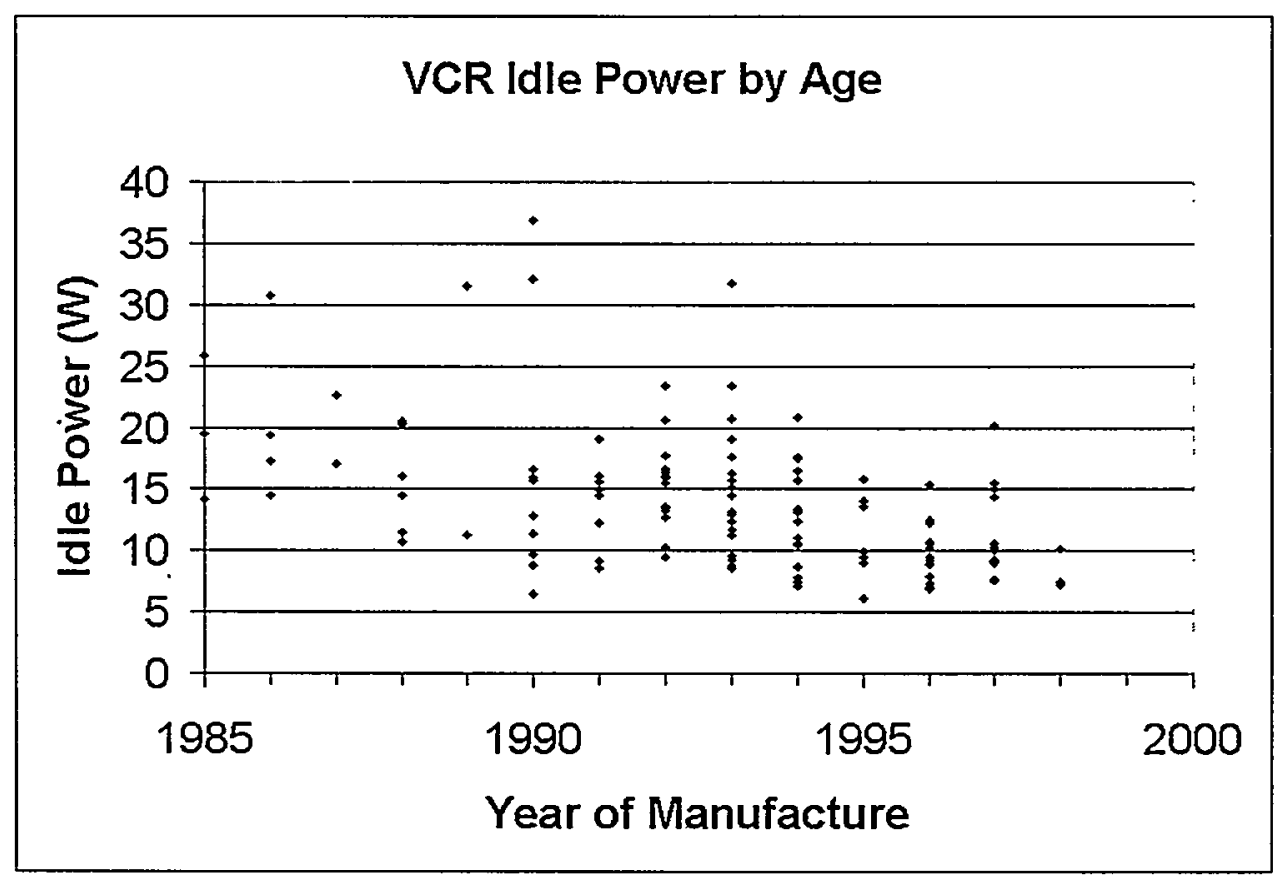

(a)

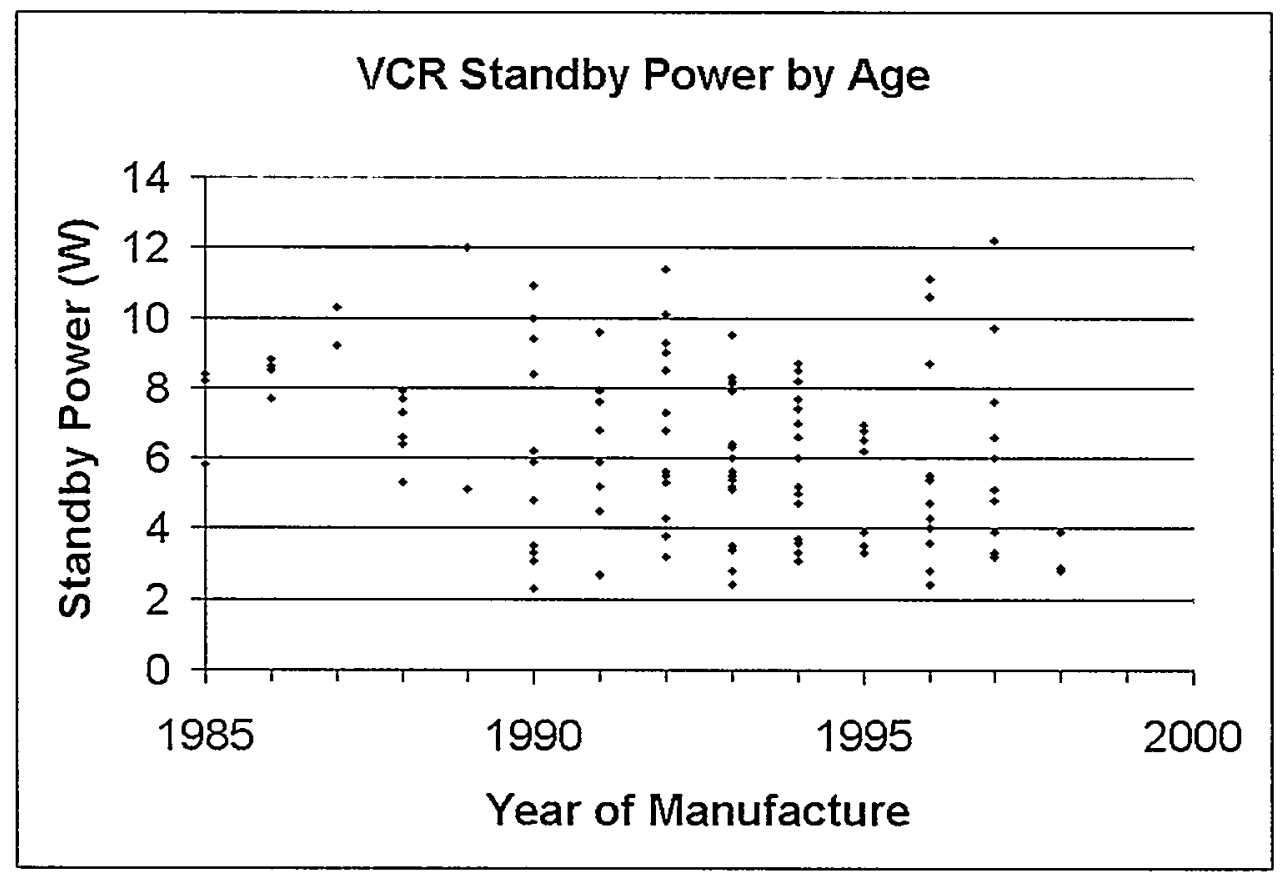

(b) 
Figure E5. Effect of manufacturer on VCR power use

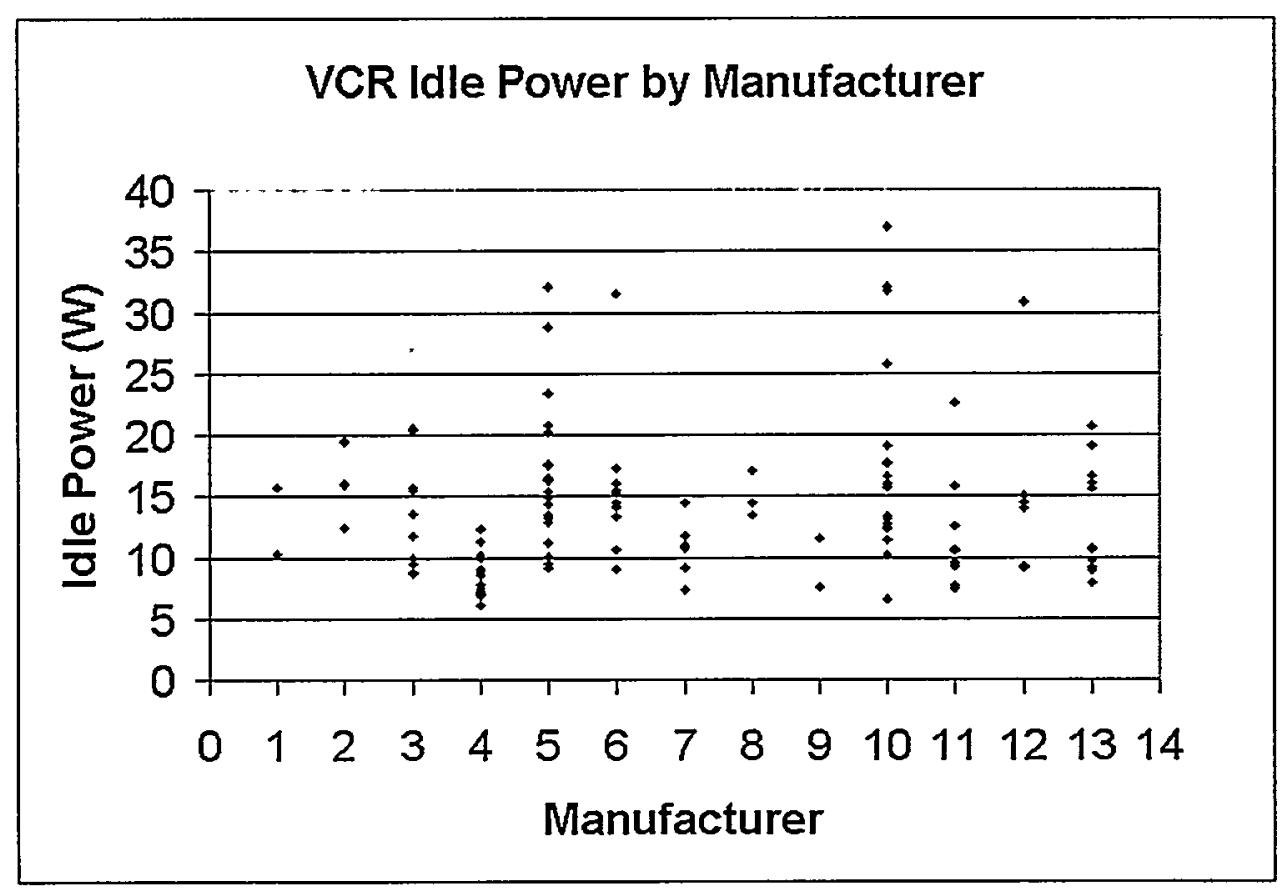

(a)

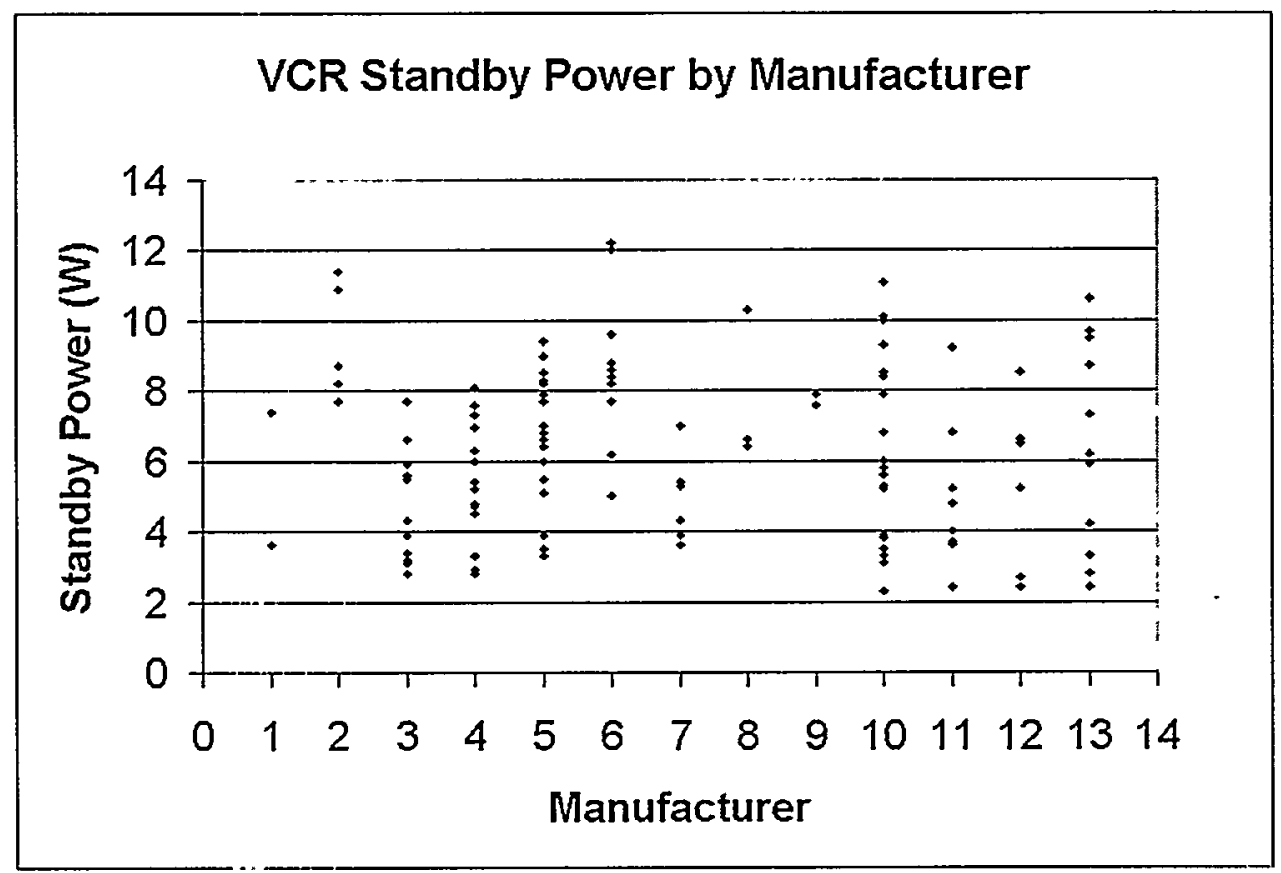

(b) 


\section{Appendix F: Historic Trends in TV and VCR Power Draw}

\section{TVs}

Figure F1. TV trends: active-mode power draw

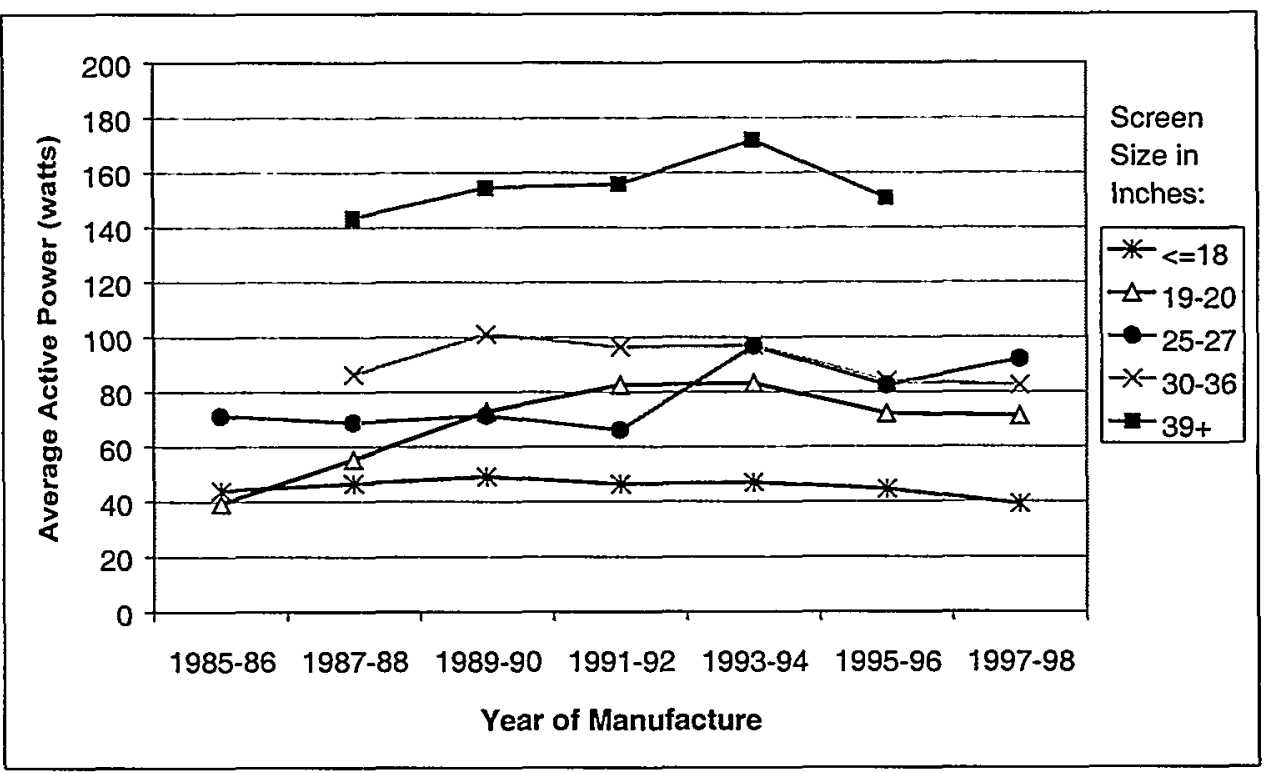

Figure F2. TV trends: standby-mode power draw

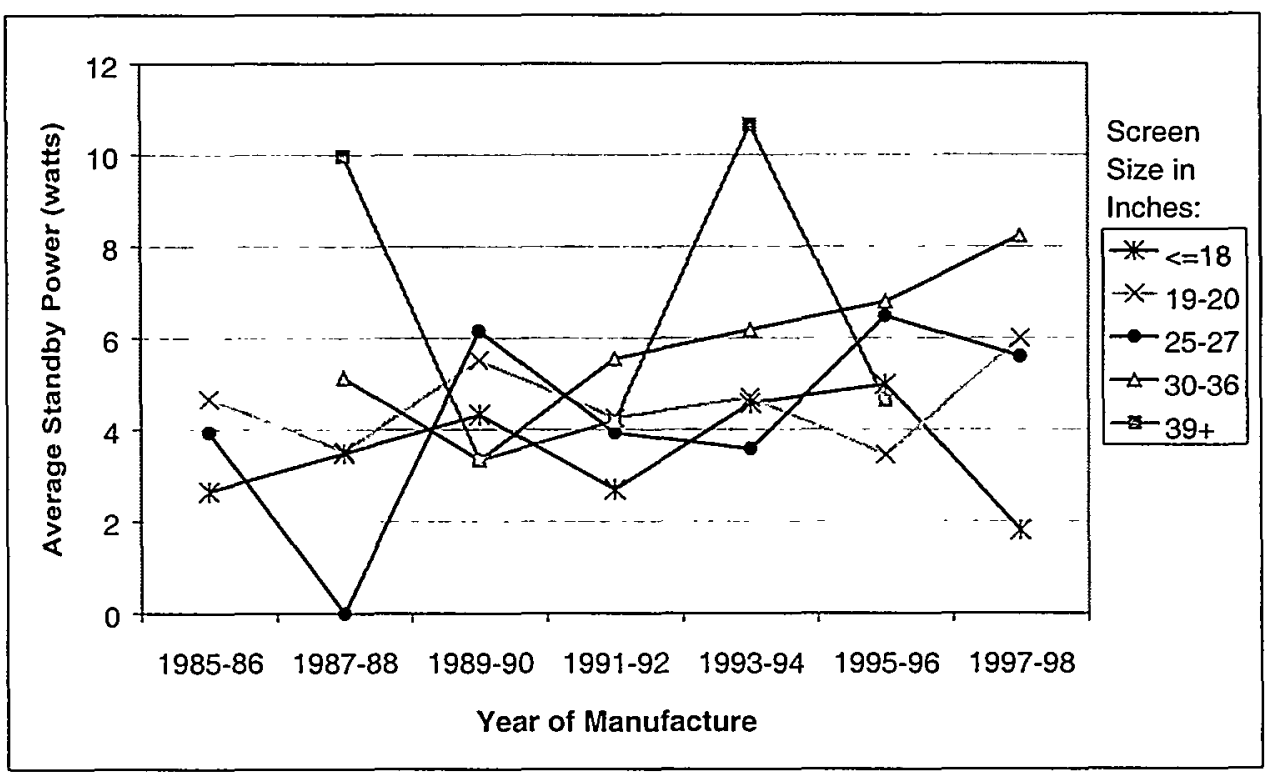




\section{VCRs}

Figure F3. VCR trends: Idle-mode power draw

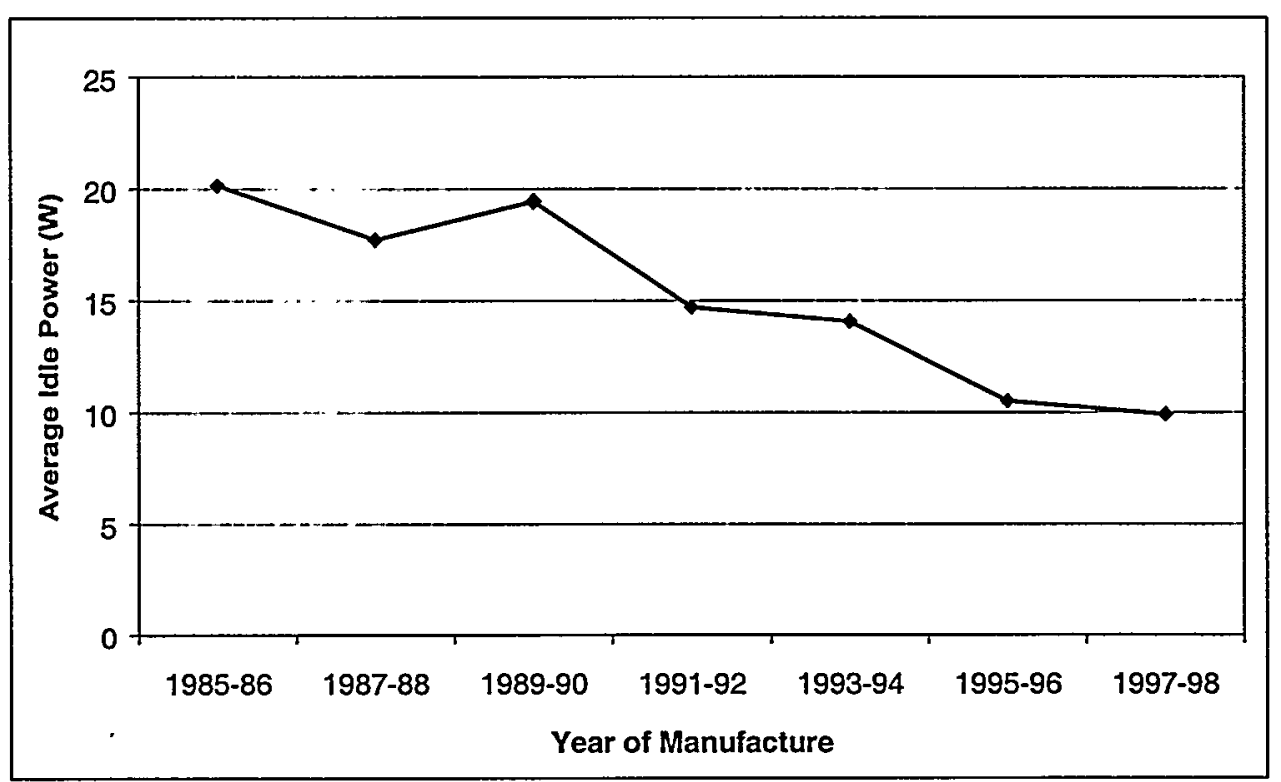

Figure F4. VCR trends: Standby-mode power draw

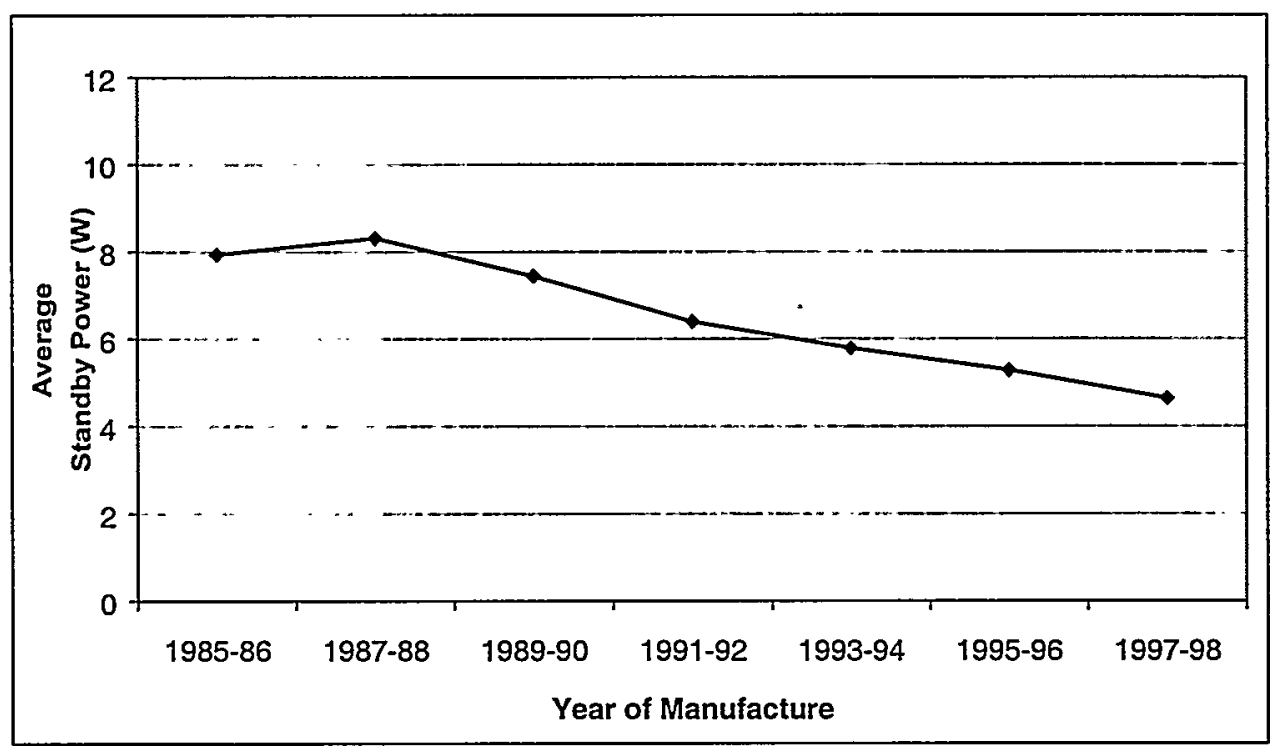




\section{Appendix G: Effect of TV screen size on power draw}

Active power consumption clearly increases as TV screen size increases, as shown in Figure G1. However, the relationship between standby power consumption and screen size is not clear, as shown in Figure G2.

Figure G1. Average active power consumption values by screen size

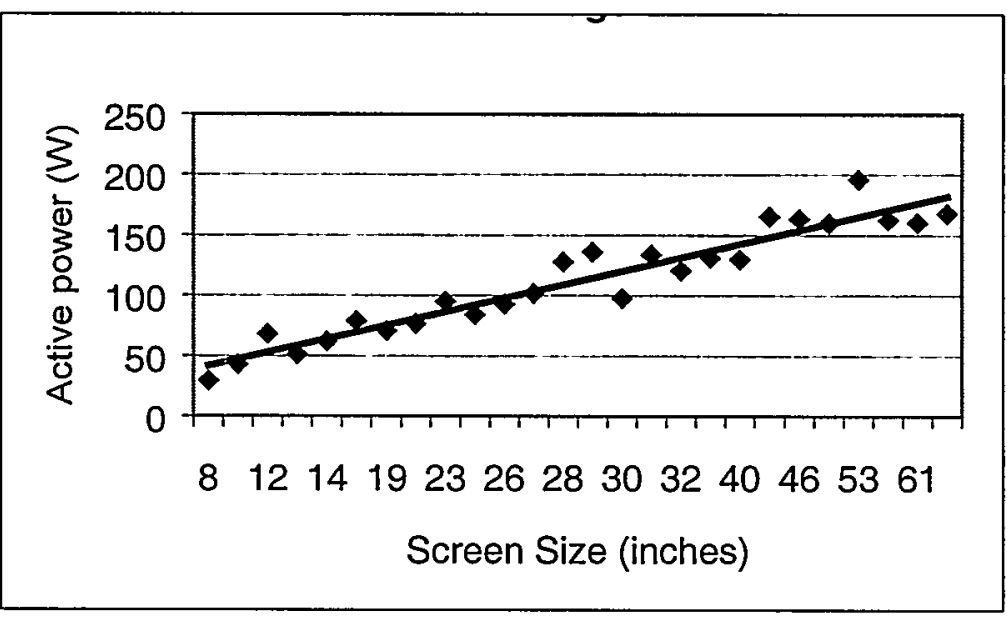

Figure G2. Average standby power consumption values by screen size

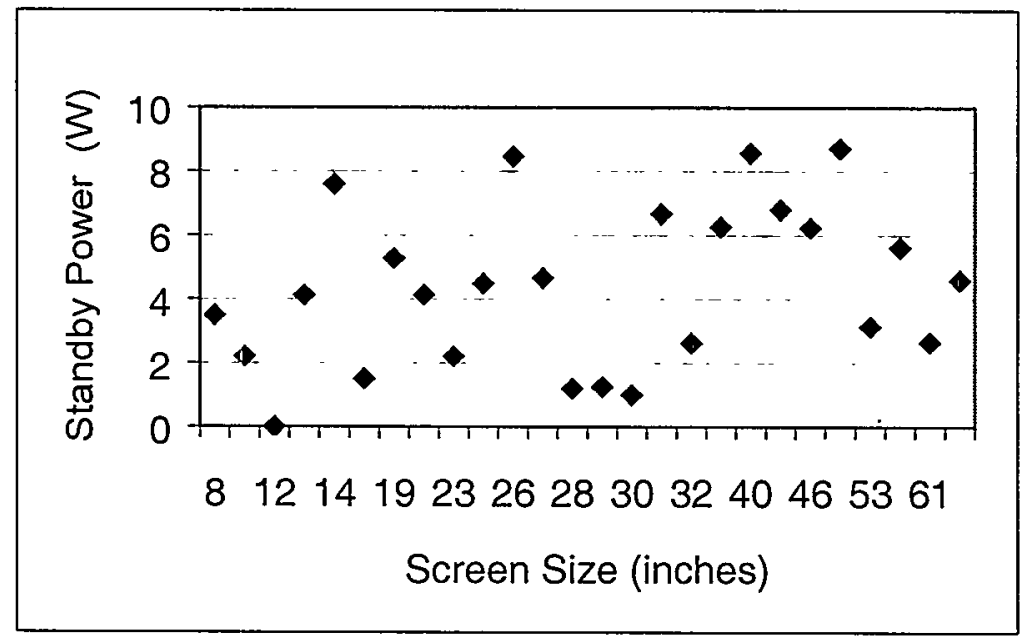


Appendix G: Effect of TV screen size on power draw

The analysis of covariance discussed in Section 4.3 suggests that there may be some connection between screen size and standby power draw. However, a comparison between the average standby power draw values of different sizes units of two TV manufacturers suggests that manufacturer is a much more important factor in the determination of standby power draw than is screen size.

Figure G3. Average standby power draw values of two TV manufacturers by screen size

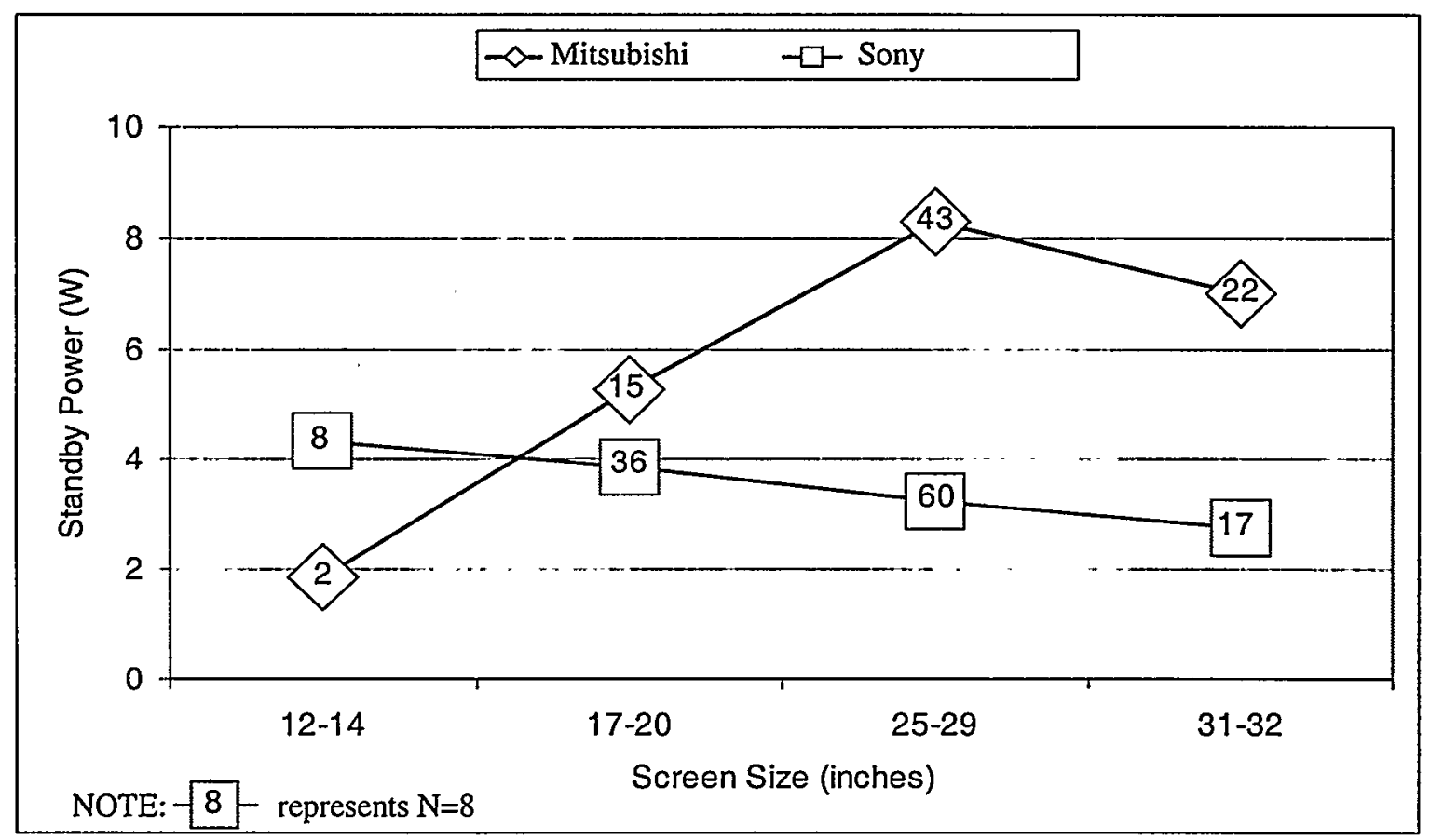


Appendix H: VCR Power Measurement Data

\begin{tabular}{|c|c|c|c|c|c|c|c|}
\hline Brand & Model & Year & Off (W) & On (W) & Rated (W) & Remote & Source \\
\hline Goldstar & GVRF468 & 1996 & 3.6 & 10.3 & 19 & $\mathrm{x}$ & FSEC \\
\hline Philips-Mag & VRU222AT & 1996 & 4.3 & 7.3 & 17 & $\mathrm{x}$ & FSEC \\
\hline Thomson & PSVR57 & 1996 & 4.0 & 12.5 & 22 & $\mathrm{x}$ & FSEC \\
\hline Thomson & VG2056 & 1996 & 4.0 & 9.5 & 17 & $\mathrm{x}$ & FSEC \\
\hline Thomson & VG4056 & 1996 & 4.0 & 9.3 & 17 & $\mathrm{x}$ & FSEC \\
\hline Thomson & VG4251 & 1996 & 3.6 & 10.6 & 19 & $\mathrm{x}$ & FSEC \\
\hline Zenith & VR2106 & 1996 & 2.8 & 7.9 & 16 & $x$ & FSEC \\
\hline Zenith & VR4156 & 1996 & 8.7 & 8.9 & 19 & $\mathrm{x}$ & FSEC \\
\hline Zenith & VR4206HF & 1996 & 2.4 & 9.2 & 18 & $\mathrm{x}$ & FSEC \\
\hline Zenith & VR4256HF & 1996 & 10.6 & 10.7 & 19 & $\mathrm{x}$ & FSEC \\
\hline Matsushita & PV4401 & 1995 & 3.3 & 6.1 & 18 & $\mathrm{x}$ & LBNL \\
\hline Matsushita & VHQ580 & 1995 & 7.0 & 9.9 & 23 & $\mathrm{x}$ & LBNL \\
\hline Matsushita & PV7452 & 1997 & 6.0 & 9.0 & 23 & $\mathrm{x}$ & LBNL \\
\hline Mitsubishi & HSU770 & 1997 & 6.6 & 20.2 & 35 & $\mathrm{x}$ & LBNL \\
\hline Mitsubishi & HSU790 & 1997 & 5.1 & 14.4 & 22 & $\mathrm{x}$ & LBNL \\
\hline Other & SV211E & 1995 & 6.2 & 9.0 & 17 & $\mathrm{x}$ & LBNL \\
\hline Other & GV 6060 & 1997 & 12.2 & 15.5 & 29 & $\mathrm{x}$ & LBNL \\
\hline Thomson & VR519 & 1997 & 4.8 & 7.7 & 18 & $\mathrm{x}$ & LBNL \\
\hline Toshiba & M750 & 1995 & 6.5 & 14.0 & 22 & $x$ & LBNL \\
\hline Toshiba & M728 & 1997 & 6.6 & 15.0 & 23 & $\mathrm{x}$ & LBNL \\
\hline Goldstar & VRB438 & 1994 & 7.4 & 15.7 & 30 & $x$ & Repair \\
\hline Hitachi & VT1320 & 1985 & 8.2 & 19.5 & 32 & $\mathrm{x}$ & Repair \\
\hline Hitachi & FVT11100 & 1986 & 7.7 & 19.4 & 32 & $x$ & Repair \\
\hline Hitachi & VT350 & 1990 & 10.9 & 15.9 & 26 & $x$ & Repair \\
\hline Hitachi & VTF361 & 1992 & 11.4 & 16.1 & 28 & $x$ & Repair \\
\hline Hitachi & VTM181 & 1994 & 8.7 & 12.4 & 24 & $x$ & Repair \\
\hline $\mathrm{JVC}$ & HRD750 & 1988 & 7.7 & 20.5 & 30 & $x$ & Repair \\
\hline JVC & HRS4700 & 1988 & 6.6 & 20.3 & 34 & $x$ & Repair \\
\hline JVC & HRD200 & 1990 & 5.9 & 15.7 & 26 & $\mathrm{x}$ & Repair \\
\hline $\mathrm{JVC}$ & HRD720 & 1992 & 3.2 & 9.5 & 24 & $x$ & Repair \\
\hline JVC & HRD865U & 1992 & 4.3 & 13.6 & 23 & $\mathrm{x}$ & Repair \\
\hline JVC & HRDX40 & 1992 & 5.6 & 15.5 & 24 & $\mathrm{x}$ & Repair \\
\hline JVC & HRS6700 & 1992 & 5.5 & 20.6 & 35 & $x$ & Repair \\
\hline JVC & HRD910 & 1993 & 3.4 & 11.7 & 24 & $x$ & Repair \\
\hline
\end{tabular}




\begin{tabular}{|c|c|c|c|c|c|c|c|}
\hline Brand & Model & Year & Off $(W)$ & On (W) & Rated (W) & Rem & Source \\
\hline JVC & HRDX44U & 1993 & 2.8 & 8.8 & 19 & $\mathrm{x}$ & Repair \\
\hline JVC & HRDX 420 & 1994 & 3.1 & 8.7 & 19 & $\mathrm{x}$ & Repair \\
\hline JVC & HRD870 & 1995 & 3.9 & 13.6 & 23 & $\mathrm{x}$ & Repair \\
\hline JVC & HRJ620 & 1997 & 3.2 & 10.0 & 21 & $\mathrm{x}$ & Repair \\
\hline Matsushita & VH6400 & 1990 & 4.8 & 8.8 & 18 & $\mathrm{x}$ & Repair \\
\hline Matsushita & PV2101 & 1991 & 4.5 & 8.6 & 18 & $\mathrm{x}$ & Repair \\
\hline Matsushita & VH6415 & 1991 & 7.6 & 12.3 & 23 & $\mathrm{x}$ & Repair \\
\hline Matsushita & PV4260 & 1992 & 7.3 & 10.2 & 23 & $\mathrm{x}$ & Repair \\
\hline Matsushita & PV2301 & 1993 & 6.3 & 8.6 & 19 & $\mathrm{x}$ & Repair \\
\hline Matsushita & PV4362 & 1993 & 8.1 & 11.3 & 23 & $\mathrm{x}$ & Repair \\
\hline Matsushita & PV2401 & 1994 & 5.2 & 7.8 & 18 & $\mathrm{x}$ & Repair \\
\hline Matsushita & VHQ42 & 1994 & 4.7 & 7.1 & 18 & $\mathrm{x}$ & Repair \\
\hline Matsushita & VHQ620 & 1996 & 4.7 & 7.0 & 18 & $\mathrm{x}$ & Repair \\
\hline Matsushita & VHQ620 & 1996 & 5.4 & 6.9 & 18 & $\mathrm{x}$ & Repair \\
\hline Matsushita & VHQ820 & 1998 & 2.9 & 7.5 & 18 & $\mathrm{x}$ & Repair \\
\hline Matsushita & VHQ820 & 1998 & 2.8 & 7.2 & 18 & $\mathrm{x}$ & Repair \\
\hline Mitsubishi & HS400UR & 1984 & 8.5 & 28.8 & 42 & $\mathrm{x}$ & Repair \\
\hline Mitsubishi & HS339 & 1989 & 5.1 & 11.2 & 23 & $\mathrm{x}$ & Repair \\
\hline Mitsubishi & HSU82 & 1990 & 9.4 & 32.1 & 47 & $\mathrm{x}$ & Repair \\
\hline Mitsubishi & HSU32 & 1991 & 7.9 & 14.9 & 26 & $\mathrm{x}$ & Repair \\
\hline Mitsubishi & HSU250 & 1992 & 5.5 & 13.5 & 23 & $\mathrm{x}$ & Repair \\
\hline Mitsubishi & HSU56 & 1992 & 6.8 & 16.4 & 28 & $\mathrm{x}$ & Repair \\
\hline Mitsubishi & HSU65 & 1992 & 9.0 & 23.4 & 37 & $\mathrm{x}$ & Repair \\
\hline Mitsubishi & HS34 & 1993 & 5.5 & 12.9 & 22 & $\mathrm{x}$ & Repair \\
\hline Mitsubishi & HSU110 & 1993 & 5.1 & 13.2 & 23 & $\mathrm{x}$ & Repair \\
\hline Mitsubishi & HSU58 & 1993 & 6.4 & 16.3 & 29 & $\mathrm{x}$ & Repair \\
\hline Mitsubishi & HSU6I & 1993 & 8.3 & 23.4 & 35 & $x$ & Repair \\
\hline Mitsubishi & HSU500 & 1994 & 7.0 & 16.5 & 29 & $\mathrm{x}$ & Repair \\
\hline Mitsubishi & HSU52 & 1994 & 7.7 & 17.6 & 30 & $\mathrm{x}$ & Repair \\
\hline Mitsubishi & HSU54 & 1994 & 6.0 & 17.5 & 28 & $\mathrm{x}$ & Repair \\
\hline Mitsubishi & HSU69 & 1994 & 8.5 & 20.8 & 34 & $\mathrm{x}$ & Repair \\
\hline Mitsubishi & HSU760 & 1994 & 8.2 & 20.8 & 34 & $\mathrm{x}$ & Repair \\
\hline Mitsubishi & HSU550 & 1995 & 3.5 & 9.5 & 20 & $\mathrm{x}$ & Repair \\
\hline Mitsubishi & HSU580 & 1995 & 3.5 & 9.5 & 20 & $\mathrm{x}$ & Repair \\
\hline
\end{tabular}




\begin{tabular}{|c|c|c|c|c|c|c|c|}
\hline Brand & Model & Year & Off (W) & $\overline{\text { On }(W)}$ & Rated (W) & $\overline{\text { Remo }}$ & Source \\
\hline Mitsubishi & HSU410 & 1996 & 5.5 & 15.4 & 28 & $\mathrm{x}$ & Repair \\
\hline Mitsubishi & HSU430 & 1997 & 3.3 & 9.2 & 19 & $\mathrm{x}$ & Repair \\
\hline Mitsubishi & HSU570 & 1998 & 3.9 & 10.1 & 20 & $x$ & Repair \\
\hline Other & HN915 & 1984 & 7.7 & 13.3 & 34 & $\mathrm{x}$ & Repair \\
\hline Other & VCR 875 & 1985 & 8.4 & 14.1 & 26 & $x$ & Repair \\
\hline Other & SVC7500 & 1986 & 8.6 & 17.3 & 32 & $x$ & Repair \\
\hline Other & VRVCR885 & 1986 & 8.8 & 14.5 & 27 & $x$ & Repair \\
\hline Other & DS8000U & 1989 & 12.0 & 31.5 & 45 & $\mathrm{x}$ & Repair \\
\hline Other & N958U & 1991 & 9.6 & 16.1 & 28 & $\mathrm{x}$ & Repair \\
\hline Other & VCR4000 & 1993 & 8.2 & 15.2 & 27 & $\mathrm{x}$ & Repair \\
\hline Other & HVM110 & 1994 & 5.0 & 10.6 & 25 & $\mathrm{x}$ & Repair \\
\hline Philips-Mag & VR9525 & 1984 & 7.0 & 11.7 & 21 & $\mathrm{x}$ & Repair \\
\hline Philips-Mag & VR1260AT01 & 1988 & 5.3 & 10.7 & 22 & $x$ & Repair \\
\hline Philips-Mag & VR3460 & 1993 & 5.4 & 14.5 & 25 & $\mathrm{x}$ & Repair \\
\hline Philips-Mag & VR9362 & 1994 & 3.6 & 11.0 & 19 & $\mathrm{x}$ & Repair \\
\hline Philips-Mag & VRT422 & 1997 & 3.9 & 9.1 & 19 & $\mathrm{x}$ & Repair \\
\hline Sanyo & FVH905 & 1987 & 10.3 & 17.1 & 28 & $x$ & Repair \\
\hline Sanyo & FVH6300 & 1988 & 6.4 & 14.5 & 24 & $\mathrm{x}$ & Repair \\
\hline Sanyo & VHR9385 & 1994 & 6.6 & 13.4 & 26 & $\mathrm{x}$ & Repair \\
\hline Sharp & XA200 & 1988 & 7.9 & 11.5 & 24 & $\mathrm{x}$ & Repair \\
\hline Sharp & VCA555 & 1997 & 7.6 & 7.6 & 20 & $x$ & Repair \\
\hline Sony & SL2410 & 1985 & 5.8 & 25.8 & 45 & $\mathrm{x}$ & Repair \\
\hline Sony & EVCl00 & 1990 & 2.3 & 6.5 & 12 & $\mathrm{x}$ & Repair \\
\hline Sony & SLHF1000 & 1990 & 10.0 & 36.9 & 55 & $\mathrm{x}$ & Repair \\
\hline Sony & SLV690 & 1990 & 3.5 & 12.8 & 26 & $\mathrm{x}$ & Repair \\
\hline Sony & SLV696 & 1990 & 3.1 & 11.4 & 25 & $\mathrm{x}$ & Repair \\
\hline Sony & SLVR5UC & 1990 & 8.4 & 32.1 & 45 & $\mathrm{x}$ & Repair \\
\hline Sony & SLV555 & 1991 & 6.8 & 19.1 & 33 & $\mathrm{x}$ & Repair \\
\hline Sony & SL390 & 1992 & 3.8 & 15.9 & 26 & $\mathrm{x}$ & Repair \\
\hline Sony & SLV373 & 1992 & 8.5 & 16.0 & 28 & $\mathrm{x}$ & Repair \\
\hline Sony & SLV585 & 1992 & 5.3 & 17.7 & 30 & $\mathrm{x}$ & Repair \\
\hline Sony & SLV900 & 1992 & 9.3 & 12.7 & 24 & $\mathrm{x}$ & Repair \\
\hline Sony & SLV900HF & 1992 & 10.1 & 13.3 & 25 & $\mathrm{x}$ & Repair \\
\hline Sony & SLVR 1000 & 1992 & 6.8 & 16.6 & 30 & $x$ & Repair \\
\hline
\end{tabular}




\begin{tabular}{|c|c|c|c|c|c|c|c|}
\hline Brand & Model & Year & Off $(W)$ & On (W) & Rated (W) & Remo & Source \\
\hline Sony & SLV373 & 1993 & 5.6 & 15.7 & 28 & $x$ & Repair \\
\hline Sony & SLV585 & 1993 & 6.0 & 19.1 & 30 & $x$ & Repair \\
\hline Sony & SLV595 & 1993 & 3.5 & 12.4 & 25 & $\mathrm{x}$ & Repair \\
\hline Sony & SLV686 & 1993 & 5.2 & 17.6 & 30 & $x$ & Repair \\
\hline Sony & SLVU5R & 1993 & 7.9 & 31.8 & 45 & $x$ & Repair \\
\hline Sony & SLV696 & 1994 & 3.3 & 13.1 & 25 & $x$ & Repair \\
\hline Sony & SLV760 & 1996 & 11.1 & 12.3 & 27 & $\mathrm{x}$ & Repair \\
\hline Sony & SLV495 & 1997 & 3.9 & 10.2 & 23 & $x$ & Repair \\
\hline Thomson & VPT390 & 1987 & 9.2 & 22.6 & 38 & $x$ & Repair \\
\hline Thomson & VG4025 & 1993 & 2.4 & 9.6 & 21 & $\mathrm{x}$ & Repair \\
\hline Thomson & VG4033 & 1994 & 5.2 & 7.5 & 18 & $\mathrm{x}$ & Repair \\
\hline Thomson & VH64 & 1994 & 3.7 & 10.5 & 22 & $x$ & Repair \\
\hline Thomson & PSVR61 & 1995 & 6.8 & 15.8 & 23 & $x$ & Repair \\
\hline Toshiba & SV970 & 1986 & 8.5 & 30.8 & 46 & $x$ & Repair \\
\hline Toshiba & M221 & 1991 & 5.2 & 14.5 & 27 & $\mathrm{x}$ & Repair \\
\hline Toshiba & M449 & 1991 & 2.7 & 9.1 & 21 & $\mathrm{x}$ & Repair \\
\hline Toshiba & M228 & 1993 & 2.4 & 9.3 & 21 & $\mathrm{x}$ & Repair \\
\hline Zenith & VR9775 & 1979 & 4.2 & 19.1 & 30 & $x$ & Repair \\
\hline Zenith & VR 1800 & 1988 & 7.3 & 16.0 & 29 & $x$ & Repair \\
\hline Zenith & HVRG 170 & 1990 & 3.3 & 9.7 & 19 & $\mathrm{x}$ & Repair \\
\hline Zenith & VRL4170 & 1990 & 6.2 & 16.6 & 30 & $x$ & Repair \\
\hline Zenith & VRF165 & 1991 & 5.9 & 15.6 & 24 & $\mathrm{x}$ & Repair \\
\hline Zenith & VR2420 & 1993 & 9.5 & 20.7 & 35 & $\mathrm{x}$ & Repair \\
\hline Zenith & VR4256 & 1997 & 9.7 & 10.6 & 19 & $x$ & Repair \\
\hline
\end{tabular}




\section{Appendix I. VCR Power Measurements Used to Determine Average Play/Record Power Draw}

\begin{tabular}{lllrrrrl}
\hline Brand Name & Model & Year & Off (W) & On (W) & Play (W) & Rated (W) & Source \\
\hline Panasonic & PV-4451 & 1994 & 6.5 & 9.7 & 13.5 & 23.0 & LBNL \\
Panasonic & PV-4651 & 1996 & 6.9 & 10.0 & 14.2 & & LBNL \\
Hitachi & VT-1310A & 1984 & 9.7 & 19.9 & 26.0 & 32.0 & LBNL \\
Symphonic & SV211E & 1995 & 6.2 & 9.0 & 13.7 & 17.0 & LBNL \\
Mitsubishi & HS-339UR & 1986 & 6.1 & 12.9 & 18.3 & 26.0 & LBNL \\
Quasar & VHQ580 & 1995 & 7.0 & 9.9 & 13.5 & 23.0 & LBNL \\
Sony & SLV-595HF & 1990 & 3.9 & 13.7 & 17.5 & 25.0 & LBNL \\
Panasonic & PV-4114 & 1991 & 6.4 & 10.8 & 13.2 & 19.0 & LBNL \\
Panasonic & PV-4151 & 1991 & 6.3 & 10.2 & 14.2 & 23.0 & LBNL \\
Magnavox & VRU242AT01 & 1996 & 5.6 & 8.8 & 13.5 & 17.0 & LBNL \\
Panasonic & PV-1330 & 1996 & 6.6 & 11.5 & 13.8 & 20.0 & LBNL \\
Panasonic & PV-4401 & 1995 & 3.3 & 6.1 & 9.8 & 18.0 & LBNL \\
Sanyo & VHR-5420 & 1990 & 4.6 & 9.3 & 14.0 & 18.0 & LBNL \\
Fisher & FVH-4508 & 1992 & 4.6 & 11.2 & 14.3 & 18.0 & LBNL \\
Sony & SLV-585HF & 1993 & 6.3 & 18.3 & 22.8 & 30.0 & LBNL \\
Sony & SLV-640HF & 1996 & 5.9 & 14.7 & 18.4 & 27.0 & LBNL \\
Toshiba & M750 & 1995 & 6.5 & 14.0 & 16.4 & 22.0 & LBNL \\
Montgomery Ward JSJ10625 & & 7.9 & 13.6 & 20.2 & 24.0 & LBNL \\
JVC & HR-J200U & 1992 & 1.5 & 7.9 & 14.5 & 19.0 & LBNL \\
Hitachi & VT-F462A & 1993 & 12.8 & 18.3 & 21.4 & 28.0 & LBNL \\
RCA & VKT-550 & 1991 & 11.1 & 25.5 & 34.5 & 36.0 & LBNL \\
\hline Average & & & 6.5 & 12.6 & 17.0 & 23.3 & \\
& & & & & &
\end{tabular}

